\title{
Atomic Spectrometry Update - A review of advances in environmental analysis
}

Owen T. Butler, ${ }^{a *}$ Warren R.L. Cairns, ${ }^{b}$ Jennifer M. Cook, ${ }^{c}$ and Christine M Davidson. ${ }^{d}$

${ }^{a}$ Health and Safety Laboratory, Harpur Hill, Buxton, UK SK17 9JN

owen.butler@hsl.gsi.gov.uk

* review coordinator

${ }^{\mathrm{b}} \mathrm{CNR}-\mathrm{IDP} A$, Universita Ca' Foscari, 30123 Venezia, Italy

${ }^{c}$ British Geological Survey, Keyworth, Nottingham, UK NG12 5GG

${ }^{\mathrm{d}}$ University of Strathclyde, Cathedral Street, Glasgow, UK G1 1XL

This is the $32^{\text {nd }}$ annual review of the application of atomic spectrometry to the chemical analysis of environmental samples. This Update refers to papers published approximately between August 2015 and June 2016 and continues the series of Atomic Spectrometry Updates (ASUS) in Environmental Analysis ${ }^{1}$ that should be read in conjunction with other related ASUs in the series, namely: clinical and biological materials, foods and beverages ${ }^{2}$; advances in atomic spectrometry and related techniques ${ }^{3}$; elemental speciation $^{4}$; X-ray spectrometry ${ }^{5}$; and metals, chemicals and functional materials ${ }^{6}$.

In the field of air analysis, highlights within this review period included the development of a new prototype fluorescence instrument for the ultratrace determination of oxidised mercury species, and coupling of elemental analysers to CRDS alongside the development of FTIR and Raman techniques for the improved characterisation of carbonaceous aerosols.

In the arena of water analysis, methods continued to be reported for the speciation of As, $\mathrm{Cr}$ and $\mathrm{Hg}$ species and, following on from last year, Gd species derived from MRI agents discharged at low level from medical facilities into water courses. Improved methods for the determination of legacy compounds such as organoleads and tins made use of plasma techniques that nowadays are more tolerant of organic solvents. Instrumental developments reported included the use of MC-ICP-MS for isotopic tracer studies and a review of TXRF techniques and associated preconcentration procedures for trace element analysis. 
In the field of plant and soil analysis, there is a welcome trend in that more workers appear to be optimising their analytical methods (or at least checking their performance, e.g. by analysis of CRMs) even if the main purpose of their study is environmental application rather than fundamental spectroscopy. On-going challenges include: the fact that most speciation methods reported are still too complicated, costly or time consuming, for routine use; the need for more and a wider range of CRMs, especially for speciation analysis and for use with laser-based techniques; and the lack of harmonised analytical methodology, which hinders international environmental regulatory monitoring efforts.

In geological applications, a variety of techniques have been employed in the drive towards high resolution multi-elemental imaging of complex solid samples. Recent developments in cell design, aerosol transport and data acquisition for LA-ICP-MS, combined with improvements in ICP mass spectrometer design, provided evidence of its potential for very rapid quantitative $3 D$ imaging. Elemental and isotope imaging by NanoSIMS enabled accurate U-Pb dating of mineral domains too small for reliable measurements by LA-ICP-MS. Although megapixel synchrotron XRFS is still in its infancy, it too should open up new horizons in the study of trace and major element distributions and speciation in geological materials and offer a complementary method to other imaging techniques. The deployment of ICP-MS/MS technology has resulted in successful method development to overcome several intractable isobaric interferences in the analysis of geological materials by single quadrupole ICP-MS with LA and solution sample introduction. Many more environmental applications using this approach are likely to be reported in future ASUs.

Feedback on this review is most welcome and the review coordinator can be contacted using the email address provided. 
Air analysis

$1.1 \quad$ Review papers

1.2 Sampling techniques

$1.3 \quad$ Reference materials and calibrants

$1.4 \quad$ Sample preparation

$1.5 \quad$ Instrumental analysis

1.5.1 Atomic absorption, emission and fluorescence spectrometry

1.5.2 Mass spectrometry

1.5.2.1 Inductively coupled plasma mass spectrometry

1.5.2.2 Other mass spectrometry techniques

1.5.3 X-ray spectrometry

1.5.4 Other spectrometric techniques

1.5.5 Intercomparisons and data analytics

$2 \quad$ Water analysis

2.1 Sample preparation and storage

2.2 Sample preconcentration and extraction

$2.3 \quad$ Speciation and fractionation analysis

2.3.1 Review papers

2.3.2 Elemental speciation

2.3.3 Characterisation and determination of nanomaterials

$2.4 \quad$ Instrumental analysis

2.4.1 Atomic absorption spectrometry

2.4.2 Inductively coupled plasma atomic emission spectrometry

2.4.3 Inductively coupled plasma mass spectrometry

2.4.4 Laser induced breakdown spectroscopy

2.4.5 Vapour generation techniques

2.4.6 X-ray spectrometry

3 Analysis of soils, plants and related materials

$3.1 \quad$ Review papers

$3.2 \quad$ Sample preparation

3.2.1 Sample dissolution and extraction

3.2.2 Sample preconcentration

3.3 Instrumental analysis

3.3.1 Atomic absorption spectrometry 
3.3.2 Atomic emission spectrometry

3.3.3 Atomic fluorescence spectrometry

3.3.4 Inductively coupled plasma mass spectrometry

3.3.5 Accelerator mass spectrometry

3.3.6 Thermal ionisation mass spectrometry

3.3.7 Laser induced breakdown spectroscopy

3.3.8 X-ray spectrometry

$4 \quad$ Analysis of geological materials

4.1 Reference materials and data quality

4.2 Solid sample introduction

4.2.1 Laser ablation inductively coupled plasma mass spectrometry

4.2.2 Laser induced breakdown spectroscopy

4.3 Sample dissolution, separation and preconcentration

4.4 Instrumental analysis

4.4.1 Atomic absorption and emission spectrometry

4.4.2 Inductively coupled plasma mass spectrometry

4.4.3 Other mass spectrometric techniques

4.4.3.1 Thermal ionisation mass spectrometry

4.4.3.2 Secondary ion mass spectrometry

4.4.3.3 Accelerator mass spectrometry

4.4.3.4 Noble gas mass spectrometry

4.4.4 X-ray spectrometry

$5 \quad$ Glossary of terms

6 References 


\section{$1 \quad$ Air analysis}

\subsection{Review papers}

Review papers summarised current and emerging technologies for the detection, characterisation and quantification of inorganic engineered-nanomaterials in complex samples $^{7}$ (217 references) and, upon their release, into the wider environment ${ }^{8}$ (80 references). An interesting review of laser-based techniques ${ }^{9}$ (180 references) covered the insitu characterisation of tailored nanomaterials, synthesised from gas-phase precursors. Progress in the analysis of nanomaterials for toxicological purposes was reported ${ }^{10}$ (91 references), as was the suitability of methods to measure solubility ${ }^{11}$ (116 references), an important physiochemical parameter within emerging nanoregulation. In a thoughtprovoking review ${ }^{12}$ (53 references), the question "do ICP-MS based methods fulfill the EU monitoring requirements for the determination of elements in our environment?" was answered in the affirmative but it was considered that challenges such as sample contamination, robust implementation of suitable QA/QC programmes and lack of harmonisation in the reporting of data remained. Other useful review papers summarised new environmental applications of ICP-MS/MS ${ }^{13}$ (54 references), progress in PIXE for the analysis of aerosol samples ${ }^{14}$ (24 references), analytical approaches for the determination of As in air $^{15}$ (139 references), emerging applications for a new SEM-EDX/Raman spectroscopic system within environmental, life and material sciences ${ }^{16}$ (45 references) and a review on field-based measurements ${ }^{17}$ (110 references) which discussed the advantages and limitations in the use of portable instruments for environmental analysis.

\subsection{Sampling techniques}

Particle-collection efficiency is an important consideration in selecting suitable filter media for workplace air monitoring. New data for commonly used filters confirmed ${ }^{18}$ that MCE, PTFE and PVC filters have relatively high collection efficiencies for particles much smaller than their nominal pore size and are considerably more efficient than polycarbonate and Ag-membrane filters. Personal air samplers designed to collect NPs (nanodeposition samplers) often use nylon meshes to trap small particles but porous polyurethane foam was considered $^{19}$ a suitable alternative with low elemental impurities and good collection efficiencies. Although large particles (30-100 $\mu \mathrm{m})$ found in workplace air can be inhaled, commonly used size-resolved samplers, such as cascade impactors, are generally limited to handling particles sizes of $<20 \mu \mathrm{m}$. Two new prototype samplers capable of collecting larger 
particles were based ${ }^{20}$ upon the principles of a vertical elutriator and it will be interesting to watch their future development.

Evaluation of the performance of impactor samplers continued to be reported. Two ISO methods for the in-stack sampling of both $\mathrm{PM}_{2.5}$ and $\mathrm{PM}_{10}$ employing both conventional and virtual impactors were compared ${ }^{21}$ by use both in the laboratory and in the field at a coalfired plant. The conventional impactor performed worse as it overestimated $\mathrm{PM}_{2.5}$ concentrations due to particle bounce and re-entrainment even when an adhesive coating was applied to the impaction plates. Collecting sufficient sample mass for detailed chemical characterisation in supporting health effects studies requires air samplers operating at substantially higher flow rates than the $1-2 \mathrm{~m}^{3} \mathrm{~h}^{-1}$ typically used currently. The design and validation of two new high volume $\mathrm{PM}_{2.5}$ impactors operating at 57 and $66 \mathrm{~m}^{3} \mathrm{~h}^{-1}$ has been reported ${ }^{22,23}$ as has a new impactor design ${ }^{24}$ that can sample either $\mathrm{PM}_{1}$ or $\mathrm{PM}_{2.5}$ at a nominal $10.5 \mathrm{~m}^{3} \mathrm{~h}^{-1}$ flow rate.

Continuous analytical systems are proving useful for the time-resolved measurements of aerosol chemical composition which are needed to elucidate a greater understanding of atmospheric processes and reactions. With the objective of unattended continuous long-term weekly sampling of size segregated ambient particulate matter, a sampling system ${ }^{25}$ consisting of a modified 3-stage rotating drum impactor in series with a sequential filter sampler was used to collect $<0.36 \mu \mathrm{m}, 0.36-1.0 \mu \mathrm{m}, 1.0-2.4 \mu \mathrm{m}$ and $2.4-10.0 \mu \mathrm{m}$ particle size fractions. Accumulated sample deposits were subsequently analysed either by thermal desorption GC-TOF-MS (organic species) or by XRFS (elemental species). The sequential spot sampler is a design that uses a water-based condensation growth technique to grow fine particles into $\mu \mathrm{m}$-sized droplets which can subsequently be impacted as dry spots. In one particular design ${ }^{26}$, impaction of a droplet resulted in a sample spot of $\sim 1 \mathrm{~mm}$ diameter within a well of a 96 place collection plate. Subseqent droplets were deposited sequentially in clean wells thereby facilitating the collection of time-resolved air samples. In one application of this new system, a multi-well plate recovered from the field was processed in the laboratory wherein each spot was extracted with water and analysed by IC for its nitrate and sulfate content. This multi-well plate approach has good potential as the plates could potentially be incorporated in a range of instrumental autosampler systems thereby facilitating automation of extraction and analysis. The semi-automatic measurement ${ }^{27}$ of soluble $\mathrm{Cu}$ and $\mathrm{Pb}$ in atmospheric samples was achieved by coupling a deposition sampler to an ASV detection system that employed screen-printed electrodes. In a one-month field study, this approach proved reliable with low ng $\mathrm{L}^{-1}$ LODs. Successful validation involved analysis of water 
CRMs and comparison with data obtained by ICP-MS analysis. The fate of anthrogeneic $\mathrm{Hg}$ emissions in the atmosphere is influenced by the exchange of $\mathrm{Hg}^{0}$ with the earth surface but the accurate determination of $\mathrm{Hg}^{0}$ fluxes has proved technically challenging as airborne concentration differences between up-draughts and down-draughts can be very small $(<0.5 \mathrm{ng}$ $\mathrm{m}^{-3}$ ). An improved REA system ${ }^{28}$ built around a single AFS detector system had twin-inlets and pairs of $\mathrm{Au}$ preconcentration cartridges for the concurrent sampling and analysis of $\mathrm{Hg}^{0}$ in both up and down-draughts. This sophisticated system possessed a $\mathrm{Hg}^{0}$ reference gas calibration generator that enabled instrumental drift to be monitored and, if necessary, recalibrations to be undertaken.

Interesting new biosampler systems have been proposed. After a gun is fired, gun shot residue deposited on a shooter's hand disappears gradually through washing or contact with surfaces so detection on skin is limited by the need to sample within eight hours of the firing. Particles trapped within nasal mucus however had ${ }^{29}$ potentially longer residence times. Swabbing with an EDTA-wetted cotton bud and digestion in acid was all that was needed to prepare samples. Particle concentrations were lower than those found in hand swab samples but this was not an issue if a sensitive technique such as ETAAS were employed. Progress continued $^{30}$ in the LA-ICP-MS measurement of the isotopic composition and concentration of $\mathrm{Pb}$ in the dentine and enamel of deciduous teeth which gave a record of historical $\mathrm{UK} \mathrm{Pb}$ exposure during fetal development and early childhood. Children born in 2000, after the withdrawal of leaded petrol in 1999, had lower dentine $\mathrm{Pb}$ concentrations than children born in 1997 and an isotopic ratio fingerprint that correlated very closely with modern day Western European industrial $\mathrm{PM}_{2.5 / 10}$ aerosols. In contrast, for those born in 1997, the isotopic ratio fingerprint was a binary mixture of industrial aerosols and leaded petrol emissions. Exhaled breath condensate (EBC), the condensate from exhaled breath during regular tidal breathing, has been proposed ${ }^{31}$ as a useful medium which, when used alongside established urine biomonitoring, can give a more comprehensive picture of worker exposure to $\mathrm{Cr}^{\mathrm{VI}}$. Collection used a portable sampler similar to a breathalyser with a peltier cooler unit for condensation of the exhaled breath. Single-use mouthpiece, plumbing and clean test tubes were used for each sample taken. The EBC was diluted ten-fold with an EDTA solution and analysed by microbore LC-ICP-MS. The Cr speciation profile in spiked EBC samples could be maintained for up to 6 weeks if stored at $4{ }^{\circ} \mathrm{C}$ but not if samples were frozen. 


\subsection{Reference materials and calibrants}

Reference materials (thin film standards) available for calibration of XRFS do not necessarily mimic real-world filters collected in air quality monitoring programmes. $\mathrm{New} \mathrm{Pb}$ reference filters were generated ${ }^{32}$ by mounting air samplers, with the appropriate filter substrate, within an enclosed aerosol chamber and challenging them with $\mathrm{Pb}$-containing aerosols produced from ICP-grade standards using a desolvating nebuliser. Filters were prepared to mimic mass loadings typically found in surveys and equivalent to airborne concentrations of between 0.0125 and $0.70 \mu \mathrm{g} \mathrm{m}^{-3}$. Extension of this work in preparing filters with other elements is now underway. Methods for the generation of test $\mathrm{Pb}$ or $\mathrm{PbO} \mathrm{NPs}$ involved $^{33}$ either the thermal decomposition and oxidation of lead bis(2,2,6,6,-tetramethyl3,5-heptanedionate) or the evaporation and condensation of metallic $\mathrm{Pb}$. The latter approach was deemed to be more suitable due to its simplicity, high production rate and the welldefined composition of the NP formed. A novel porous tube reactor ${ }^{33}$ facilitated the production of NPs from the gas phase and offered a controlled process for the synthesis of ultrafine metal particles with subsequent oxidation and dilution steps. Magnetic Fe and maghemite were synthesised using Fe pentacarbonyl as a gas-phase precursor and NPs with primary particle sizes of 24 and $29 \mathrm{~nm}$ and geometric mean diameters of $110 \mathrm{~nm}$ and $150 \mathrm{~nm}$ produced. Data agreed well with those derived from modelling which, for Fe NPs, predicted a primary particle size of $36 \mathrm{~nm}$ and an agglomerate size of $134 \mathrm{~nm}$.

The generation and testing of gas standards is of widespread interest. High purity nitrogen or air, often referred to as "zero gas", is essential as a blank standard for calibrating instruments used in air quality monitoring. Providing traceable and accurate quantification of impurities in such gases is challenging as the LODs of analytical techniques required are often similar to the concentrations of the measurands in question. A useful review paper ${ }^{34}$ (21 references) described the status of the measurement science and available data on the performance of a selection of zero air generators and purifiers. Although gas standards in pressurised metal cylinders are popular, there is potential for selective adsorption onto the metal surfaces. In a new study ${ }^{35}$ on the reversible adsorption process between trace species $\mathrm{CH}_{4}, \mathrm{CO}, \mathrm{CO}_{2}$ and $\mathrm{H}_{2} \mathrm{O}-$ and cylinder surfaces such as aluminium and steel, the authors recommended that for highly precise trace gas analysis aluminium cylinders should be used, temperature fluctuations should be minimised to limit desorption and diffusion effects and cylinder usage should be restricted to units pressurised above 30 bar. 


\subsection{Sample preparation}

In a microwave-assisted extraction procedure ${ }^{36}$ for the speciation of $\mathrm{Sb}^{\mathrm{III}}$ and $\mathrm{Sb}^{\mathrm{V}}$ in $\mathrm{PM}_{10}$ airborne particles collected on quartz fibre filters, leaching with $0.05 \mathrm{M}$ hydroxylammonium chlorohydrate solution was recommended. This new approach recovered spikes quantitatively and extracted more $\mathrm{Sb}$ from samples than the hither-to used ultrasonic extraction procedure. Optimal digestion conditions ${ }^{37}$ for the dissolution of $\mathrm{TiO}_{2}$ NPs collected on air filter samples involved the use a $\mathrm{H}_{2} \mathrm{SO}_{4}: \mathrm{HNO}_{3}$ acid mixture $(2: 1 \mathrm{v} / \mathrm{v})$ heated to $210{ }^{\circ} \mathrm{C}$.

An operationally defined sequential leach procedure $^{38}$ for $\mathrm{Mn}$ speciation in welding fume involved four-steps: a $0.1 \mathrm{M}$ ammonium acetate leachate for soluble Mn components; a $25 \%(v / v)$ acetic acid leachate to dissolve $\mathrm{Mn}^{0 / I I}$ species; a $0.5 \%(w / v)$ hydroxylamaine hydrochloride in $25 \%(v / v)$ acetic acid leachate to dissolve $\mathrm{Mn}^{\mathrm{III} / \mathrm{V}}$ species and a final $\mathrm{HCl}-$ $\mathrm{HNO}_{3}$ acid mix to digest the residue. Recoveries for test samples consisting of pure Mn compounds (Mn nitrate solution, Mn powder, $\mathrm{Mn}^{\mathrm{II} / I I I}$ oxide) were in the range from 88 to $103 \%$. A SiMn alloy and two certified welding fume RMs were subsequently tested but in these cases total Mn recoveries were only $68-75 \%$ suggesting, in this reviewer's opinion, that the final acid digestion step was not agressive enough. Analysis of fumes derived from flux welding demonstrated that the dominant forms were $\mathrm{Mn}^{0 / I I}$ and insoluble $\mathrm{Mn}$. For fume derived from an arc weld process, the dominant form was the $\mathrm{Mn}^{\mathrm{II} / \mathrm{IV}}$ fraction. Interested readers are referred to a review ${ }^{39}$ (112 references) on Mn speciation.

New approaches for the preparation of particulate samples for subsequent instrumental analysis included tangential flow filtration used ${ }^{40}$ to preconcentrate black carbon particles from ice-water, remove matrix salts and limit particle aggregation, prior to TEM analysis. The continuous flow of sample solution tangentially across a filter membrane not only minimised particle clogging but also facilitated the filtration of unwanted dissolved matrix salts. The interrogation of aerosol samples is often challenging due to the limited sample quantity available. The use of an automated graphitisation equipment enabled ${ }^{41}$ small quanitities of carbon-containing particulates, collected on quartz filters, to be converted effectively into a graphite target for subsequent AMS analysis. Recoveries were $>80 \%$ and reproducible $\mathrm{C}^{14}$ values were obtained for sample masses in the range 50-300 $\mu \mathrm{g}$. Strategies for the preparation of samples for LIBS have been reviewed ${ }^{42}$ (145 references). A new micromanipulator system ${ }^{43}$ facilitated a better handling of radioactive fall-out particles found in sediment samples prior to analysis using SEM and SR techniques. 


\subsection{Instrumental analysis}

\subsubsection{Atomic absorption, emission and fluorescence spectrometry}

The direct analysis of particles remains attractive as onerous sample preparatory steps can be minimised or even eliminated. The determination ${ }^{44}$ of $\mathrm{Cl}$ in pulverised coal samples using solid sampling $H R-C S-A A S$ exploited the characteristic molecular absorption of the $\mathrm{SrCl}$ molecule at $635.862 \mathrm{~nm}$. Under optimised conditions of pyrolysis at $700{ }^{\circ} \mathrm{C}$ and atomisation at $2100{ }^{\circ} \mathrm{C}$, the LOD and $\mathrm{M}_{\mathrm{o}}$ were 0.85 and $0.24 \mathrm{ng}$, respectively. Results for five, well homogenised, coal CRMs (BCR 180,181,182 and NIST SRM 1630a and 1632b) agreed with certified values. Refreshingly, the authors concluded however that similar analytical performance may not be possible for coarser-grained real-world coal samples given that the proposed method consumed a sample mass of only $\sim 0.15 \mathrm{mg}$. They suggested that one possible option would be to increase the sample mass taken for analysis in conjunction with the selection of a less sensitive molecular transition line. In a fast screening method involving ETV-ICP-AES ${ }^{45}, \mathrm{P}, \mathrm{S}$ and Si impurities in Ag NPs were determined at a rate of 35 samples per hour. The important point in this proposed method was that the entire sample could be vaporised thereby enabling simultaneous measurement of the emission from both the impurity elements and the Ag matrix. No tedious weighing procedure was therefore required. The LODs for $\mathrm{P}, \mathrm{S}$ and $\mathrm{Si}$ in a dry powder Ag matrix, were 4.2, 62 and15 $\mu \mathrm{g} \mathrm{g}^{-1}$, respectively.

A commercially available AFS analyser was modified ${ }^{46}$ to undertake airborne measurements of atmospheric $\mathrm{Hg}$ as part of the ongoing CARIBIC project. Salient features included the use of: two $\mathrm{Au}$ cartridges to achieve continuous sampling (while one was sampling the other was being desorbed); a pressure-stabilised AFS detector cell to ensure a stable detector response; and a molecular sieve to remove the $0.25 \%(\mathrm{v} / \mathrm{v}) \mathrm{CO}_{2}$ from the argon carrier gas as this would otherwise have quenched the AFS signal. In an attempt to minimise the number of calibrant gases taken on board, this gas supply was also used to calibrate the onboard $\mathrm{CO}_{2}$ gas analyser.

Developing $L I B S$ as a quantitative technique is a goal that is shared by a number of research groups. Ideally the measurement requirements are that the sample be completely dissociated and diffused within the plasma on time-scales conducive with analysis thereby resulting in analyte emission at the bulk plasma temperature with a signal that is linear with mass concentration. Following experiments involving the interrogation of multi-elemental test aerosols, it was concluded ${ }^{47}$ that local perturbations of plasma properties can occur so significant analyte-in-plasma residence times (tens of $\mu \mathrm{s}$ ) were therefore necessary. Another 
study ${ }^{48}$ concluded that the goal of achieving accurate compositional measurements without the use of calibrants was only possible if the delay between the laser pulse and the detector gate ramained short, i.e. $<1 \mu$ s. Investigations into the use of on-line LIBS for the elemental analysis of powered coals have been reported ${ }^{49,50}$. In the first paper ${ }^{49}$, a tapered sampling tube was useful both for enriching the coal particles within the laser focus spot (another design goal when applying LIBS to the analysis of aerosol samples) and to reducing the influence of air entrainment and fluctuations in plasma conditions. In the second paper ${ }^{50}$, on the influence of omnipresent moisture, it was concluded that part of the laser energy could indeed be expended on ionising the surrounding water vapour. This resulted in less coal mass being ablated and consequently in lower emission intensities. For more information on fundamental developments in atomic spectrometry readers are directed to our companion $\mathrm{ASU}^{3}$.

\subsubsection{Mass spectrometry}

1.5.2.1 Inductively coupled plasma mass spectrometry. The advent of a new ICP-MS/MS instrument has encouraged development of new applications. In one ${ }^{51}$, three cell modes: single quadrupole $(\mathrm{Be}, \mathrm{Pb}$ and $\mathrm{U})$; $\mathrm{MS} / \mathrm{MS}$ with $\mathrm{NH}_{3}-\mathrm{He}(\mathrm{Co}, \mathrm{Cr})$ and $\mathrm{MS} / \mathrm{MS}$ with $\mathrm{O}_{2}(\mathrm{As}$, $\mathrm{Cd}, \mathrm{Mn}, \mathrm{Ni}$ and $\mathrm{Se}$ ) were used for quantification in cigar smoke. The elimination of unwanted interfering isobaric ions was achieved using a shifted analyte masses mode (via ammonical clusters or oxides) which gave better LODs than those obtained with a single-quadrupole ICP-MS instrument. For example, the LOD for Mn was reduced from $13 \mu \mathrm{g} \mathrm{g}^{-1}$ to $<3 \mu \mathrm{g} \mathrm{g}^{-1}$ and that for Se from $0.7 \mu \mathrm{g} \mathrm{g}^{-1}$ to $<0.02 \mu \mathrm{g} \mathrm{g}^{-1}$. In a somewhat unusual study ${ }^{52}$, ICP-MS/MS was used to study the abiotic methylation reaction of inorganic $\mathrm{Hg}$ with VOCs. Several VOCs (acetic acid, ethyl acetate, methyl benzene and methyl iodide) reacted with $\mathrm{Hg}$ to form methyl $\mathrm{Hg}$ at a conversation rate of $1-2 \%$. One is left to ponder whether ion chemistry within an ICP-MS system can be truly representative of atmospheric processes but also whether this rather innovative approach involving an alternative use of an ICP-MS system could be useful for studying other gaseous reactions. A useful tutorial review ${ }^{13}$ ( 55 references) describing this new instrument has been published.

Speciation applications involving the use of HPLC-ICP-MS included ${ }^{53}$ the coupling of AEC to ICP-MS for the simultaneous speciation of chromate, molybdate, tungstate and vanadate in alkaline extracts of welding fume. At the high alkalinity conditions employed, the $\mathrm{CrO}_{4}{ }^{2-}, \mathrm{MoO}_{4}{ }^{2-}$ and $\mathrm{WO}_{4}{ }^{2-}$ species gave single sharp chromatographic peaks but the peak for $\mathrm{VO}_{4}{ }^{3-}$ was slightly broader. The LODs ranged from $0.02 \mathrm{ng} \mathrm{ml}^{-1}$ for $\mathrm{CrO}_{4}{ }^{2-}$ to $\mathrm{ca} .0 .1 \mathrm{ng} \mathrm{ml}^{-1}$ for the other measurands. Method accuracy was checked using either IRMM CRM $545\left(\mathrm{Cr}^{\mathrm{VI}}\right.$ 
in welding fume loaded on a filter) or, for the other analytes, spiked samples. Results for $\mathrm{Cr}$ were within the certification range and spike recoveries were 98-101\%. Five As species $\left(\mathrm{As}^{\mathrm{III}}, \mathrm{As}^{\mathrm{V}}, \mathrm{MA}, \mathrm{DMA}\right.$ and TMAO) in water extracts from air filter samples were determined $^{54}$ by HPLC-HG-ICP-MS. The total extractable As content was $0.03-0.7 \mathrm{ng} \mathrm{m}^{-3}$ and the relative abundance in the sequence $\mathrm{As}^{\mathrm{V}}>\mathrm{TMAO}>\mathrm{DMA}>\mathrm{As}{ }^{\mathrm{III}}>\mathrm{MA}$. There were no discernable seasonality effects although TMAO concentrations were higher in winter samples than in summer samples. In a similar study ${ }^{55}$ on the extraction of As species, up to $54 \%$ of an $\mathrm{As}^{\mathrm{III}}$ spike added to extracts was oxidised to $\mathrm{As}^{\mathrm{V}}$. This finding emphasised the challenge of converting laboratory-based speciation science into real-world applications where such transformations can occur readily.

The LA-ICP-MS technique enables swift interrogation of particles with minimal sample preparation but further work is required to develop calibration strategies for quantitation. One proposed approach ${ }^{56}$, involving the use of MC-ICP-MS, offered a rapid, accurate and precise method for the determination of isotopic ratios in U-containing particles. The methodology involved the use of adhesive-tape-sampling to fix particles, SSB to correct for mass fractionation effects and repeat analysis of suitable CRMs such as NBL CRM 124-1 $\left(\mathrm{U}_{3} \mathrm{O}_{8} 24\right.$ element impurity standard) and NRCCRM GBW 04234/04236 (U isotopic abundance in $U_{6}$ ). The relative uncertainties in ${ }^{235} \mathrm{U} /{ }^{238} \mathrm{U},{ }^{234} \mathrm{U} /{ }^{235} \mathrm{U}$ and ${ }^{236} \mathrm{U} /{ }^{238} \mathrm{U}$ measurements were $<0.05,1.7$ and $1.8 \%$, respectively, and the isotopic ratios determined were in good agreement with certified values. A new procedure ${ }^{57}$ for the determination of the trace element content in powdered environmental samples did not require matrix-matched CRMs. Powdered samples were mixed with an $\mathrm{AgO}$ internal standard and a $\mathrm{Na}_{2} \mathrm{~B}_{4} \mathrm{O}_{7}$ binder and pelletised. Powdered CRMs with varying matrix composition and analyte content were prepared and analysed in the same way for quantification. Applicability of the procedure was demonstrated by the successful quantification of $\mathrm{As}, \mathrm{Cu}, \mathrm{Ni}$ and $\mathrm{Zn}$ in four different matrix CRMs: NIST SRM 1648a (urban particulate matter); NIST SRM 2709 (San Joaquin Soil); IRMM CRM 144 (sewage sludge) and IRMM CRM 723 (road dust). Three of these materials were used as calibrants and the fourth analysed as an unknown sample.

Using an ICP-MS instrument as detector for the on-line measurement of particles is a fertile, interesting but challenging research area. Researchers in Austria described ${ }^{58,59}$ a system for measurement of the time-resolved release of $\mathrm{Cl}, \mathrm{K}, \mathrm{Na}, \mathrm{Pb}, \mathrm{S}$ and $\mathrm{Zn}$ from single particles during biomass combustion. Researchers in Switzerland developed ${ }^{60}$ a SMPS-ICPMS system coupled with a rotating-drum device for the simultaneous determination of both the size distribution and elemental composition of NPs. Meanwhile in the Czech Republic, 
researchers used ${ }^{61}$ substrate-assisted laser desorption to introduce Au NPs from a plastic surface into an ICP-MS instrument. A 61\% transport efficiency was achieved using $56 \mathrm{~nm}$ sized reference NPs. In a more fundamental study ${ }^{62}$, particles $\left(\mathrm{Al}_{2} \mathrm{O}_{3}, \mathrm{Ag}, \mathrm{Au}, \mathrm{CeO}_{2}\right.$ and $\mathrm{Y}_{2} \mathrm{O}_{3}$ ) in the 100-1000 $\mathrm{nm}$ size range were injected into an ICP-MS system in order to calculate relative detector response factors. The response factors ranged between $10^{-5}$ and $10^{-}$ 11 .

1.5.2.2 Other mass spectrometry techniques. Developments in other MS techniques for gaseous analysis included a new analyser ${ }^{63}$ for the speciation of trace levels of atmospheric oxidised $\mathrm{Hg}$ compounds, required to gain a better understanding of the biogeochemical cycle of Hg. The system consisted of an ambient air collection device (either nylon membrane or quartz wool substrate), a TD module, a cyrofocusing system and a GC-MS analytical system. A permeation-based calibration system with an associated AFS detector provided stable and quantifiable amounts of gas-phase $\mathrm{Hg}^{0}, \mathrm{HgBr}_{2}, \mathrm{HgCl}_{2}, \mathrm{Hg}\left(\mathrm{NO}_{3}\right)_{2}$ and $\mathrm{HgO}$ calibrants. In a laboratory setting, this instrument could be used to speciate $\mathrm{HgX}_{2}$ compounds at an instrumental LOD of $90 \mathrm{pg}$ but it was not possible to ascribe unequivocally mass spectra to either $\mathrm{Hg}\left(\mathrm{NO}_{3}\right)_{2}$ or $\mathrm{HgO}$ species. In field use, the LOD was $10-18 \mathrm{pg} \mathrm{m}^{-3}$ but no oxidised $\mathrm{Hg}$ species could be detected when air samples were analysed. It was concluded that either a lower LOD was required or that species transformation during sampling occured. Future work in this most challenging field will include the testing of more inert sample collection substrates and the use of alternative MS detectors. A GC-MS method ${ }^{64}$ achieved LODs of 3.3 $\mathrm{x} 10^{-8}(\mathrm{~V} / \mathrm{V})$ and $2.6 \times 10^{-9}(\mathrm{~V} / \mathrm{V})$ for atmospheric $\mathrm{Kr}$ and $\mathrm{Xe}$ gases, respectively, with a relative standard uncertainity of $c a .3 \%$.

Improvements in isotope ratio-MS included a fully automated system ${ }^{65}$ for the determination of $\Delta^{13} \mathrm{C}$ and $\Delta^{18} \mathrm{O}$ in atmospheric $\mathrm{CO}$ samples which used Schutze reagent $\left(\mathrm{I}_{2} \mathrm{O}_{5}\right.$ on silica gel) to convert extracted $\mathrm{CO}$ to $\mathrm{CO}_{2}$. Use of high-purity $\mathrm{He}$ to flush continuously the instrument system resulted in low but constant system blank signals that were $<1-3 \%$ of typical sample signals. The measurement repeatability was $<0.2 \%$ and a single measurement took 18 minutes. A commercial GC-isotope ratio-MS system modified ${ }^{66}$ for on-line carbon ID used a constant flow of $\mathrm{CO}_{2}$, enriched in ${ }^{13} \mathrm{C}$ and diluted in $\mathrm{He}$, added via the flow splitter located within the chromatography oven. The precision for isotopic ratio measurements was $c a$. $0.05 \%$ RSD $(n=50)$. The relative abundances of $\mathrm{N}_{2} \mathrm{O}$ isotopocules (molecules that have the same chemical constitution and configuration and only differ in isotopic composition) are potentially useful tracers for understanding the atmospheric 
production pathways, sinks and decomposition reactions of $\mathrm{N}_{2} \mathrm{O}$, an ozone-depleting gas. A new automated sample preparation system ${ }^{67}$ able to accommodate flask samples that previous systems could not handle consisted of a sample injection unit, a cyrogenic concentration unit, a purification unit and a cryofocusing unit, all mounted on a compact mobile trolley that could be wheeled into place and connected to the IRMS instrument. A sample could be processed in 40 minutes. The precision values of $<0.1 \%$ for $\Delta^{15} \mathrm{~N}$ and $<0.2 \%$ for $\Delta^{18} \mathrm{O}$ were comparable to those obtained with other automated but less mobile systems and better than those obtained using manual off-line preparatory systems.

Developments in MS techniques for analysis of airborne particulates included a newly developed LA-TOF-AMS system ${ }^{68}$ that consisted of two $405 \mathrm{~nm}$ scattering lasers for particle sizing, a $193 \mathrm{~nm}$ excimer laser for ablation/ionisation of particles and a TOF-MS detection system with a mass resolution of $m / \Delta m>600$. Laboratory tests gave a maximum detection efficiency of $2.5 \%$ for particles with a nominal diameter of $450 \mathrm{~nm}$.

A particle trap laser desorption mass spectrometer ${ }^{69}$ for the quantification of $\mathrm{SO}_{4}{ }^{2-}$ aerosols gave results highly correlated $\left(\mathrm{r}^{2}=0.96\right)$ with but consistently lower than those obtained using a more conventional thermal decomposition/oxidiser system coupled to a $\mathrm{SO}_{2}$ gas sensor. These discrepancies were explained by differences in the respective sampling inlets and differences in the vaporisation efficiencies of particles since the laser desorption MS system was operated at $\sim 500{ }^{\circ} \mathrm{C}$ whereas the thermal decomposition analyser ran at 1000 ${ }^{\circ} \mathrm{C}$.

The Aerodyne aerosol mass spectrometer is a commercially available and frequently used instrument for the on-line measurement of sub- $\mu \mathrm{m}$ ambient aerosols. Two papers described work undertaken to understand better the performance of this instrument. In the first ${ }^{70}$, an instrument was challenged with test aerosols ranging from $\mathrm{NH}_{4} \mathrm{NO}_{3}$ (nonrefractory) to $\mathrm{ZnI}_{2}$ (semi-refractory) in order to gain a better understanding of how well particles vaporised at $\sim 600^{\circ} \mathrm{C}$. It was concluded that the $\mathrm{W}$ vaporiser unit did not always behave inertly towards particles, that no sharp separation between non-refractory and refractory species was possible and that, as a result, measurements of semi-refractory aerosols could indeed be biased. The second paper $^{71}$ addressed errors inherent in the fitting and integration of ion peaks that could be an appreciable source of potential measurement imprecision. Coupling of the Aerodyne aerosol mass spectrometer with a Nd:YAG laser (from a single particle soot photometer) to produce an instrument known as the soot-particle aerosol mass spectrometer which could be used to measure atmospheric particles including refractory black carbon (rBC) species. A method ${ }^{72}$ for the detection and quantification of the 
trace metal contents of soot particles involved preparing synthetic calibration standards by dosing suspensions of carbon black particles with various concentrations of aqueous metal spikes. The resultant standards were then nebulised, dried and directed through a differential mobility analyser to generate a monodispersive $(300 \mathrm{~nm})$ test aerosol (i.e. dried carbon particles coated with trace metals) for soot particle-aerosol MS. In an initial field trial conducted in the vicinity of an oil fired power station, qualitative mass spectra data revealed evidence for metallic oxide and sulfate species. The Ba, Fe and V data agreed, within a factor of 2 , to those obtained using the ICP-MS of filter samples taken at the same time.

\subsubsection{X-ray spectrometry}

The analysis of particles on filters by XRFS is now well established but new approaches are always welcome. One feasibility study ${ }^{73}$ investigated whether it would be possible to analyse particles collected using the Streaker ${ }^{\mathrm{TM}}$ sampler by EDXRFS rather than by the more conventional PIXE approach. In this ambient air sampler, a filter is rotated at a constant rate under an incoming stream of particle-laden air thus forming a continuous streak which provides time-resolved elemental air concentration data. A customised XRF instrument with a focused but small collimated beam provided data as good as those obtained by PIXE analysis. Irregular dust depositions on 25-mm diameter filters mounted in the widely used IOM inhalable workplace dust sampler can pose difficulties when attempting elemental quantification using pXRFS instruments which, by their design, have intrinsically small Xray beams. Averaging four filter readings, obtained by manual rotation of filters by quarter turns, yielded ${ }^{74} \mathrm{~Pb}$ results that were within $-28 \%$ and $+38 \%$ of results obtained previously using a laboratory-based WDXRF system. The latter possessed a wider X-ray beam that could illuminate the whole filter and an automatic sample spinner to average out heterogeneities in dust deposits on filters. Measurement of $\mathrm{Pu}$ fall-out particles in soil matrices is of interest to those working in nuclear safeguarding, forensics and remediation activities. In a powerful demonstration ${ }^{75}$ of advances in analytical capabilities, the elemental composition of two $\mathrm{Pu}$-contaminated soil samples was characterised using both high resolution $\mu$ XRFS and 3D confocal XRFS. The LOD was $<15 \mathrm{pg}$ for samples with a nominal $30 \mu \mathrm{m}$ grain size. Complimentary morphologic and sizing information was available using Xray transmission microscopy and micro X-ray tomography.

The solid state speciation of airborne particles provides powerful new information on the composition of individual particles. The analysis of $\mathrm{PM}_{10}$ and $\mathrm{PM}_{2.5}$ by XANES and XRD confirmed ${ }^{55}$ the presence of $\mathrm{Ca}_{3} \mathrm{Sr}_{2}\left(\mathrm{AsO}_{4}\right)_{2.5}\left(\mathrm{PO}_{4}\right)_{0.5}(\mathrm{OH}), \mathrm{As}_{2} \mathrm{O}_{3}$ and $\mathrm{As}_{2} \mathrm{O}_{5}$ species. An 
understanding of Cs speciation in dust emissions from either municipal solid waste incineration (MSWI) or sewage sludge incineration (SSI) is important when considering disposal options of waste which may be contaminated with low levels of radionuclides. Analysis by $\mu$ XAS confirmed ${ }^{76}$ that Cs speciation in MSWI dust was best described as a potentially soluble $\mathrm{CsCl}_{2}$ species but that in SSI dust it was best described as an insoluble pollucite material, a zeolitic structure with a typical composition of $\mathrm{Cs}_{2} \mathrm{Al}_{2} \mathrm{Si}_{4} \mathrm{O}_{12} \cdot 2 \mathrm{H}_{2} \mathrm{O}$. Mercury can be associated with fly ash in emissions from coal-fired power stations. The $\mu \mathrm{XAS}$ analysis of a simulated flue gas showed ${ }^{77}$ that $\mathrm{Hg}$ was associated with $\mathrm{Br}$ and $\mathrm{Cl}$, could be bound to Fe oxides and could also occur as a cinnabar ( $\mathrm{HgS})$ species. This information would be most useful for those tasked with the safe disposal of $\mathrm{Hg}$-containing fly ash. Nuclear forensics makes use of tools such as XAS but reference spectroscopic signatures for a range of $U$ compounds in the soft X-ray spectral region are required. A new study ${ }^{78}$ compiled suitable reference spectra into a useful searchable database for a variety of common uranyl-bearing minerals including carbonates, oxyhydroxides, phosphates and silicates.

Interested readers are invited to read our companion $\mathrm{XRF} \mathrm{ASU}^{5}$ to learn more about instrumental developments and potential applications.

\subsubsection{Other analytical techniques}

Commercially available field-based IC-based systems that measure, in near real-time, water soluble airborne ionic species are useful in gaining a better insight that such species play within atmospheric processes. In these systems, particles are sampled, hydrated in a steam generator and the resultant water-soluble ions extracted and analysed using IC. It is also possible to separate gas-phase ionic species from particles that contain ionic species by using denuder technology. There is now a need to compare data generated using these new systems with data generated using more established laboratory-based IC methods to ensure continuity in monitoring data sets. One study ${ }^{79}$, conducted at an urban location, compared hourly in situ data with data derived from $24 \mathrm{~h}$ filter samples returned and analysed back in the laboratory. Overall, data correlated well for $\mathrm{Cl}^{-}, \mathrm{Mg}^{2+}, \mathrm{NH}_{4}{ }^{+}, \mathrm{NO}_{3}{ }^{-}$and $\mathrm{SO}_{4}{ }^{2-}\left(\mathrm{r}^{2}>0.83\right)$ but less so for $\mathrm{Ca}^{2+}, \mathrm{Na}^{+}, \mathrm{K}^{+}\left(\mathrm{r}^{2}<0.5\right)$. On average, the in-field approach gave substantially higher concentrations for $\mathrm{K}^{+}, \mathrm{Na}^{+}$and $\mathrm{NH}_{4}{ }^{+}$than those measured in the laboratory. In a second study ${ }^{80}$, conducted at a rural location, online measurement of $\mathrm{NH}_{4}{ }^{+}$concentrations compared favourably with off-line measurements $\left(r^{2}>0.83\right.$, mean differences $\left.<6 \%\right)$. The $\mathrm{SO}_{4}{ }^{2-}$ concentrations determined online correlated well with off-line measurements $\left(\mathrm{r}^{2}>0.84\right)$ but with mean differences of up to $35 \%$. In the case of $\mathrm{NO}_{3}^{-}$, the correlation was poor $\left(\mathrm{r}^{2}\right.$ 
$<0.1$ ) and the mean difference could be as great as $520 \%$. Performance differences could be attributed to a number of factors including: differences in the particle size selectivity of the respective sampler inlets; collection efficiencies and volatility losses within the steam-jet aerosol collector; instrument saturation effects; sampling artifacts (both positive and negative) in the off-line filter sampling method; and challenges and uncertainities in measuring low airborne concentrations of species such as $\mathrm{K}^{+}$. Nevertheless, such studies are most informative as the air monitoring community slowly transitions from laboratory-based to field-based measurements. Modification of a particle-into-liquid sampler coupled with IC $\operatorname{led}^{81}$ to a dramatic increase in performance. Twin ion exchange pre-concentration cartridges (one for cationic and one for anionic species) were inserted so that one sample could be enriched while the preceding one underwent chromatographic separation and analysis. This gave a 10- to 15 -fold improvement in LOD and, importantly, a 24-fold increase in live time coverage from 2 to 48 minutes in every hour.

A TD carbon analyser ${ }^{82}$ used with a cavity ring-down spectroscopy system enabled isotope ratio measurements to be performed on carbonaceous particulate matter. The data were in reasonable agreement with values previously reported in the literature. The precision was $<1.0 \%$. This study demonstrated the potential of the new system as an alternative to the established IRMS measurement approach. Assessing the containment performance of storage wells in carbon capture schemes requires time-resolved measurements taken at locations around potentially large sites together with the use of isotopic $\mathrm{CO}_{2}$ tracers. Use of IRMS is not feasible but the use of a CRDS system equipped with a gas sampling manifold system has been advocated ${ }^{83}$. A $\mathrm{H}_{2} \mathrm{~S}$ interference ${ }^{84}$ which biased ${ }^{12} \mathrm{CO}_{2}$ measurements high and ${ }^{13} \mathrm{CO}_{2}$ measurements low was overcome by installing a scrubber packed with $\mathrm{Cu}$ filings to remove $\mathrm{H}_{2} \mathrm{~S}$ selectively as samples entered the instrument. A CRDS system, modified for use in flight, was used ${ }^{85}$ to make $\mathrm{NO}_{2}$ measurements over the eastern seaboard of the USA. Instrumental calibrations were linear up to $150 \mathrm{nM}$. The LOD was $80 \mathrm{pM}$. The remarkably consistent airborne concentrations $\left(\sim 3 \times 10^{15}\right.$ molecules $\left.\mathrm{cm}^{-2}\right)$ from ground level up to an altitude of $2.5 \mathrm{~km}$ indicated that $\mathrm{NO}_{2}$ was widely but uniformly distributed in the air over the eastern USA.

There is growing interest in the use of quantum cascade lasers for gas monitoring applications as these systems can be portable, sensitive and selective and provide rapid analysis. A preconcentation unit, in which electrical cooling rather than the more conventional liquid $\mathrm{N}_{2}$ cooling was used, trapped ${ }^{86} \mathrm{CH}_{4}$ but not other major components (e.g. $\mathrm{N}_{2}$ and $\mathrm{O}_{2}$ ) or interferents (e.g. $\mathrm{CO}_{2}$ and $\mathrm{N}_{2} \mathrm{O}$ ). The preconcentration factors of up to 500 
resulted in an analytical precision of $0.1 \%$ for $\Delta{ }^{13} \mathrm{C}$ and $0.5 \%$ for $\Delta \mathrm{D}-\mathrm{CH}_{4}$ based upon a nominal 10-minute instrumental integration. The average differences in results obtained by this new approach and the currently used approach of Dewar sampling and IRMS were within the WMO compatability goals of $0.2 \%$ for $\Delta{ }^{13} \mathrm{C}$ and $5.0 \%$ for $\Delta \mathrm{D}-\mathrm{CH}_{4}$. Use of a new pressure-corrected calibration protocol reduced uncertainties in the airborne measurement ${ }^{87}$ of $\mathrm{CH}_{4}$ and $\mathrm{N}_{2} \mathrm{O}$ to \pm 2.47 and $\pm 0.54 \mathrm{ppb}(2 \sigma)$, respectively.

The use of thermal-optical analysis for measuring the carbonaceous content in atmospheric particles is well established. Addition ${ }^{88}$ of a multi-wavelength capability to an existing instrument, made possible by recent advances in laser diode technology, should provide better optical interrogation of filter samples in the furnace as they undergo combustion and thereby provide improved identification of the source of carbon. A method ${ }^{89}$ for calculating equivalent black carbon concentrations from elemental carbon data derived from thermo-optical analysis will make it easier to compare data derived from combustionbased and optical-based measurement systems. Determination of the organic carbon content of atmospheric particles, measured using a thermal-optical approach ${ }^{90}$, made use of an empirically-derived organic carbon volatility model. Data for this model were obtained from paired samples: quartz fibre filters that collected all organic carbon species; and quartz fibre filters mounted behind Teflon filters that collected volatile organic species but not particulate-bound organic carbon species.

Other instrumental developments and applications included an INAA method ${ }^{91}$ for measurement of 37 elements in particles trapped in ice core samples. Reduction in background instrumental noise resulted in a 1-3 order of magnitude improvement in LOD, equivalent to absolute LODs in the range $10^{-13}$ to $10^{-6} \mathrm{~g}$. Raman spectroscopy ${ }^{92}$ was the basis of a new continuous soot monitoring system used to provide the first diesel fume measurements in a controlled environmental chamber. Future work will include the use of multivariate data analytics to interrogate spectral information as well as the optimisation of instrumental hardware to improve sensitivity. The potential of the EBS and PESA techniques for measuring low Z-elements such as $\mathrm{C}, \mathrm{H}, \mathrm{N}$ and $\mathrm{O}$ collected on PTFE filters was evaluated $^{93}$. Direct measurement of organic or elemental $\mathrm{C}$ was not possible but it was suggested that $\mathrm{H}$ could be used as a proxy for organic $\mathrm{C}$ and that the elemental $\mathrm{C}$ fraction could then be calculated as the difference between total $\mathrm{C}$ and this organic $\mathrm{C}$ fraction. A non-

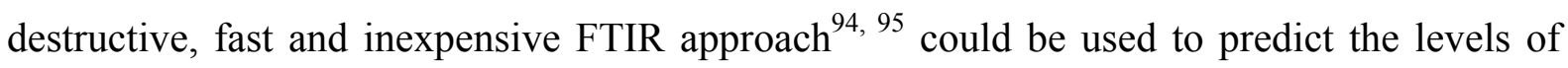
organic and elemental $\mathrm{C}$ in particulate matter collected on PTFE filters. The FT-IR spectra were calibrated, via PLSR, using OC/EC data obtained from the thermal combustion analysis 
of particulate matter sampled in a similar way but on quartz filters. Automated particle screening software ${ }^{96}$, developed for SIMS analysis, enabled those few U particles with irregular isotopic composition to be identified and to be isolated for further TIMS analysis.

\subsubsection{Intercomparisons and data analytics}

Laboratory intercomparison exercises can be most useful in assessing the performance of new methodologies and instrumentation. A study ${ }^{97}$ evaluated how well laboratories performed in dissolving new acid-soluble cellulose-based air sampling capsules designed to sample metals in workplace air. Capsules were spiked, at three loadings, with 33 elements in the range 2-100 $\mu \mathrm{g}$ per sample and triplicates sent to each of eight laboratories. A variety of hotblock, hotplate and microwave-assisted digestion protocols were used to prepare the test samples for analysis by ICP-AES. For 30 of the 33 elements the NIOSH accuracy criterion of results not deviating by $>25 \%$ from spiked value was achieved. The elements that presented difficulties were $\mathrm{Ag}$ (potential for precipitation in chloride-based solutions), In (low instrumental sensitivity) and Sn (passivation in oxiding acids). Data from this study supported the development of the new NIOSH 7306 method. Laboratories employed $^{98}$ EDXRF (using both external calibration and FP approaches) and PIXE methodologies in a comparative study of the measurement of elemental loadings on $\mathrm{PM}_{10}$ filter samples. The NIST SRM 2783 (air particulate on filter media) was analysed by all laboratories to provide data for comparison. Further data were obtained by digesting representative filters in HF using a microwave procedure for ICP-MS analysis. The data for a range of elements $(\mathrm{Br}, \mathrm{Cu}, \mathrm{Fe}, \mathrm{K}, \mathrm{Mn}, \mathrm{Pb}, \mathrm{S}, \mathrm{Sr}$ and $\mathrm{Ti}$ ) were consistently within $20 \%$ of each other. Data were also comparable with those obtained by ICP-MS except for those for Fe and $\mathrm{Zn}$. Cross-contamination was a possible explanation for these discrepancies. In summary, the authors concluded that it was possible for laboratories with different instruments, setups and calibration approaches to make comparable measurements on filter samples.

Undertaking instrumental intercomparisons in the field can be both time consuming and logistically challenging! In a comprehensive exercise ${ }^{99}, 47$ CRDS instruments were tested to assess their performances for measuring atmospheric $\mathrm{CH}_{4}, \mathrm{CO}, \mathrm{CO}_{2}$ and $\mathrm{H}_{2} \mathrm{O}$ species. Only 15 instruments were actually tested in the field following an initial screening in the laboratory. As might be expected, newer models performed better than older ones and the overall recommendations included: instrument performance should be verified in the laboratory using a standardised protocol before deployment in the field; instruments should be stabilised for 10 minutes prior to undertaking measurement; in the field calibrations should 
be performed initially every 2 weeks for the first 6 months and subsequently after every instrument restart. The first ever large scale intercomparison ${ }^{100}$ of aerosol mass spectrometers, carried out at a field station outside Paris, took 3 weeks to complete. The first week was dedicated to instrumental set-up, tuning and calibration and then comparative studies took place in the second and third weeks. Chemical species (ammonium, chloride, nitrate, organic matter and sulfate) in the non-refractory sub $\mathrm{PM}_{1}$ fraction were measured using 13 different instruments. Taking the median as a reference value, correlations were strong $\left(\mathrm{R}^{2}>0.9\right)$ for all systems across all measurands except chloride for which correlation was poorer. It was suggested that this was due to instrumental sensitivity issues when attempting to measure low atmospheric concentrations. Recommendations included guidance on how best to perform calibrations and standardised protocols for data processing.

In two interesting studies, elemental ratio data have been used to track potential emissions from specific industrial point sources. In the first ${ }^{101}, \mathrm{La} / \mathrm{Ce}$ ratios were determined in $\mathrm{PM}_{2.5}$ filter samples taken from the vicinity of petroleum refineries as these elements are characteristic emission tracers from fluidised-bed catalytic cracker (FCC) columns. The use of a high-throughput hot-block digestion for rapid ICP-MS analysis of 64 filter samples was verified (80-90\% elemental recoveries) using NIST SRM 1648a (urban particulate matter) and SRM 2783 (air particulate on filter media). Subsequent modelling could not reliably apportion measured $\mathrm{PM}_{2.5}$ to FCC emissions suggesting that the impact of refinery particulate emissions on local air quality was minimal. In the second study ${ }^{102}, \mathrm{Cd} / \mathrm{Cu}, \mathrm{Cd} / \mathrm{Pb}, \mathrm{Cr} / \mathrm{Pb}$ and $\mathrm{Cu} / \mathrm{Pb}$ ratios were determined in filters collected from the chimney stacks of six municipal waste incinerators and at locations $10 \mathrm{~km}$ downwind. The stack samples, taken on quartz fibre filters, were analysed by ICP-MS following a $\mathrm{HNO}_{3}$-HF microwave-assisted digestion using the EN 14385 method. The ambient air $\mathrm{PM}_{10}$ samples, collected on cellulose filters, were analysed by ICP-MS following a $\mathrm{HNO}_{3}-\mathrm{H}_{2} \mathrm{O}_{2}$ microwave-assisted digestion using the EN 14902 protocol. Method performance checks used BCR CRM-038 (fly ash from pulverised coal) and NIST SRM 1648A (urban particulate matter). There was no evidence of emissions impacting upon local air quality around four installations and at the other two installations the influence of emissions was minimal.

\section{Water analysis}

\subsection{Sample preparation and storage}

Two papers on oceanographic studies compared on-board sample preparation with return of samples to the laboratory for processing. The first ${ }^{103}$ studied the partitioning of As, 
$\mathrm{Ba}, \mathrm{Cd}, \mathrm{Cu}, \mathrm{Fe}, \mathrm{Li}, \mathrm{Mg}, \mathrm{Mn}, \mathrm{Pb}, \mathrm{U}, \mathrm{V}$ and $\mathrm{Zn}$ between the dissolved and particulate fractions in water samples from oceanic hydrothermal vents. When the samples were filtered on board, results for dissolved fraction were higher than if the samples were sent back to the laboratory for processing. As a consequence, results for samples taken back to the laboratory overestimated the particulate fraction for all the elements studied. In the case of Fe, the underestimation of the dissolved fraction was up to $96 \%$. Although the measurement bias for $\mathrm{Li}, \mathrm{Mg}, \mathrm{Mn}$ and $\mathrm{U}$ for the dissolved fraction of $\leq 3 \%$ was deemed acceptable, for all other elements in situ filtration was necessary. The authors concluded that filtration after freezing should not be used for deep sea elemental fractionation studies. In the second study ${ }^{104}$ on the $\mathrm{Hg}$ isotopic composition of Arctic seawater, samples were collected and either preconcentrated on board immediately or stored in the dark and preconcentrated in the laboratory. Samples preconcentrated in the laboratory had more positive $\delta^{202} \mathrm{Hg}$ values than those prepared on board, probably due to abiotic reduction of $\mathrm{Hg}$ in the dark by organic matter during storage and shipment. A fractionation factor of $1.49 \pm 0.12 \%$ for $\delta^{202} \mathrm{Hg}$ was applied to correct for this effect.

The stability and degradation of elemental species under storage has been of interest for a long time. In a study ${ }^{105}$ of the degradation of butyl tin compounds in surface waters, where isotopically labelled DBT, MBT and TBT samples were stored in glass, polypropylene or PTFE containers, both biodegradation and photolytic degradation were mechanisms for species interconversion. Dealkylation was higher for samples stored in polypropylene bottles than for those stored in glass or PTFE bottles. Storage in amber glass bottles in the dark at $18^{\circ} \mathrm{C}$ resulted in little dealkylation after two weeks but after four months $19 \%$ of the DBT spike was converted to MBT. No degradation of TBT was observed, however. Pillay and Kindness ${ }^{106}$ re-confirmed that addition of EDTA to water samples helped to preserve As species in the presence of up to $50 \mathrm{mg} \mathrm{L-1} \mathrm{Fe} \mathrm{and} \mathrm{Mn} \mathrm{but} \mathrm{not} \mathrm{in} \mathrm{the} \mathrm{presence} \mathrm{of} \mathrm{the} \mathrm{same}$ amount of sulfide. Simulated pore water was spiked with $50 \mu \mathrm{g} \mathrm{L}^{-1} \mathrm{As}^{\mathrm{III}}, \mathrm{As}^{\mathrm{V}}, \mathrm{DMA}^{\mathrm{V}}$ and $\mathrm{MMA}^{\mathrm{V}}$ and $100 \mu \mathrm{g}$ L-1 monothioarsenate ${ }^{\mathrm{V}}$ and tetrathioarsenateV. Following addition of EDTA to a final concentration of $0.025 \mathrm{M}$, the samples were aliquoted into plastic vials and stored at $-20{ }^{\circ} \mathrm{C}$. If only $\mathrm{Fe}$ and $\mathrm{Mn}$ were present, the species were preserved for up to 2 months but in the presence of $\mathrm{S}^{2-}$ some of the As species degraded almost immediately.

\subsection{Sample preconcentration and extraction}

Reflecting the maturity of this field, review articles are written every year on various aspects of sample preconcentration. This year was no different. Deng et al. ${ }^{107}$ (135 
references) provided a comprehensive review on the application of preconcentration and separation techniques in AFS, covering not only preconcentration but also separation techniques such as CVG in various solid and liquid matrices. A review ${ }^{108}$ (76 references) on the use of biosorbents for SPE of toxic elements in waters covered the use of algae, bacteria, fungi and yeasts as new absorbents. Hagarova and $\mathrm{Urik}^{109}$ (60 references) reviewed new approaches to CPE. They focussed on either speeding up or improving the selectivity of this popular method for the determination of trace metals.

The most significant developments in analyte preconcentration for water analysis are summarised in Tables 1 and 2 .

\subsection{Speciation and fractionation analysis}

\subsubsection{Review papers.}

Most reviews of speciation analysis covered several matrices, including waters, but that ${ }^{110}$ (77 references) on $\mathrm{Tl}$ speciation was specific to water analysis. Recent advances in the

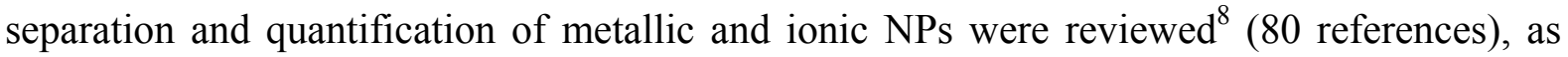
was the use of NPs and nanoscale sorbents for the speciation of trace elements in the environment $^{111}$ (103 references). Mercury is always of interest and two reviews covered sample preparation and quantification ${ }^{112}$ (90 references) and advances in separation and detection techniques since $2013^{113}$ (157 references). Other reviews are included in the soils and plants section of this ASU. For a broader overview of speciation analysis, the reader is referred to our companion $\mathrm{ASU}^{114}$ (215 references).

\subsubsection{Elemental speciation.}

Faster separation was achieved ${ }^{115}$ for redox As species in river sediment pore waters by operating an HPIC system at a flow rate of $400 \mu \mathrm{L} \mathrm{min}^{-1}$. Separation occurred within 4 mins but analthough an additional 4 mins was required for effective column reconditioning. The LODs with ICP-MS detection ranged from $0.05\left(\mathrm{As}^{\mathrm{V}}\right)$ to $0.25\left(\mathrm{MMA}^{\mathrm{V}}\right)$. The accuracy of the method was checked against the NRCC CRMs SLRS-4 (River water) and SLEW-3 (Estuarine water) and the sum of $\mathrm{As}^{\mathrm{III}}$ and $\mathrm{As}^{\mathrm{V}}$ concentrations agreed with the certified total As value. This method was considered to be suitable for the analysis of pore waters from "poorly contaminated" sediment samples.

Methods for multielemental speciation are quite rare due to the compromise conditions required. A Polish research group developed ${ }^{116}$ two chromatographic methods for the separation of $\mathrm{As}^{\mathrm{III}}, \mathrm{As}^{\mathrm{V}}$ and $\mathrm{Cr}^{\mathrm{VI}}$ in water, using a Hamilton PRP X-100 $4.6 \times 150 \mathrm{~mm}$ 
normal bore anion-exchange column. Although both methods used isocratic elution at a constant $\mathrm{pH}$ of 9.2 and a flow rate of $1.4 \mathrm{~mL} \mathrm{~min}^{-1}$, one method employed a mobile phase of $22 \mathrm{mM}\left(\mathrm{NH}_{4}\right)_{2} \mathrm{HPO}_{4}$ and $25 \mathrm{mM} \mathrm{NH}_{4} \mathrm{NO}_{3}$ and the other $22 \mathrm{mM}\left(\mathrm{NH}_{4}\right)_{2} \mathrm{HPO}_{4}$ and $65 \mathrm{mM}$ $\mathrm{NH}_{4} \mathrm{NO}_{3}$. The first mobile phase gave higher signal and a shorter analysis time $(<3$ mins for elution of the analytes) whereas the second gave an improved separation resulting from the longer elution time of 6 mins. The LODs with ICP-MS detection in reaction mode ranged from $0.090\left(\mathrm{As}^{\mathrm{V}}\right)$ to $0.16\left(\mathrm{As}^{\mathrm{III}}\right) \mu \mathrm{g} \mathrm{L}_{-1}$ for the first method and $0.062\left(\mathrm{As}^{\mathrm{V}}\right)$ to $0.15\left(\mathrm{Cr}^{\mathrm{VI}}\right)$ for the second. Method validation involved the spiking of real samples at three concentration levels but, strangely, different concentrations were used to evaluate the two methods, namely 0.5, 3.0 ad 9.0 $\mu \mathrm{g} \mathrm{L}^{-1}$ for the first and 5, 25 and $50 \mu \mathrm{g} \mathrm{L}^{-1}$ for the second. All recoveries were close to $100 \%$. The same authors ${ }^{117}$ used the same column and HPLC-ICP-MS instrumentation to separate $\mathrm{As}^{\mathrm{III}}, \mathrm{As}^{\mathrm{V}}, \mathrm{Cr}^{\mathrm{VI}}, \mathrm{Sb}^{\mathrm{III}}$ and $\mathrm{Sb}^{\mathrm{V}}$ within 15 mins. A binary elution system of $3 \mathrm{mM} \mathrm{Na}_{2}$ EDTA at $\mathrm{pH} 4.6$ and $36 \mathrm{mM} \mathrm{NH}_{4} \mathrm{NO}_{3}$ at $\mathrm{pH} 9.0$ at a flow rate of $1.5 \mathrm{~mL}$ $\min ^{-1}$ and injection volume $100 \mu \mathrm{L}$ were used. The LODs ranged from $0.038\left(\mathrm{Sb}^{\mathrm{V}}\right)$ to 0.098 $\left(\mathrm{Cr}^{\mathrm{VI}}\right) \mu \mathrm{g} \mathrm{L}^{-1}$ and spike recoveries from $93 \%\left(\mathrm{As}^{\mathrm{V}}\right)$ to $110 \%\left(\mathrm{As}^{\mathrm{III}}\right)$ for a $0.5 \mu \mathrm{g} \mathrm{L}^{-1}$ spike in drinking water samples.

The speciation analysis of $\mathrm{Cr}$ usually involves determination of the concentration of just one species and calculation of the other as a difference from the total concentration. A non-chromatographic chromium speciation method was developed ${ }^{118}$ to preconcentrate selectively and thereby separate both $\mathrm{Cr}^{\mathrm{III}}$ and $\mathrm{Cr}^{\mathrm{VI}}$. Mesoporous amino-functionalised $\mathrm{Fe}_{3} \mathrm{O}_{4}-\mathrm{SiO}_{2}$ magnetic NPs were used to extract $\mathrm{Cr}^{\mathrm{VI}}$ from a $45 \mathrm{~mL}$ sample at $\mathrm{pH}$ 5.0. The remaining $\mathrm{Cr}^{\mathrm{III}}$ was then extracted as a complex with 4-(2-thiazolylazo) resorcinol using CPE. The $\mathrm{Cr}^{\mathrm{VI}}$ was extracted into $0.5 \mathrm{~mL}$ of $2.5 \mathrm{M} \mathrm{HCl}$ from the magnetically-recovered NPs whereas the $\mathrm{Cr}^{\mathrm{III}}$ cloud point phase was diluted with $600 \mu \mathrm{L}$ of $0.1 \mathrm{M} \mathrm{HNO}_{3}$. The $\mathrm{Cr}$ content of both phases was determined by FAAS. The LODs were $3.2 \mu \mathrm{g} \mathrm{L}^{-1}$ for $\mathrm{Cr}^{\mathrm{III}}$ and $1.1 \mu \mathrm{g} \mathrm{L}^{-1}$ for $\mathrm{Cr}^{\mathrm{VI}}$. Recoveries from spiked tap, mineral and lake water samples were $91-103 \%$ for both species at a $45 \mu \mathrm{g} \mathrm{L}^{-1}$ spike concentration.

Investigations into the presence of $G d$ contrast agents in the waters around Munster University and in the Ruhr valley continued ${ }^{119}$. The sensitivity of a HILIC-ICP-MS procedure reported previously was improved by changing the column to a Diol-functionalised HILIC column with USN sample introduction. A binary eluent of $25 \% 50 \mathrm{mM}$ ammonium formate at $\mathrm{pH} 3.7$ and $75 \%$ acetonitrile was used to elute the analytes isocratically at a flow rate of 800 $\mu \mathrm{L} \min ^{-1}$. A $5 \mu \mathrm{L}$ sample loop and ICP-SF-MS detection provided a LOD of $0.6 \mathrm{pM}$ for total Gd, sufficient to detect the contrast agents in various stages of the water treatment process 
and to show that species transformation products such as ionic Gd were not formed during normal municipal water treatment processes.

An interesting non-chromatographic method ${ }^{120}$ for the determination of mercury species in water and edible oils involved the use of magnetic $\mathrm{Fe}_{3} \mathrm{O}_{4} \mathrm{NPs}$ functionalised either with silver and then sodium 2-mercaptoethane-sulphonate to make them specific for $\mathrm{Hg}^{2+}$ or with L-cysteine to make them specific for inorganic mercury and organo-mercury species (i.e. total mercury). The authors used $\mathrm{AgNO}_{3}$ as a modifier in measurements by ETAAS because the large amounts of iodine introduced during sample preparation would otherwise have made $\mathrm{Hg}$ more volatile during the ashing cycle. The LOD for $\mathrm{Hg}$ with a preconcentration factor of 196 was $0.01 \mu \mathrm{g} \mathrm{L}^{-1}$. It seems a pity that the authors did not take the opportunity to extract sequentially organo-mercury species from the sample. Although this method was not sufficiently sensitive for the analysis of uncontaminated waters, it was successfully applied to waters from a mining site where, unsurprisingly, all the mercury was present as $\mathrm{Hg}^{2+}$. In a CE-ICP-MS method ${ }^{121}$ for the determination of $\mathrm{MeHg}$, EtHg and $\mathrm{Hg}^{2+}$ in waters, the sensitivity was improved by up to 100 -fold. This was achieved by combining extraction and preconcentration of the analytes from $500 \mathrm{~mL}$ samples using dispersive SPE with field-amplified sample stacking injection, in which an amplified electric field applied at the injection point of the capillary column enriched the analytes. Using ICP-MS detection with a microconcentric nebuliser, the LOQs were $0.37,0.45$ and $0.26 \mathrm{pg} \mathrm{mL}^{-1}$ for $\mathrm{MeHg}$, EtHg and $\mathrm{Hg}^{2+}$, respectively. For $2 \mathrm{pg} \mathrm{mL}^{-1}$ spikes of tap water, the recoveries ranged from $92 \%$ for $\mathrm{EtHg}$ to $108 \%$ for $\mathrm{MeHg}$ and the RSD (n=3) ranged from 5-6\%. Results for the Chinese CRM GBW08603 (water) agreed well with the certified value for $\mathrm{Hg}^{2+}$.

Methods continue to be published for legacy pollutants such as organolead or organotin compounds even though their use is banned. A rapid HPLC-ICP-MS method ${ }^{122}$ for the speciation of $\mathrm{Pb}$ in water used a column packed with $5 \mu \mathrm{m} \mathrm{C}_{18}$ bonded-silica stationary phase and sodium 1-pentanesulfonate as an ion pairing agent. This is essentially a procedure first used in the early 1990s and improved through use of modern instrumentation which is more tolerant to organic solvents. All the $\mathrm{Pb}$ species were separated in $<5$ mins using a binary gradient programme consisting of $5 \mathrm{mg} \mathrm{L}^{-1}$ sodium 1-pentanesulfonate solution buffered to $\mathrm{pH} 5$ as an ion pairing agent and methanol. The proportion of methanol was increased from 5 to $90 \%$ in $1 \mathrm{~min}$ at a flow rate of $1.2 \mathrm{~mL} \mathrm{~min}^{-1}$. Under these conditions, the LOD was $0.01 \mu \mathrm{g}$ $\mathrm{L}^{-1}$ for $\mathrm{Pb}^{2+}$ and $0.02 \mu \mathrm{g} \mathrm{\textrm {L } ^ { - 1 }}$ for triethyl, trimethyl and triphenyl lead. The calibration was linear over 0.1-10 $\mu \mathrm{g} \mathrm{Pb} \mathrm{L}^{-1}$ for $20 \mu \mathrm{L}$ sample injections. Spike recoveries from seawaters were $92 \%$ (trimethyl lead) to $104 \%$ (triphenyl lead). In a rapid HPLC-ID-ICP-MS method ${ }^{123}$ 
for quantification of organotin compounds in water and sediment samples, six organotin species were eluted from a high-throughput Zorbax XDB Eclipse $\mathrm{C}_{18}$ bonded-silica in $<7$ mins using a binary gradient programme. Mobile phase A consisted of $0.0625 \%$ tropolone, $0.1 \%$ triethylamine and $6 \%$ glacial acetic acid (v/v) in LC-grade $\mathrm{H} 2 \mathrm{O}$ whereas mobile phase B was $100 \%$ acetonitrile. The mobile phase composition increased from $45 \%$ B to $55 \%$ B in 0-5 s following injection. Bond Elut SPE cartridges were used to preconcentrate the analytes in $250 \mathrm{~mL}$ water samples and to remove the matrix. In contrast to the experience of other researchers, the authors reported that the mobile phase caused no plasma instability or baseline drift. The method LODs ranged from $1.5 \mathrm{ng} \mathrm{L}^{-1}$ (MBT) to $25.6 \mathrm{ng} \mathrm{L}^{-1}$ (TPhT) but spike recoveries using external calibration were poor (33\% for TPhT to $68 \%$ for DPhT) . Therefore ID was necessary to compensate for these recoveries. This improved the LODs and

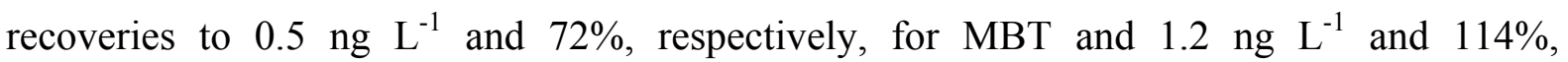
respectively, for TBT. This made HPLC-ICP-MS with IDA a viable alternative to GC-ICPMS.

\subsubsection{Characterisation and determination of nanomaterials.}

The separation of CdSe-ZnS and InP-ZnS quantum dots ${ }^{124}$ from their dissolved ionic species was achieved using a SEC column packed with a $5 \mu \mathrm{m}$ particle size stationary phase with $12.5 \mathrm{~nm}$ pore size. The mobile phase $\left(1 \mathrm{~mL} \mathrm{~min}^{-1}\right)$ consisted of a $20 \mathrm{mM}$ citrate buffer to prevent agglomeration of the quantum dots, 5mM EDTA as a complexing ligand to ensure elution of the ions, $4 \mathrm{mM}$ ammonium lauryl sulfate as a surfactant to reduce particle interactions with the column and $20 \mathrm{mg} \mathrm{L}^{-1}$ formaldehyde as a biocide. The quantum dots and ions were detected by ICP-MS with a linear range from 10 to $200 \mu \mathrm{g} \mathrm{L}^{-1}$. Recoveries of known quantities injected onto the column were $97 \%(\mathrm{Cd})$ and $102 \%(\mathrm{Zn})$ for quantum dots and between $87 \%(\mathrm{Zn})$ and $108 \%(\mathrm{Cd})$ for their ions. These good column recoveries resulted in LODs for the quantum dots of $3.0(\mathrm{Cd})$ to $10.0(\mathrm{Zn}) \mu \mathrm{g} \mathrm{\textrm {L } ^ { - 1 }}$. The method was therefore suitable for following the dissolution kinetics of quantum dots in waste waters. These results compared very well with those obtained by centrifuge ultrafiltration of the samples.

The separation of Ag ions from Ag NPs was a hot topic this year. A research group in Taiwan used $^{125}$ a 3D printer to create a 768 turn knotted-coil reactor capable of separating dissolved $\mathrm{Ag}+$ from the NPs. During method development, municipal waste waters were spiked and the two species separated using xanthan/phosphate-buffered saline as a dispersion medium that also stabilised the two Ag species. The ICP-MS LODs of $0.86(\mathrm{Ag}+)$ and 0.52 (Ag NPs) ng $\mathrm{L}^{-1}$ were low enough to detect Ag ions and NPs at concentrations expected in 
samples from waste water treatment plants although, in the samples analysed, the concentrations $(\mathrm{n}=5)$ of $\mathrm{Ag}$ NPs $\left(311.9 \pm 21.8 \mathrm{ng} \mathrm{L}^{-1}\right)$ and $\mathrm{Ag}+\left(18.8 \pm 2.1 \mathrm{ng} \mathrm{L}{ }^{-1}\right)$ were surprisingly high. Samples had to be analysed within $12 \mathrm{~h}$ of collection as the proportion of silver present in the ionic form rose from $5.3 \%$ at sampling to $66.9 \%$ after $48 \mathrm{~h}$ due to NP dissolution. The proposal ${ }^{126}$ to use asymmetric flow FFF-ICP-MS as an alternative to CPE coupled with ICP-MS or ETAAS for separation and detection of $\mathrm{Ag} \mathrm{NPs} \mathrm{and} \mathrm{Ag}^{+}$might seem strange as CPE was originally used as an alternative to asymmetric flow FFF but has poor extraction efficiencies for hydrophilic NPs such as those with an organic coating. To avoid loss in the FFF system, the $\mathrm{Ag}^{+}$ions were complexed with penicillamine. With a $5 \mathrm{~mL}$ sample loop and using the membrane both to preconcentrate and separate the analytes, the LOD was $4 \mathrm{ng} \mathrm{kg}^{-1}$ for Ag NPs. Although originally developed for biological samples, the method was adopted successfully for the determination of NPs in river waters with varying humic acid contents. An alternative approach ${ }^{127}$ was the use of hollow fibre FFF together with a minicolumn packed with Amberlite IR120 cation-exchange resin to trap Ag+ in the radial flow. It was possible to separate and quantify Ag NPs with nominal diameters of 1.4, 10, 20, 40 and $60 \mathrm{~nm}$ in surface water samples with a LOD of ca. $3 \mu \mathrm{g} \mathrm{L}{ }^{-1}$. Silver ions were eluted from the minicolumn with $5 \mathrm{mM} \mathrm{Na}_{2} \mathrm{~S}_{2} \mathrm{O}_{3}$ at a flow rate of $1 \mathrm{~mL} \mathrm{~min}{ }^{-1}$. The LOD was $1.6 \mu \mathrm{g} \mathrm{L}^{-1}$. It is debatable whether better results could have been obtained if dilute $\mathrm{HNO}_{3}$ had been used as in most applications of this column. Recoveries of $10 \mu \mathrm{g} \mathrm{\textrm {L } ^ { - 1 }}$ spikes from lake water ranged from $108 \%$ for $\mathrm{Ag}^{+}$to $77.9 \%$ for $60 \mathrm{~nm} \mathrm{Ag}$ NPs.

\subsection{Instrumental analysis}

\subsubsection{Atomic absorption spectrometry.}

The main innovations continued to be the development of new methods that make use of high resolution continuum source $A A S$. This technique was used ${ }^{128}$ in a novel approach for determining $\mathrm{Cl}$ isotope ratios in mineral waters by monitoring the molecular vibrational transitions at $262.238 \mathrm{~nm}$ for $\mathrm{Al}^{35} \mathrm{Cl}$ and $262.222 \mathrm{~nm}$ for $\mathrm{Al}^{37} \mathrm{Cl}$. When $10 \mathrm{mg}$ of $\mathrm{Al}$ was added as an in-tube reactant and $20 \mathrm{mg}$ of $\mathrm{Pd}$ as a modifier before injection of $10 \mu \mathrm{L}$ of sample, $\mathrm{AlCl}$ was formed in situ in the ETAAS furnace. Accuracy was checked using NIST SRM 975a (Isotopic Standard for Chlorine). The precision of 2\% RSD ( $\mathrm{n}=20)$, obtained for a $200 \mathrm{ng}$ spike of this SRM in water, was insufficient for discriminating natural variations in $\mathrm{Cl}$ isotope ratios but suitable for tracer experiments or IDA measurements. The same instrument in FAAS mode was used ${ }^{129}$ to determine $\mathrm{Cd}, \mathrm{Cu}, \mathrm{Fe}, \mathrm{Ni}, \mathrm{Mn}, \mathrm{Pb}$ and $\mathrm{Zn}$ sequentially in $1+1$ diluted seawater after standard additions. Forty spectra for each element were collected over a 
$3 \mathrm{~s}$ read time and the signal summed over 5 analytical pixels for all the elements except $\mathrm{Mn}$, which had an optimum of 3 pixels. The LODs with an air-acetylene flame ranged from 6.6 $(\mathrm{Cu})$ to $142(\mathrm{~Pb}) \mu \mathrm{g} \mathrm{L}^{-1}$. Spike recoveries from seawater ranged from $94.7 \%$ for $\mathrm{Fe}(0.25 \mathrm{mg}$ $\mathrm{L}^{-1}$ spike $)$ to $107.8 \%$ for $\mathrm{Pb}\left(0.5 \mathrm{mg} \mathrm{L}^{-1}\right.$ spike $)$. Results for the Spectrapure Standards CRM SPS-WW2 (wastewater) agreed well with the certified values.

\subsubsection{Inductively coupled plasma atomic emission spectrometry.}

The renaissance of the ultrasonic nebuliser continued. One was attached ${ }^{130}$ to an axial view ICP-AES instrument for the determination of trace levels of $\mathrm{Hf}$, Th and $\mathrm{U}$ in various matrices including water. The USN gave slightly lower LODs than pneumatic nebulisation with desolvation. Results for the NIST CRM 1640 (trace elements in natural water) were in good agreement with the certified values. An USN improved ${ }^{131}$ the sensitivity of ICP-AES for the determination of trace elements in surface waters by about an order magnitude compared to pneumatic nebulisation. The LODs of $0.024(\mathrm{Cd})$ to $0.05(\mathrm{Cu}) \mu \mathrm{g} \mathrm{L}^{-1}$ were sufficient for the monitoring of Danube river water.

\subsubsection{Inductively coupled plasma mass spectrometry.}

A review of the determination of $\mathrm{Pu}$ in seawater by ICP-MS ${ }^{132}$ (99 references) covered matrix separation, sample preparation (coprecipitation, valence adjustment, chemical separation) and purification procedures.

The determination of $\delta^{11} \mathrm{~B}$ isotope ratios by $M C-I C P-M S$ was speeded up ${ }^{133}$ simply by using matrix-matched standards instead of matrix separation in the analysis of seawater and porewaters. The determination of $\mathrm{Br}$ isotope ratios was simplified ${ }^{134}$ by removing the major ions on Dowex ${ }^{\circledR} 50 \mathrm{WX} 8$ cation-exchange resin and evaporating the resulting solution at $90^{\circ} \mathrm{C}$ to preconcentrate the $\mathrm{Br}$ without causing fractionation. The $\delta^{81} \mathrm{Br}$ values measured in the IRMM CRM BCR-403 (seawater) were consistent with those reported in the literature. This approach was also used ${ }^{135}$ to simplify measurement of $\mathrm{Cl}$ isotope ratios in seawater. Operating a MC-ICP-MS instrument at edge-mass resolution (i.e. removing interference peaks by "aiming" the analyte peak at the edge of the detector) allowed ${ }^{136}$ the direct measurement of ${ }^{34} \mathrm{~S} /{ }^{32} \mathrm{~S}$ in sulfate from environmental samples. The expanded uncertainty $\mathrm{U}$ $(\mathrm{k}=2)$ was as low as $\pm 0.3 \%$ (for a single measurement).

The ultratrace determination of REEs in saline ground waters was achieved ${ }^{137}$ by combining $\mathrm{Fe}(\mathrm{OH})_{3}$ co-precipitation with an aerosol dilution system. The coprecipitation removed $93 \%$ of the matrix and preconcentrated the REEs 15 -fold and the aerosol dilution 
reduced residual matrix effects such as oxide formation by a factor of 10 . The LODs using ICP-MS ranged from $0.05 \mathrm{ng} \mathrm{L}^{-1}$ for Lu to $0.6 \mathrm{ng} \mathrm{L}^{-1}$ for Nd. Results for the NRCC CRM NASS-6 (seawater) agreed with values reported in the literature.

\subsubsection{Laser induced breakdown spectroscopy.}

The applicability of $L I B S$ to water analysis is slowly being improved by adapting ideas from other atomic spectroscopy methodologies. In the determination ${ }^{138}$ of $\mathrm{Cu}, \mathrm{Fe}, \mathrm{Mg}$, $\mathrm{Mn}, \mathrm{Na}, \mathrm{Pb}$ and $\mathrm{Zn}$ spikes in water samples, probing the droplet cloud generated by an USN with the laser improved $\mathrm{S} / \mathrm{N}$ and gave LODs of $0.00596(\mathrm{Na})$ to $21.7(\mathrm{~Pb}) \mathrm{mg} \mathrm{L}^{-1}$, sufficient for the measurement of all these elements except $\mathrm{Pb}$ in natural waters. A preconcentration method typically used in XRFS was applied ${ }^{139}$ to LIBS. Drying a sample drop onto a solid substrate improved LODs such that $\mathrm{Cu}$ and $\mathrm{Mn}$ (but not $\mathrm{Cd}$ and $\mathrm{Pb}$ ) could be determined in the High Purity Standards CRM (Trace metals in drinking water) with results in good agreement with the certified values.

\subsubsection{Vapour generation techniques.}

One of the advantages of photochemical vapour generation is that all chemical species have a similar generation yield, as demonstrated by Gao et al. ${ }^{140}$ who used multivariate optimisation to determine total As in seawater by PVG-ICP-MS. Signal suppression by the matrix was eliminated through use of a mixture of $20 \%(\mathrm{v} / \mathrm{v})$ formic and $20 \%$ acetic acid (v/v) in water as the photochemical reductants. The fact that the vapour generation yields for $\mathrm{As}^{\mathrm{III}}, \mathrm{As}^{\mathrm{V}}, \mathrm{MMA}$ and DMA were the same meant that a sample prereduction step was unnecessary. The LOD of $3 \mathrm{pg} \mathrm{g}^{-1}$ represented a 15-fold improvement over that obtained using direct solution nebulisation and was comparable to that obtained using conventional HG-ICP-MS. Results for the NRCC CRMs NASS-6 (seawater) and CASS-5 (nearshore seawater) agreed with the certified values. This work was replicated ${ }^{141}$ in the determination of $\mathrm{Sb}$ in water and seawater. In this study, the photochemical reductants ( $5 \%$ formic and $15 \%$ acetic acids $(\mathrm{v} / \mathrm{v})$ ) were used after irradiation of the samples with a deep UV (185nm) lamp. The LODs were $0.0006 \mathrm{ng} \mathrm{g}^{-1}$ for external calibration and $0.0002 \mathrm{ng} \mathrm{g}^{-1}$ with ID calibration. The recoveries of spikes from the NRCC CRMs NASS-6 (seawater) and CASS-5 (nearshore seawater) were quantitative. Results for NIST SRM 1640a (trace elements in water) and NRCC CRM SLRS-6 (river water) agreed with the certified values. Mercury in high salinity petroleum production water was determined ${ }^{142}$ by PVG-ICP-AES using a 17 W UV grid lamp with tandem gas liquid separators to reduce the amount of 
aerosol reaching the plasma. The sample was processed on-line in a continuous flow of $1.63 \mathrm{M}$ formic acid at $\mathrm{pH} 1.5$ with an irradiation time of $30 \mathrm{~s}$ to give a LOD of $1.2 \mu \mathrm{g} \mathrm{L}^{-1}$. Recoveries of spikes from real samples varied from 79 to $121 \%$ using standard addition.

Given the effort involved, development of new multi-elemental chemical vapour generation methods is always welcome. In one paper ${ }^{143}$, SPE with magnetic NPs functionalised with [1,5-bis(2-pyridyl)-3-sulphophenyl methylene] thiocarbonohydrazide was used together with a CVG-ICP-AES system fitted with a commercial combined cyclonic spray chamber and gas-liquid separator to determine $\mathrm{As}, \mathrm{Bi}, \mathrm{Cd}, \mathrm{Co}, \mathrm{Cr}, \mathrm{Cu}, \mathrm{Hg}, \mathrm{Mn}, \mathrm{Pd}, \mathrm{Pt}$, $\mathrm{Sb}, \mathrm{Se}, \mathrm{Sn}$ and $\mathrm{Zn}$ in natural waters. The NPs were loaded onto a microcolumn in a FI system and $\mathrm{NaBH}_{4}$ used as the reductant. The calibration graphs were linear from $0.5-200 \mu \mathrm{g} \mathrm{L}^{-1}$ and the LODs ranged from 0.01 (As) to $5.11(\mathrm{Sn}) \mu \mathrm{g} \mathrm{L^{-1 }}$ for vapour-forming elements and from $3.16(\mathrm{Mn})$ to $11.3(\mathrm{Zn}) \mu \mathrm{g} \mathrm{L} \mathrm{L}^{-1}$ for those elements conventionally nebulised, i.e. $\mathrm{Co}, \mathrm{Cu}, \mathrm{Cr}$, $\mathrm{Mn}$ and $\mathrm{Zn}$. The method was validated against CRMs NRCC SLRS-4 (river water), NWRI TMDA 54.4 (fortified lake water), Spectra Pure Standards SW2 Batch 125 (surface water) and NIST SRM 1643e (trace elements in water).

\subsubsection{X-ray spectrometry.}

Rainwater was analysed ${ }^{144}$ for $\mathrm{Co}, \mathrm{Cr}, \mathrm{Cu}, \mathrm{Fe}, \mathrm{K}, \mathrm{Mn}, \mathrm{Ni}, \mathrm{Pb}, \mathrm{S}, \mathrm{Sr}, \mathrm{V}$ and $\mathrm{Zn}$ by synchrotron radiation TXRFS after collection on an acrylic reflector and addition of $\mathrm{Ga}$ as internal standard. The LODs from $0.08(\mathrm{Ca})$ to $0.85(\mathrm{~Pb}) \mu \mathrm{g} \mathrm{L}^{-1}$ were achieved with a sample volume of $5 \mathrm{~mL}$ and a read time of $200 \mathrm{~s}$.

At the opposite end of the instrument scale, $\mathrm{Cd}$ and $\mathrm{Pb}$ concentrations in water were determined using a portable EDXRF instrument in the field ${ }^{145}$. The elements were preconcentrated from a $1 \mathrm{~L}$ sample onto filter paper coated with immobilised $\mathrm{TiO}_{2}$. The linear range was 1.0 to $50 \mu \mathrm{g} \mathrm{L}^{-1}$ for both elements and the method LODs $0.69(\mathrm{Cd})$ and $0.51(\mathrm{~Pb})$ $\mu \mathrm{g} \mathrm{L}^{-1}$. The method was validated by analysis of the Chinese CRMs GBW(E)080401 (Cd in natural water) and GBW(E)080398 (Pb in natural water) and comparison of the results with those obtained by ICP-MS. 
Table 1 Preconcentration methods using solid phase extraction for the analysis of water

\begin{tabular}{|c|c|c|c|c|c|c|c|}
\hline Analytes & Matrix & Substrate & $\begin{array}{l}\text { Coating or modifying } \\
\text { agent }\end{array}$ & Detector & $\begin{array}{l}\text { Figures of Merit } \\
\text { ( } \mu g \mathrm{~L}^{-1} \text { unless } \\
\text { otherwise stated) } \\
\end{array}$ & Method Validation & Reference \\
\hline $\begin{array}{l}\text { total As } \\
\left(\operatorname{sum}_{\mathrm{As}} \mathrm{III}^{\mathrm{N}}\right. \\
\left.\text { and } \mathrm{As}^{\mathrm{V}}\right) \\
\text { MMA, } \\
\text { DMA }\end{array}$ & $\begin{array}{l}\text { River water } \\
\text { and sediment } \\
\text { pore water }\end{array}$ & acrylamide gel & $\mathrm{ZnFe}_{2} \mathrm{O}_{4}$ & ICP-MS & $\begin{array}{l}\text { Passive DGT } \\
\text { sampler LOD not } \\
\text { reported }\end{array}$ & $\begin{array}{l}\text { Comparison with HPIC- } \\
\text { ICP-MS results }\end{array}$ & 146 \\
\hline $\begin{array}{l}\mathrm{As}, \mathrm{Cd}, \mathrm{Cr} \\
\mathrm{Cu}, \mathrm{V}, \mathrm{Zn}\end{array}$ & $\begin{array}{l}\text { Environmental } \\
\text { waters }\end{array}$ & MWCNT & $\begin{array}{l}\text { Aminopropyl modified } \\
\text { silica }\end{array}$ & ICP-AES & $\begin{array}{l}0.11(\mathrm{Cd}) \text { to } 0.91 \\
(\mathrm{Cu}), 6 \mathrm{~mL} \text { sample }\end{array}$ & $\begin{array}{l}\text { IERM GSBZ } \\
50009-88 \text { and GSBZ } \\
50029-94 \text { (Environmental } \\
\text { Water) }\end{array}$ & 147 \\
\hline $\mathrm{Au}$ & $\begin{array}{l}\text { Water and } \\
\text { waste water }\end{array}$ & Graphene oxide & $\begin{array}{l}\text { Precipitated } \mathrm{Fe}^{\mathrm{II}}, \mathrm{Fe}^{\mathrm{III}} \\
\text { mix }\end{array}$ & FAAS & $\begin{array}{l}4 \mathrm{ng} \mathrm{L}^{-1}, 50 \mathrm{~mL} \\
\text { sample }\end{array}$ & $\begin{array}{l}\text { NRCC CRM CCU-1b } \\
\text { (Copper concentrate) }\end{array}$ & 148 \\
\hline$\overline{\mathrm{Bi}}$ & $\begin{array}{l}\text { River and sea } \\
\text { water }\end{array}$ & MWCNT & L-proline & $\begin{array}{l}\text { FI-HG- } \\
\text { AAS }\end{array}$ & $\begin{array}{l}0.7 \mathrm{ng} \mathrm{L}^{-1}, 5 \mathrm{~mL} \\
\text { sample }\end{array}$ & $\begin{array}{l}\text { NIST SRM 1643e (trace } \\
\text { elements in water) }\end{array}$ & 149 \\
\hline $\mathrm{Cd}, \mathrm{Cu}, \mathrm{Pb}$ & $\begin{array}{l}\text { Water, } \\
\text { cigarette and } \\
\text { fertiliser } \\
\text { samples }\end{array}$ & MWCNT & Triethylenetetramine & FAAS & $\begin{array}{l}0.3(\mathrm{Cd}) \text { to } 3.7(\mathrm{~Pb}), \\
100 \mathrm{~mL} \text { sample }\end{array}$ & $\begin{array}{l}\text { NWRI CRM TMDA-53.3 } \\
\text { (fortified water) and } \\
\text { TMDA-64.2 (Lake } \\
\text { Ontario water) }\end{array}$ & 150 \\
\hline $\mathrm{Cd}, \mathrm{Pb}$ & Water & MWCNT & None & $\begin{array}{l}\text { CS- } \\
\text { ETAAS }\end{array}$ & $\begin{array}{l}0.001(\mathrm{Cd}) \text { and } 0.03 \\
(\mathrm{~Pb}), 20 \mathrm{~mL} \text { sample }\end{array}$ & $\begin{array}{l}\text { NIST SRM 1643e (Trace } \\
\text { Elements in Water) and } \\
\text { ERM-CA011b (Hard } \\
\text { Drinking Water) }\end{array}$ & 151 \\
\hline $\begin{array}{l}\mathrm{Cd}, \mathrm{Co}, \mathrm{Cu} \\
\mathrm{Fe}, \mathrm{Mn}, \mathrm{Ni} \\
\mathrm{Pb}\end{array}$ & $\begin{array}{l}\text { Environmental } \\
\text { waters }\end{array}$ & $\begin{array}{l}\operatorname{Pr}(\mathrm{OH})_{3} \text { co- } \\
\text { precipitate }\end{array}$ & None & FAAS & $\begin{array}{l}0.71(\mathrm{Co}) \text { to } 5.18 \\
(\mathrm{~Pb}), 450 \mathrm{~mL} \text { sample }\end{array}$ & $\begin{array}{l}\text { NWRI CRM TMDA-54.4 } \\
\text { (fortified water) and NIST } \\
\text { SRM 1570a (spinach } \\
\text { leaves) }\end{array}$ & 152 \\
\hline $\begin{array}{l}\mathrm{Cd}, \mathrm{Cr}, \mathrm{Cu} \\
\mathrm{Fe}, \mathrm{Mn}, \mathrm{Ni}\end{array}$ & Water & Membrane filter & $\begin{array}{l}\text { 1-(2-pyridylazo)-2- } \\
\text { naphthol and Y }\end{array}$ & EDXRFS & $\begin{array}{l}0.3(\mathrm{Cr}) \text { to } 2.0(\mathrm{~Pb}), \\
50 \mathrm{~mL} \text { sample }\end{array}$ & $\begin{array}{l}\text { Spike recovery and } \\
\text { comparison with ETAAS }\end{array}$ & 153 \\
\hline
\end{tabular}




\begin{tabular}{|c|c|c|c|c|c|c|c|}
\hline $\mathrm{Pb}, \mathrm{Zn}$ & & & & & & results & \\
\hline $\begin{array}{l}\mathrm{Co}, \mathrm{Cr}, \mathrm{Cu} \\
\mathrm{Ni}, \mathrm{Pb}, \mathrm{Zn}\end{array}$ & Water & $\begin{array}{l}\text { Dispersed graphene } \\
\text { oxide NPs }\end{array}$ & $\begin{array}{l}\text { 2-(5-bromo-2- } \\
\text { pyridylazo)-5- } \\
\text { diethylaminophenol }\end{array}$ & EDXRFS & $\begin{array}{l}0.07(\mathrm{Ni}) \text { to } 0.25 \\
(\mathrm{Cr}), 50 \mathrm{~mL} \text { sample }\end{array}$ & Spike recovery & 154 \\
\hline $\mathrm{Cr}^{\mathrm{VI}}$ & $\begin{array}{l}\text { Sea and lake } \\
\text { water }\end{array}$ & Graphene membrane & none & TXRFS & $0.08,50 \mathrm{~mL}$ sample & $\begin{array}{l}\text { NRCC CRM CASS-4 } \\
\text { (seawater) and NWRI EC } \\
\text { CRM NWTM-27.2 (lake } \\
\text { water) }\end{array}$ & 155 \\
\hline $\mathrm{Hg}$ & Natural water & Silica monolith & $\mathrm{Au}$ NPs & TD-AFS & $\begin{array}{l}1.31 \mathrm{ng} \mathrm{L}^{-1}, 4 \mathrm{~mL} \\
\text { sample }\end{array}$ & $\begin{array}{l}\text { Spike recovery from } \\
\text { seawater and analysis by } \\
\text { CV-AFS using U.S. EPA } \\
\text { method } 1631\end{array}$ & 156 \\
\hline $\mathrm{Hg}$ & Water & Silver NPs & None & $\begin{array}{l}\text { CS- } \\
\text { ETAAS }\end{array}$ & $\begin{array}{l}0.005,10 \mathrm{~mL} \\
\text { sample }\end{array}$ & Spike recovery & 157 \\
\hline $\mathrm{I}$ & Water & $\begin{array}{l}\text { Activated carbon } \\
\text { disks }\end{array}$ & None & WDXRFS & $29,20 \mathrm{~mL}$ sample & $\begin{array}{l}\text { Spike recovery and } \\
\text { comparison with ICP-MS }\end{array}$ & 158 \\
\hline $\mathrm{Mo}, \mathrm{Sb}, \mathrm{V}$ & $\begin{array}{l}\text { Environmental } \\
\text { water samples }\end{array}$ & $\begin{array}{l}\text { Ultrasound-dispersed } \\
\mathrm{Al}_{2} \mathrm{O}_{3} \mathrm{NPs}\end{array}$ & $\mathrm{Fe}_{3} \mathrm{O}_{4}$ & ICP-AES & $\begin{array}{l}0.16 \mathrm{ng} \mathrm{L}^{-1}(\mathrm{Sb}) \text { to } \\
0.18(\mathrm{~V}) \mathrm{ng} \mathrm{L} \mathrm{L}^{-1}, 50 \\
\mathrm{~mL} \text { sample }\end{array}$ & $\begin{array}{l}\text { HPS CRM CWW-TM-B } \\
\text { (Certified waste water) } \\
\text { and CWW-TM-A (waste } \\
\text { water standard) and other, } \\
\text { CRMs (source and } \\
\text { material unreported) }\end{array}$ & 159 \\
\hline
\end{tabular}


Table 2 Preconcentration methods using liquid phase extraction for the analysis of water

\begin{tabular}{|c|c|c|c|c|c|c|c|}
\hline Analytes & Matrix & Method & Reagents & Detector & $\begin{array}{l}\text { Figures of merit } \\
\text { ( } \mu g L^{-1} \text { unless } \\
\text { otherwise stated) }\end{array}$ & Method validation & Reference \\
\hline $\mathrm{Ag} \mathrm{NPs}$ & Water & DLLME & $\begin{array}{l}\text { 1-octyl-3-methylimidazolium } \\
\text { hexafluorophosphate, methanol }\end{array}$ & ICP-MS & $\begin{array}{l}0.01,9 \mathrm{~mL} \\
\text { sample }\end{array}$ & Spike recovery & 160 \\
\hline $\begin{array}{l}\mathrm{Ag}, \mathrm{Cd}, \mathrm{Co}, \mathrm{Cr}, \\
\mathrm{Cu}, \mathrm{Fe}, \mathrm{Ga}, \mathrm{In}, \\
\mathrm{Mn}, \mathrm{Ni}, \mathrm{Pb}, \mathrm{Zn}\end{array}$ & Water & Dual CPE & $\begin{array}{l}\text { 8-hydroxyquinoline, Triton } \\
114\end{array}$ & ICP-MS & $\begin{array}{l}0.012(\mathrm{Cu}) \text { to } 0.36 \\
(\mathrm{Ga}), 50 \mathrm{~mL} \\
\text { sample }\end{array}$ & Spike recovery & 161 \\
\hline $\begin{array}{l}\mathrm{Ag}, \mathrm{Cd}, \mathrm{Co}, \mathrm{Ni} \\
\mathrm{Pb}\end{array}$ & $\begin{array}{l}\text { Water and } \\
\text { waste water }\end{array}$ & $\mathrm{CPE}$ & APDC, Triton ${ }^{\mathrm{TM}} \mathrm{X}-114$, ethanol & FAAS & $\begin{array}{l}0.42(\mathrm{Ag}) \text { to } 1.42 \\
(\mathrm{~Pb}), 10 \mathrm{~mL} \\
\text { sample }\end{array}$ & $\begin{array}{l}\text { NIST SRM 1643e } \\
\text { (trace elements in } \\
\text { water) }\end{array}$ & 162 \\
\hline $\mathrm{As}^{\mathrm{III}}, \mathrm{Se}^{\mathrm{IV}}, \mathrm{Te}^{\mathrm{IV}}$ & Water & DLLME & DDTC, bromobenzene, methanol & $\begin{array}{l}\text { ETV- } \\
\text { ICP-MS }\end{array}$ & $\begin{array}{l}0.56(\mathrm{Te}) \text { to } 8.6 \\
(\mathrm{Se}) \mathrm{ng} \mathrm{L} \mathrm{L}^{-1}, 5 \mathrm{~mL} \\
\text { sample }\end{array}$ & $\begin{array}{l}\text { IERM GSB Z50004- } \\
88, \text { GBW (E) } \\
080395 \text { and } \\
\text { GBW (E) 080548 } \\
\text { (environmental } \\
\text { water samples) }\end{array}$ & 163 \\
\hline $\mathrm{Co}, \mathrm{Cu}, \mathrm{Ni}, \mathrm{Zn}$ & Water & DLLME & $\begin{array}{l}\text { DDTC, methanol, 1,2- } \\
\text { dibromoethane, DMSO }\end{array}$ & ETAAS & $\begin{array}{l}0.89(\mathrm{Zn}) \text { to } 1.82 \\
\mathrm{ng} \mathrm{L}{ }^{-1}(\mathrm{Cu}), 35 \\
\mathrm{~mL} \text { sample }\end{array}$ & $\begin{array}{l}\text { NRCC CRM SLRS4 } \\
\text { (Riverine water) }\end{array}$ & 164 \\
\hline $\mathrm{Cr}^{\mathrm{VI}}$ & Water & DLLME & DDTC, 1-undecanol and ethanol & LIBS & $3.1,1 \mathrm{~mL}$ sample & $\begin{array}{l}\text { LGC ERM CA011a } \\
\text { (Hard drinking } \\
\text { water) }\end{array}$ & 165 \\
\hline
\end{tabular}




\section{$3 \quad$ Analysis of soils, plants and related materials}

\subsection{Review papers}

Element-specific reviews focused on As speciation in environmental media ${ }^{166}$ (a book chapter with 127 references); As speciation in environmental, biological and food samples by HPLC-ICP-MS and HPLC-HG-AFS ${ }^{167}$ (479 references); methods for the measurement of Cs isotopes $^{168}$ (122 references); Hg speciation in water, sediment and soil ${ }^{112}$ (90 references); Mn speciation by coupled techniques ${ }^{169}$ (63 references) and Te in environmental samples ${ }^{170}$ (72 references). A review ${ }^{171}$ (73 references) of analytical strategies for the determination of As in rice concluded that approaches currently available to obtain quantitative information on As species are too complicated for routine use in human health risk assessment. The authors of a review $^{172}$ (146 references) on Se supplementation, bioavailability and determination highlighted the need for improved analytical methods, together with new CRMs, for Se speciation analysis.

Two review articles concerning the analysis of plants were of interest. The first ${ }^{173}$ (119 references) provided a comprehensive overview of metal and metalloid speciation, covering sampling and sample pre-treatment, direct and indirect analytical techniques, and recent studies on $\mathrm{As}, \mathrm{Cd}, \mathrm{Mn}, \mathrm{Ni}, \mathrm{Pb}, \mathrm{Sb}$ and $\mathrm{Se}$. The second ${ }^{174}$ (81 references) discussed analytical approaches for the study of metal binding by phytochelatins, a topic of importance for the development of appropriate strategies for the phytoremediation of contaminated land.

A review ${ }^{175}$ (110 references) on the growth in application of non-destructive spectroscopy with chemometric data processing to environmental samples covered vibrational techniques (both IR and Raman) and XRFS, and included numerous examples of studies involving soil and plant analysis.

Rabajczyk $^{176}$ (113 references) provided a useful overview of analytical approaches for the measurement of metal NPs in solid environmental samples with particular emphasis on soil and sediments.

\subsection{Sample preparation}

\subsubsection{Sample dissolution and extraction}

The more noteworthy examples of the many sample digestion and analyte extraction methods published are discussed in the following section. Further examples are summarised in Table 3.

Methods applicable to soil or sediment analysis included a purge-and-trap procedure ${ }^{177}$ for determination of acid-volatile $\mathrm{S}$ in river sediment which involved acidification of the sample 
with $\mathrm{HCl}$, trapping of the released $\mathrm{H}_{2} \mathrm{~S}$ in $0.1 \mathrm{M} \mathrm{NaOH}$ and determination of $\mathrm{S}$ in the trapping solution by ICP-AES. An ashing temperature of $<500{ }^{\circ} \mathrm{C}$ was recommended ${ }^{178}$ in the determination of $\mathrm{Pu}$ in soil by SF-ICP-MS because refractory silicates formed if a higher temperature were used during sample pre-treatment. These could not subsequently be dissolved in $\mathrm{HNO}_{3}$ and led to underestimation of the Pu content. Underestimation of analyte content due to the presence of recalcitrant minerals was also found ${ }^{179}$ in a comparison of EDXRFS and ICP-MS for the determination of $\mathrm{Cr}$ and $\mathrm{Zr}$ in soils. Even though hot $\mathrm{HF}-\mathrm{HClO}_{4}$ digestion was used in the ICP-MS method, incomplete dissolution of $\mathrm{CrFe}_{2} \mathrm{O}_{4}$ and $\mathrm{ZrSiO}_{4}$ probably occurred.

Methods applicable to plants included a procedure ${ }^{180}$ for $\mathrm{Sb}$ speciation that used a silicabased, hydrophilic, strong-anion-exchange cartridge to separate $\mathrm{Sb}^{\mathrm{III}}$ and $\mathrm{Sb}^{\mathrm{V}}$ in citric acid extracts prior to quantification by ETAAS with $\mathrm{PdNO}_{3}$ matrix modifier. The efficiency of the separation was verified by HPLC-ICP-MS. A rapid method ${ }^{181}$ for extraction and purification of $\mathrm{B}$ in bark, wood and leaf samples for measurement of concentration by ID-ICP-MS and $\delta^{11} \mathrm{~B}$ by MC-ICP-MS involved three stages: MAE of $100 \mathrm{mg}$ sample in $10 \mathrm{~mL}$ of $1 \mathrm{M} \mathrm{HCl}-\mathrm{HNO}_{3}(1+2)$; cation removal using BioRad AG50W-X12 resin and removal of DOC and $\mathrm{Si}$ by microsublimation. An extraction protocol ${ }^{182}$ was notable in that it allowed multiple isotope systems to be studied simultaneously and so allowed the natural variability in $\mathrm{B}, \mathrm{Cd}, \mathrm{Cu}, \mathrm{Fe}, \mathrm{Pb}$, $\mathrm{Sr}, \mathrm{Tl}$ and $\mathrm{Zn}$ concentrations and isotope ratios to be measured, by SF-ICP-MS and MC-ICP-MS, respectively, in leaves, needles and mushrooms. The procedure involved high pressure acid digestion $\left(0.5 \mathrm{~g}\right.$ sample $\left.+5 \mathrm{~mL} \mathrm{HNO}_{3}\right)$ followed by a two-stage chromatographic matrix separation using BioRad AG MP-1M and Eichrom Sr-Spec columns. A set of ' $\delta$-zero' standards with concentrations typical of birch leaves was processed to ensure that the procedure did not artificially introduce isotope fractionation.

A closed-vessel microwave-assisted extraction method ${ }^{183}$ for the determination of $\mathrm{B}$ and Si used $\mathrm{NH}_{4} \mathrm{~F}$ as an alternative to hazardous HF. The optimised conditions, obtained using fractional factorial design, involved the extraction of $50 \mathrm{mg}$ samples with $5 \mathrm{~mL}$ of $100 \mathrm{~g} \mathrm{~L}^{-1}$ $\mathrm{NH}_{4} \mathrm{~F}$ at $180{ }^{\circ} \mathrm{C}$ for $15 \mathrm{~min}$. The procedure gave good recoveries (96-108\% for B and $84-101 \%$ for Si) from several CRMs including IRMM BCR 060 (aquatic plant), NCS DC 73350 (poplar leaves), NRCCRM GBW 07602 and 07603 (both bush branches and leaves). A research team in China ${ }^{184}$ built a novel dynamic MAE system in which soil samples were packed into columns and irradiated in a microwave oven at $375 \mathrm{~W}$ whilst $20 \mathrm{~mL}$ of $20 \%(w / w) \mathrm{HNO}_{3}$ was pumped through. Leachates were collected, centrifuged and diluted prior to analysis by ICP-AES. Results for the analysis of soils NRCCRM GBW 07401 and GBW 08303 showed close to quantitative 
recoveries for $\mathrm{Cu}, \mathrm{Mn}, \mathrm{Pb}$ and $\mathrm{Zn}$ (95-112\%), but low recoveries for $\mathrm{Co}, \mathrm{Cr}$ and $\mathrm{Ni}$ (60-79\%). Other workers ${ }^{185}$ took the approach of grinding their samples, slurrying the powder with acid (usually $6 \mathrm{M} \mathrm{HNO}_{3}$ but dependent on sample type) and pumping the slurry at $5 \mathrm{~mL} \mathrm{~min}^{-1}$ through a specially designed high pressure coiled perfluoroalkoxy tube reactor within a $500 \mathrm{~W}$ microwave cavity. Results for ICP-AES analysis of NIST SRM 1515 (apple leaves) were reasonable. Although, both of these flow digestion systems were operated off-line, there is scope for further development leading to on-line analysis.

The procedure ${ }^{186}$ chosen following a comparison of methods for the MAE of sediment for the determination of $\mathrm{Nd}$ and $\mathrm{Sr}$ isotope ratios by HR-ICP-MS involved overnight leaching of 50 mg samples in $2 \mathrm{~mL} \mathrm{HNO}_{3}+1 \mathrm{~mL} \mathrm{HCl}$ followed by addition of $1 \mathrm{~mL}$ HF prior to microwave heating. The use ${ }^{187}$ of $1 \% \mathrm{HNO}_{3}$ instead of enzymatic extraction with cellulase gave better recoveries for the determination of As in NIES CRM 106 (unpolished rice flour) and NRCCRM GBW 10015 (spinach), better mass balance with respect to total As concentrations and maintained the integrity of the As species for determination by HPLC-ICP-MS.

Species stability during sample extraction is a perennial challenge in speciation analysis. Difficulties encountered in the measurement ${ }^{188}$ of Tl by HPLC-ICP-MS included the reduction of $\mathrm{Tl}^{\mathrm{III}}$ to $\mathrm{Tl}^{\mathrm{I}}$ in contact with plant extracts and speciation changes on freezing. A thorough reevaluation of a MAE method previously used successfully for analysis of NIST SRM 2701 (hexavalent chromium in contaminated soil) by ID-HPLC-ICP-MS was necessary ${ }^{189}$ when an unexpected and complete reduction of $\mathrm{Cr}^{\mathrm{VI}}$ to $\mathrm{Cr}^{\mathrm{III}}$ occurred during analysis of contaminated soil from Lombardia, Italy. A milder, single-step digestion $\left(5 \mathrm{~min}\right.$ at $\left.80^{\circ} \mathrm{C}\right)$ replaced the earlier twostage process $\left(5 \mathrm{~min}\right.$ at $90{ }^{\circ} \mathrm{C}$ followed by $5 \mathrm{~min}$ at $\left.110{ }^{\circ} \mathrm{C}\right)$. Numerous parameters ${ }^{190} \mathrm{such}$ as digestion conditions (open vs. closed vessels), digestions reagents, and even the nature of the sample itself were all found to affect the redox speciation of Te during sample preparation, and hence results obtained by HG-AFS. The need for standard analytical protocols was noted.

A useful study ${ }^{191}$ combined X-ray analysis with a sequential extraction procedure to investigate the binding forms of $\mathrm{Cu}$ in eight Japanese soil and sediment RMs. The XANES analysis of the residue remaining at each stage of the BCR sequential extraction revealed that $\mathrm{CuSO}_{4}$ and elemental $\mathrm{Cu}$ accounted for much of the analyte isolated in the acid-soluble fraction and not $\mathrm{Cu}$ associated with exchange sites on clay minerals and $\mathrm{CaCO}_{3}$, which are the nominal target phases. The $\mathrm{Cu}$ in the reducible fraction originated from $\mathrm{Fe} / \mathrm{Mn}(\mathrm{O}) \mathrm{OH}$, and $\mathrm{Cu}$ in the oxidisable fraction from organic matter and sulfides, as was expected. A new four-step procedure $^{192}$ specially adapted for the study of REE mobilisation in soil and mine tailings involved sequential extraction into $0.05 \mathrm{M} \mathrm{CaNO}_{3}, 0.1 \mathrm{M}$ citric acid, $0.05 \mathrm{M} \mathrm{NH}_{2} \mathrm{OH} . \mathrm{HCl}$ and 
1.4M $\mathrm{HNO}_{3}$. A key advantage was the ability to target soluble REE phosphates separately. These are often abundant, especially in tailings, but would be included with other minerals in the residual fraction by the $\mathrm{BCR}$ protocol. A rapid variant ${ }^{193}$ on the $\mathrm{BCR}$ extraction used sonication to reduce the total time required for extraction of $\mathrm{Zn}$ from soil samples from $48 \mathrm{~h}$ to $27 \mathrm{~min}$. The operational nature of sequential extraction procedures was highlighted in a study ${ }^{194}$ of $\mathrm{P}$ in soil. This showed that manipulation of sample extracts after isolation - even by filtration or dilution affected results obtained by ICP-AES.

\subsubsection{Sample preconcentration}

Numerous preconcentration procedures for specific analytes have been reported. Methods for the analysis of soils, plants or related materials, or those developed for other sample matrices that used soil or plant CRMs for validation, are summarised in Tables 4-6. A notable development was the marked rise in use of switchable polarity solvents in LPME.

\subsection{Instrumental analysis}

\subsubsection{Atomic absorption spectrometry}

Response surface methodology was used ${ }^{195}$ to determine that a solution containing $0.0674 \mathrm{~g}$ tartaric acid $+0.1950 \mathrm{~g}$ citric acid $+0.0273 \mathrm{~g}$ sucrose, diluted to $10 \mathrm{~mL}$ with $0.5 \%(v / v)$ $\mathrm{HNO}_{3}$, represented the optimal chemical modifier for the determination of $\mathrm{Pb}$ in plants and water by ETAAS. Results for NIST SRM 151 (apple leaves) and NIST SRM 1570a (spinach leaves) were similar to certified values. The LOD was $0.14 \mu \mathrm{g} \mathrm{L}^{-1}$. The characteristic mass was comparable to that obtained with classical $\mathrm{Pd}-\mathrm{Mg}$ or $\mathrm{Pd}-\mathrm{NH}_{4} \mathrm{NO}_{3}$ modifiers.

Interest continues in the use of $T D-A A S$ for the rapid determination of $\mathrm{Hg}$ in solid samples, with workers in the Czech Republic ${ }^{196}$ and Brazil ${ }^{197}$ exploring cheaper alternatives to the use of commercial direct $\mathrm{Hg}$ analysers. Both groups designed their own furnace/quartz tube atom cell assemblies and used them with (elderly) atomic spectrometers interfaced to digital converters for signal output in the analysis of local soil samples.

Developments in HG-AAS included the use of gold- or silver-mercury amalgamated cathodes $^{198}$ for the electrochemical generation of stibine prior to determination by FAAS. Method performance was comparable with the best previously reported, with a LOD of $0.007 \mu \mathrm{g}$ $\mathrm{L}^{-1}$. The measured Sb concentration in NRCC PACS-2 (marine sediment) was not significantly different from the certified value, based on a student t-test at $95 \%$ CI. A combination ${ }^{199}$ of 
alkaline extraction in $0.5 \mathrm{M} \mathrm{NaOH}$ and HG-ETAAS with Ir permanent modifier was used successfully to measure $\mathrm{Se}^{\mathrm{IV}}$ in soil, with determination of total Se by complementary techniques and estimation of $\mathrm{Se}^{\mathrm{VI}}$ by difference.

Research teams in Brazil continued to champion CS-AAS, reporting several analytical methods based on SS-HR-CS-ETAAS. These included procedures for the determination of: $\mathrm{Pb}$ in (plant-derived) biomass ${ }^{200}$; $\mathrm{Cr}$ in infant formulas (verified with NIST SRM 1563a (tomato leaves) and hence applicable to plants) ${ }^{201} ; \mathrm{Cd}, \mathrm{Ni}$ and $\mathrm{V}$ in spices (also validated by means of plant CRMs) ${ }^{202}$; $\mathrm{Cu}$ and $\mathrm{Hg}$ in phosphate fertilisers ${ }^{203}$; $\mathrm{Si}$ in plants $^{204}$; $\mathrm{Mn}, \mathrm{Ni}, \mathrm{Rb}$ and $\mathrm{Sr}$ in catuaba, coffee, ginger, ginseng, guarana and mate ${ }^{205}$; and Mo and Ni in plant-derived materials including straw and bagasse ${ }^{206}$. A feature of the latter study was the successful use of Co as an internal standard to correct for matrix interference in the determination of $\mathrm{Ni}$.

\subsubsection{Atomic emission spectrometry}

Developments in radiation sources for the determination of $\mathrm{Hg}$ included a novel CVAPGD system ${ }^{207}$ optimised using Design of Experiments and applied to $5 \mathrm{M} \mathrm{HCl}$ extracts of mosses to generate a map of $\mathrm{Hg}$ concentrations in the urban area of Wrocklaw, Poland. The LOD was $0.07 \mu \mathrm{g} \mathrm{L}^{-1}$ and the RSD $\leq 5 \%(\mathrm{n}=3)$. Other workers ${ }^{208}$ coupled GC with a DBD for $\mathrm{Hg}$ speciation in rice. Samples were digested in methanolic $\mathrm{KOH}$ and then the analytes preconcentrated by headspace SPME on a porous carbon-coated fibre for introduction to the instrument. The LODs were $0.5 \mu \mathrm{g} \mathrm{kg}^{-1}$ for inorganic $\mathrm{Hg}, 0.75 \mu \mathrm{g} \mathrm{kg}^{-1}$ for $\mathrm{MeHg}$, and $1.0 \mu \mathrm{g} \mathrm{kg}^{-1}$ for EtHg. In the absence of a rice CRM certified for $\mathrm{Hg}$ species, the method was validated by spiking experiments (recoveries 90-105\%) and comparison with HPLC-ICP-MS data.

Work on tungsten coil AES continues, with a new method reported ${ }^{209}$ for determination of $\mathrm{Mn}$ in sludge, alloy and soil. The LOD was reduced from $c a$. 0.6 to $<0.2 \mathrm{mg} \mathrm{L}^{-1}$ and the accuracy improved by combining the signals for the 403.07, 403.31 and $403.45 \mathrm{~nm}$ lines.

A study ${ }^{130}$ on the determination of Hf, Th and U by axially viewed ICP-AES with USN compared results obtained for the analyses of NIST SRM 694 (phosphate rock), NIST SRM 2710 (Montana soil) and NCS DC70319 (Tibet sediment) at several wavelengths following MAE using three different acid mixtures. Optimal digestion conditions and spectral lines for each analyte, in each type of sample, were recommended.

\subsubsection{Atomic fluorescence spectrometry}

Advances in $C V G$-AFS included an optimised method ${ }^{210}$ for direct determination of As in soil. A 5-10 mg test portion was placed in a glass tube in a furnace and $0.2 \mathrm{~mL} 30 \%(\mathrm{~m} / \mathrm{v})$ 
sodium formate, $0.05 \mathrm{~mL} \mathrm{10 \%} \mathrm{thiourea} \mathrm{and} 0.05 \mathrm{~mL} \mathrm{1:1} \mathrm{HCl}$ were added. The mixture was then pyrolysed at $500{ }^{\circ} \mathrm{C}$ and the evolved gases swept into a $\mathrm{H}_{2}$-Ar flame. Results for NRCCRM GBW07453 and GBW07450 (both soils) were almost identical to certified values. The use ${ }^{211}$ of $\mathrm{LiAlH}_{4}$ as a solid reductant for the CVG of As, $\mathrm{Hg}$ and $\mathrm{Sb}$ was demonstrated for the first time. Analytes were extracted from solid samples using an ionic liquid. Aliquots $(10 \mu \mathrm{L})$ of the extracts were manually pipetted onto excess reductant in a reactor, and the resulting $\mathrm{AsH}_{3}, \mathrm{Hg}^{0}$ and $\mathrm{SbH}_{3}$ carried by a stream of Ar into a standard commercial AFS instrument for detection. The LODs were $0.2,0.5$ and $0.1 \mu \mathrm{g} \mathrm{L}{ }^{-1}$ for $\mathrm{As}, \mathrm{Hg}$ and $\mathrm{Sb}$, respectively.

A HPLC-CV-AFS method for the determination of $\mathrm{MeHg}$ in rice ${ }^{212}$ was adapted from an earlier procedure applied to water, sediment and marine biota. Modifications included the use of a larger test portion $(300 \mathrm{mg})$, treatment with $\mathrm{HCl}$ to reduce the extract viscosity and the introduction of a circular plastic 'foam breaker' to the gas-liquid separator. Since no CRM exists for this analysis, the procedure was validated by use of spike recovery tests and comparison with species-specific ID-GC-ICP-MS data.

\subsubsection{Inductively coupled plasma mass spectrometry}

Tirek et al. ${ }^{213}$ discussed the fitness-for-purpose of ICP-MS for fulfilling EU environmental monitoring requirements. They identified sample contamination, limited implementation of QC programmes and lack of harmonisation between member states as key challenges that are yet to be fully addressed.

The first report ${ }^{214}$ of the coupling of a commercial direct mercury analyser to ICP-MS represents a useful advance in the analysis of solids. The sample was combusted, Hg species converted to $\mathrm{Hg}^{0}$, then $\mathrm{Hg}^{0}$ collected on gold-coated sand, as carried out in conventional procedures. However, instead of desorbing the analyte into the analyser's single beam spectrometer for determination by AAS, the $\mathrm{Hg}^{0}$ was flushed into a SF-ICP-MS instrument. Calibration was achieved by introduction of $\mathrm{Hg}$ into the analyser. The LOD was $1.2 \mathrm{ng} \mathrm{kg} \mathrm{g}^{-1}$, based on analysis of a $250 \mathrm{mg}$ sediment sample. Results for NIST SRM 2709 (sediment), NIST SRM 1547 (peach leaves) and NRCC DORM-3 (fish muscle) were 94-108\% of target values when external calibration was used, and 98-101\% when IDA was used. A new FI-CVG-ICP-MS method $^{215}$ for the determination of $\mathrm{As}, \mathrm{Hg}$ and $\mathrm{Pb}$ also provided excellent recoveries for analysis of CRMs, NIST SRM 1547 (peach leaves) and SRM 1573a (tomato leaves), when plant samples were introduced into the instrument in the form of a slurry containing $0.5 \%(\mathrm{~m} / \mathrm{v})$ powdered sample, $0.1 \%(\mathrm{~m} / \mathrm{v})$ citric acid and $2 \%(\mathrm{v} / \mathrm{v}) \mathrm{HCl}$. 
Advances in quantitative analysis by LA-ICP-MS was the topic of a detailed review ${ }^{216}$ (174 references) that covered not only environmental but also biological and medical applications. Approaches for calibration were compared critically and the need for more CRMs highlighted - especially CRMs that are homogeneous on a smaller scale than is typically the case with those currently available. Two of the review's authors ${ }^{57}$ further explored these issues in their study on the use of non-matrix-matched CRMs for quantification of $\mathrm{Cd}, \mathrm{Cu}, \mathrm{Ni}$ and $\mathrm{Zn}$. Using sodium tetraborate binder and silver oxide internal standard, along with collision/reaction cell technology, it was shown that any three of the CRMs NIST SRM 1648a (urban particulate matter), NIST SRM 2709 (San Joaquin Soil), IRMM BCR 144 (sewage sludge) and IRMM BCR 723 (road dust) could serve as calibrants for analysis of the fourth, giving results within $5 \%$ of certified values. Another study ${ }^{217}$ - the focus of which was mainly sample preparation - also used CRMs as calibrants, but with $\mathrm{GeO}_{2}$ internal standard. Sediment was slurried with ethanol and finely ground $\left(\mathrm{d}_{50}<3 \mu \mathrm{m}\right)$ in a mill for $40 \mathrm{~min}$, before drying at $40{ }^{\circ} \mathrm{C}$ and pressing into pellets. Other workers ${ }^{218}$ proposed the use of aqueous standards dried onto filter paper as calibrants for the LA-ICP-MS analysis of plants, and use of the ${ }^{13} \mathrm{C}$ in the paper as an internal standard (because of its similar concentration in paper and botanical tissue). More than $80 \%$ of results obtained for determination of 11 elements agreed with certified values in NIST SRM 1515 (apple leaves), NIST SRM 1575 (pine needles), IRMM BCR 060 (aquatic plant) and IRMM BCR 062 (olive leaves).

In the measurement of isotope ratios by $M C-I C P-M S$, Georg and Newman ${ }^{219}$ discovered a potential limitation in the use of $\mathrm{Tl}$ to correct for mass bias in the determination of $\mathrm{Hg}$ in sediment using an instrument fitted with high sensitivity cones. The occurrence of isobaric $\mathrm{Hg}$ hydrides at the $\mathrm{Tl}$ isotope masses could readily be overcome by using standard cones but highlighted the need to check for concentration-dependent hydride formation when carrying out any analyses in which the analyte and internal standard have isotopes overlapping in mass. In an optimised analytical procedure for the determination of $\mathrm{Sr}$ isotopes in plants $^{220}$, the average ${ }^{87} \mathrm{Sr} /{ }^{86} \mathrm{Sr}$ ratio measured in NIST SRM 1515 (apple leaves) was $0.71398 \pm 0.00004$. A procedure $^{221}$ for spatially resolved $\mathrm{Pu}$ isotope measurement was applied successfully to nuclear fuel particles deposited in soil around the Chernobyl Nuclear Power Plant. The use of $\mathrm{D}_{2}$ in place of $\mathrm{H}_{2}$ in the collision cell of a MC-ICP-MS instrument improved ${ }^{222}$ measurement of ${ }^{41} \mathrm{~K} /{ }^{39} \mathrm{~K}$ isotope ratios in a variety of samples, including plants. A method ${ }^{223}$ for isotope ratio measurement of $\mathrm{MeHg}$ extracted from sediment avoided the isotopic fractionation that can occur when a transient peak produced by chromatographic separation is introduced directly into a MCICP-MS instrument through use of an off-line preconcentration procedure. 
Simplifications in sample preparation made possible by the availability of $I C P-M S / M S$ included a single-column chromatography procedure ${ }^{224}$ for determination of ${ }^{135} \mathrm{Cs}$ concentrations and ${ }^{135} \mathrm{Cs} /{ }^{137} \mathrm{Cs}$ isotope ratios in soil and sediment, and a fast method ${ }^{225}$ for measuring ${ }^{90} \mathrm{Sr}$, ${ }^{137} \mathrm{Cs},{ }^{238} \mathrm{Pu},{ }^{239} \mathrm{Pu}$ and ${ }^{240} \mathrm{Pu}$ in soil digests. In a study ${ }^{226}$ of the quantitative determination of $\mathrm{C}$, it was suggested that routine measurement of residual $\mathrm{C}$ content, along with more conventional analytes, in plant digests by ICP-MS/MS could allow the efficiency of sample digestion to be assessed.

Analytical methods featuring chromatographic separation coupled with ICP-MS included an ionic-liquid-enhanced HPLC-ICP-MS method ${ }^{227}$ for As and Se speciation applicable to rice; a HPLC-VG-ICP-MS method ${ }^{228}$ for $\mathrm{Hg}^{\mathrm{II}}$ and $\mathrm{MeHg}$ in plants in which incorporation of a VG unit built in-house enhanced sensitivity relative to HPLC-ICP-MS by at least an order of magnitude; and a ID-HPLC-ICP-MS method ${ }^{123}$ that could be used to separate MBT, DBT, TBT, MPhT, DPhT and TPhT isolated from sediment extracts in $6.5 \mathrm{~min}$, yielding LOD values in the range $0.5-1.2 \mathrm{ng} \mathrm{L}^{-1}$. The latter method was proposed as an alternative to the more commonly used GC-ICP-MS approach, with the advantage that there is no need for analyte derivatisation prior to separation. A procedure ${ }^{229}$ for measurement of six polybrominated diphenyl ethers in sewage sludge by GC-ICP-MS was validated by spike addition (recoveries 95-104\%) and comparison with ID-GC-ICP-MS data.

Continuing interest in the environmental behaviour and fate of NPs has prompted the development of new methods. The concentrations of Ag NPs adsorbed into the structure of Arabidopsis thaliana plants were determined ${ }^{230}$ by SP-ICP-MS following an enzymatic digestion with Macerozyme R-10. The concentrations of $\mathrm{Cu}$ NPs in colloidal extracts of soil were also determined $^{231}$ by SP-ICP-MS. Another study $^{232}$ used FFF-SF-ICP-MS and stable isotope labelling to distinguish ${ }^{57} \mathrm{Fe} @ \mathrm{SiO}_{2}$ engineered NPs (iron oxide NPs isotopically enriched in ${ }^{57} \mathrm{Fe}$ and coated with a $\mathrm{SiO}_{2}$ shell) spiked into a resuspended river sediment slurry from the natural colloidal Fe background on the basis of their distinct isotopic fingerprints.

\subsubsection{Accelerator mass spectrometry}

Recent technological developments at AMS facilities should enhance capacity for analysis of soils, plants and related material. For example, the $1 \mathrm{MV}$ AMS system at the Centro Nacional de Aceleradores, Seville, Spain ${ }^{233}$ can now be used to measure ${ }^{236} \mathrm{U}$ routinely at environmental levels. Improvements at the Micro Analysis Laboratory Tandem Accelerator, University of Tokyo, Japan ${ }^{234}$ have been made for the measurement of ${ }^{129} \mathrm{I}$ (much of it arising in the aftermath of the Fukushima Daiichi Nuclear Power Plant accident) and ${ }^{236} \mathrm{U}$. 
There have also been improvements in sample preparation for AMS. Satou et al. ${ }^{235}$ reported an improved approach that chemically separated $\mathrm{Sr}$ from the sample matrix then used a mixed (1:4) $\mathrm{SrF}_{2}+\mathrm{PbF}_{2}$ target to produce intense beam currents for the measurement of ${ }^{90} \mathrm{Sr}$ in soil. Liu et $a{ }^{236}$ described a method for ${ }^{129} \mathrm{I}$ measurement that required minimal sample preparation and so could be very useful in emergency situations in which large numbers of samples need to be analysed rapidly for contamination assessment. Stable ${ }^{127}$ I carrier was added to $\mathrm{Nb}$ matrix powder, mixed with dried seaweed or sediment powder, and finally pressed directly into a target holder.

\subsubsection{Thermal ionisation mass spectrometry}

Methods for isotope ratio measurement have been reported for various elements. Application $^{237}$ of a method for the extraction of $\mathrm{Pu}$ and $\mathrm{U}$ from soils to samples from around the Fukushima Daiichi Nuclear Power Plant provided evidence that nuclear fuel had been released to the atmosphere during the accident. In another study ${ }^{238}, \mathrm{Fe}_{3} \mathrm{O}_{4} @ \mathrm{SiO}_{2}$ NPs were embedded in porous poly(ethersulfone) resin functionalised with ammonium and phosphate for measurement of $\mathrm{Pu}$ in soil by a single-bead TIMS method. The careful measurement of the recovery at each stage of a procedure ${ }^{239}$ for extraction of $\mathrm{B}$ from plants showed that the heavier isotope ${ }^{11} \mathrm{~B}$ was more enriched in leaves and flowers than in other tissues. A new method ${ }^{240}$ for extracting Cs from soil and plants with use of a novel ammonium molybdophosphate-polyacrylonitrile column gave the highest precision $(2-4 \%$ at $2 \sigma){ }^{135} \mathrm{Cs} /{ }^{137} \mathrm{Cs}$ ratios reported to date by TIMS for soil samples containing Cs at the fg level.

\subsubsection{Laser induced breakdown spectroscopy}

A review article provided an excellent overview ${ }^{241}$ (145 references) of sample treatment and preparation, including approaches for solid, liquid and biological specimens. The authors considered lack of attention to the development of rigorous sample preparation protocols one of the reasons that LIBS is not yet consider a mature technique. Another review ${ }^{242}$ (298 references) discussed the determination of trace elements in environmental samples, including soils, ores and water, whilst a third ${ }^{243}$ (75 references), in Chinese with English abstract, described achievements and research trends in the application of LIBS to soil.

Developments in the application of LIBS to soils included a hemispherical plasma confinement device ${ }^{244}$ that increased the intensity of lines for $\mathrm{Cd}, \mathrm{Cu}, \mathrm{Ni}, \mathrm{Pb}$ and $\mathrm{Zn}$ two to three-fold, thereby giving LOD values of $<10 \mathrm{mg} \mathrm{kg}^{-1}$. Signal enhancement was also achieved ${ }^{245}$ for several analytes by carefully optimising the delay time between the two laser pulses in double 
pulse LIBS. Spatially resolved measurements ${ }^{246}$ revealed a difference between the spectral intensity distributions of major elements $(\mathrm{K}, \mathrm{Na})$ and those of trace elements $(\mathrm{Cu}, \mathrm{Pb})$ in plasma derived from soil NRCCRM GBW 070008. This difference was attributed to greater selfabsorption occurring for the major elements. Analysis could be improved by judicious selection of the signal-collecting zone in the plasma. Background removal using a wavelet transform algorithm markedly improved ${ }^{247}$ the accuracy for measurement of $\mathrm{Pb}$, reducing the RMSEP from $>303$ to $26 \mathrm{mg} \mathrm{kg}^{-1}$.

Amongst the numerous LIBS methods published were single-element procedures for the determination of $\mathrm{Be}^{248}, \mathrm{Cr}^{249}, \mathrm{Mn}^{250}$ and $\mathrm{Pb}^{251}$ in soil and of $\mathrm{Cr}^{252}$ and $\mathrm{Pb}^{251}$ in plants. A multianalyte method ${ }^{253}$ for the determination of $\mathrm{Al}, \mathrm{Ca}, \mathrm{K}, \mathrm{Mg}, \mathrm{Mn}$ and $\mathrm{Na}$ in tea was reported. Microsampling strategies for LIBS analysis of dried sugar cane leaves were evaluated ${ }^{254}$ and a standard protocol recommended for the determination of $\mathrm{B}, \mathrm{Ca}, \mathrm{Cu}, \mathrm{Fe}, \mathrm{K}, \mathrm{Mg}, \mathrm{Mn}, \mathrm{P}, \mathrm{Si}$ and $\mathrm{Zn}$. This involved rastering three equally spaced sampling lines perpendicular to the leaf midrib, with 48 accumulated laser pulses per line. Results obtained for $\mathrm{Ca}, \mathrm{Fe}, \mathrm{K}, \mathrm{Mn}, \mathrm{P}$ and $\mathrm{Si}$ correlated well with EDXRF data.

In common with XRFS, LIBS is being increasingly applied not only to trace element measurements but also to the determination of bulk soil properties by proxy analysis. A PLS model $^{255}$ for prediction of soil $\mathrm{pH}$ was constructed based on selected spectral lines of 50 soil samples (the calibration set) and subsequently used to predict the $\mathrm{pH}$ of 10 additional samples (the validation set). Results were within $0.4 \mathrm{pH}$ units of those obtained by conventional methods for all but one sample. Use of similar modelling approaches ${ }^{256}$ allowed the estimation of the relative proportions of sand, silt and clay in the same 60 soil samples. The potential of PLS-DA and SVM algorithms ${ }^{257}$ for use in classification of different types of rocks and soil was demonstrated in a study of Chinese CRMs.

\subsubsection{X-ray spectrometry}

Review articles included a comprehensive overview ${ }^{258}$ (108 references) of the application of TXRFS in food analysis - including the analysis of fruit, vegetables and cereals - and a wellwritten, critical and accessible introduction ${ }^{259}$ ( 84 references) to the use of synchrotron radiation in plant research.

Optimisation of calibration strategies for XRFS was addressed in several articles. One group of researchers ${ }^{260}$ established that spiking solid matrices - NIST SRM 1571 (orchard leaves), 1633b (coal fly ash) and 4357 (ocean sediment) - with multi-element standard solutions allowed estimation of not only the added elements but also others by interpolation. In contrast, 
another team ${ }^{261}$ found that addition of liquid standards was unsuccessful for the determination of $\mathrm{S}$ in soil and plants, at least at the relatively high concentrations likely to be encountered following a chemical spill. It was recommended that solid $\mathrm{CaSO}_{4}$ be added directly to a wellcharacterised natural soil for soil analysis and to cellulose powder for plant analysis.

In the detection and characterisation of Pu in soil particles by multiple complementary $X$-ray techniques, conventional $\mu$ EDXRFS highlighted ${ }^{75}$ the location of the analyte and possible inter-element associations, high-resolution XRF images were obtained of Pu hotspots, and 3D confocal $\mu$ EDXRFS was used to confirm whether the $\mathrm{Pu}$ was part of a surface feature or incorporated within the soil matrix.

Advances in the analysis of plants included the first simultaneous microchemical mapping using $\mu \mathrm{EDXRFS}^{262}$ of As and $\mathrm{P}$ in ferns grown hydroponically in As-enriched nutrient solution, and a modelling study ${ }^{263}$ of factors contributing to the XRF background spectrum in samples composed principally of light elements. A detailed evaluation ${ }^{264}$ of limitations associated with the determination of $\mathrm{F}$ in solid materials by WDXRFS used rice contaminated with $\mathrm{F}$ as a test sample. A flow chart was presented of analytical strategies to improve sensitivity and accuracy in different situations.

Wider adoption of pXRFS for elemental analysis of soil or plants has continued although, unfortunately, not all new users appear aware of previous developments in the field, resulting in a degree of 'reinvention of the wheel' (i.e. repetition of well-established knowledge in newly published articles). Amongst the more useful contributions was a study ${ }^{265}$ of the effect of moisture on results obtained by pXRFS for $\mathrm{Ba}, \mathrm{Ca}, \mathrm{Cr}, \mathrm{Cu}, \mathrm{Fe}, \mathrm{Mn}, \mathrm{Pb}, \mathrm{Rb}, \mathrm{Sn}, \mathrm{Sr}$ and $\mathrm{Zn}$ in a set of 215 soil samples, which showed that the decrease in signal with increasing water content could be modelled using the Beer-Lambert Law. Other workers ${ }^{266}$ used pXRFS to measure Al, $\mathrm{Ca}, \mathrm{Fe}, \mathrm{K}, \mathrm{Mn}, \mathrm{Si}$, Ti and $\mathrm{Zr}$ concentrations down the walls of trial pits in Australia and then calculated geochemical index values that shed light on pedogenic pathways occurring at the site. A critical comparison ${ }^{267}$ of the performance of two pXRF instruments (a XOS prototype and a Thermo Niton XL3t) concluded that neither instrument was able to determine PTEs at concentrations $<15 \mathrm{mg} \mathrm{kg}^{-1}$ with good accuracy in tea and ethnic herbal medicine products. Highly recommended for those new to the field, was an accessible introduction ${ }^{268}$ to the measurement of plant nutrients by pXRFS.

As with LIBS, the use of XRFS together with other non-destructive types of spectrometry for proxy analysis is increasing. For example, in the analysis of 700 samples from across SubSaharan Africa, diffuse reflectance FT mid-IR spectroscopy and TXRFS were successfully 
used $^{269}$ to predict soil parameters related to nutrient binding capacity such as $\mathrm{pH}$, organic matter content and some exchangeable bases. Another study ${ }^{270}$ combined Vis-NIR DRS and pXRF data from 116 arid soils in Spain to predict salinity, gypsum content, $\mathrm{Ca}$ content and $\mathrm{CaCO}_{3}$ equivalent. 
Table 3

Digestion and extraction methods used in the analysis of soils, plants and related materials

\begin{tabular}{|c|c|c|c|c|c|c|}
\hline Analyte(s) & Sample & $\begin{array}{l}\text { Type of digestion or } \\
\text { extraction }\end{array}$ & Procedural notes & Detector & Validation & Reference \\
\hline $\begin{array}{l}\mathrm{Al}, \mathrm{B}, \mathrm{Ca}, \mathrm{Cu}, \mathrm{Fe}, \\
\mathrm{K}, \mathrm{Mg}, \mathrm{Mn}, \mathrm{Mo}, \mathrm{P}, \\
\mathrm{S}, \mathrm{Si} \text { and } \mathrm{Zn}\end{array}$ & Plants & $\begin{array}{l}\text { Two stage MAE (required } \\
\text { for effective solubilisation } \\
\text { of } \mathrm{Si} \text { ) }\end{array}$ & $\begin{array}{l}0.1 \text { g sample, } \\
\text { Stage } 1: 5 \mathrm{~mL} 1 \mathrm{M} \\
\mathrm{HNO}_{3}+5 \mathrm{~mL} 30 \% \\
(v / v) \mathrm{H}_{2} \mathrm{O}_{2}, 28 \mathrm{~min} \\
\text { Stage } 2: 5 \mathrm{~mL} 1.5 \mathrm{M} \\
\mathrm{NaOH}, 25 \mathrm{~min}\end{array}$ & ICP-AES & $\begin{array}{l}\text { NIST SRM } 1515 \text { (apple leaves), } \\
\text { NIST SRM } 1573 \text { (tomato } \\
\text { leaves), IRMM BCR } 679 \text { (white } \\
\text { cabbage powder), NCS DC } \\
73349 \text { (bush branches and } \\
\text { leaves) }\end{array}$ & 271 \\
\hline $\begin{array}{l}\mathrm{Al}, \mathrm{Cd}, \mathrm{Co}, \mathrm{Cr}, \mathrm{Cu} \\
\mathrm{Fe}, \mathrm{Mn}, \mathrm{Mo}, \mathrm{Ni} \\
\mathrm{Pb}, \mathrm{Sr}, \mathrm{V}, \mathrm{Zn}\end{array}$ & Tea, wheat & Closed PTFE vessel MAE & $\begin{array}{l}0.5 \mathrm{~g} \text { sample, } 2 \mathrm{~mL} \\
\mathrm{H}_{2} \mathrm{O}_{2}+3 \mathrm{~mL} \mathrm{HNO}_{3} \\
+2 \mathrm{~mL} \mathrm{H}_{2} \mathrm{O}, 21 \mathrm{~min}\end{array}$ & ICP-AES & $\begin{array}{l}\text { NIST SRM 1567a (wheat flour), } \\
\text { NRCCRM GBW } 07602 \text { (bush } \\
\text { branches and leaves), NRCCRM } \\
\text { GBW } 08505 \text { (tea), and spike } \\
\text { recovery }\end{array}$ & 272 \\
\hline As species & Rice & Water bath with shaking & $\begin{array}{l}1 \text { g sample, water, } 60 \\
\min , 85^{\circ} \mathrm{C}\end{array}$ & HPLC-ICP-MS & $\begin{array}{l}\text { NRCCRM GBW } 10043 \text { (rice } \\
\text { flour) and GBW } 10045 \text { (rice) }\end{array}$ & 273 \\
\hline $\begin{array}{l}\mathrm{As}, \mathrm{Ba}, \mathrm{Be}, \mathrm{Bi}, \mathrm{Co} \\
\mathrm{Cr}, \mathrm{Cu}, \mathrm{Ga}, \mathrm{Li}, \mathrm{Mo}, \\
\mathrm{Ni}, \mathrm{Pb}, \mathrm{Sn}, \mathrm{Sr}, \mathrm{V} \\
\text { Tl, U, Zn }\end{array}$ & Soil & MAE & $\begin{array}{l}0.3 \text { g sample, } 10 \% \\
(v / v) \mathrm{HNO}_{3}+7 \% \\
(v / v) \mathrm{HF}\end{array}$ & ICP-MS & NRCCRM GBW 07409 (soil) & 274 \\
\hline $\begin{array}{l}\text { As, } \mathrm{Cd}, \mathrm{Co}, \mathrm{Cr}, \mathrm{Cu} \\
\mathrm{Hg}, \mathrm{Mn}, \mathrm{Ni}, \mathrm{Pb} \\
\mathrm{Se}, \mathrm{Zn}\end{array}$ & Plants & UAE & $\begin{array}{l}0.5 \text { g sample, } 10 \mathrm{~mL} \\
\mathrm{HNO}_{3}+3 \mathrm{~mL} \mathrm{HCl}+ \\
3 \mathrm{~mL} \mathrm{H}_{2} \mathrm{O}_{2}, 90 \mathrm{~min} \\
40{ }^{\circ} \mathrm{C}\end{array}$ & ICP-AES & IRMM BCR 062 (olive leaves) & 275 \\
\hline $\mathrm{As}, \mathrm{Cd}, \mathrm{Hg}, \mathrm{Pb}$ & $\begin{array}{l}\text { Medicinal } \\
\text { plants }\end{array}$ & Closed vessel MAE & $\begin{array}{l}0.5 \text { g sample, } 4 \mathrm{M} \\
\mathrm{HNO}_{3}, 1 \mathrm{~h}\end{array}$ & $\begin{array}{l}\text { ICP-MS (As, Cd, } \\
\text { Pb), CVG-ICP- } \\
\text { MS (Hg) }\end{array}$ & $\begin{array}{l}\text { NIST SRM } 1547 \text { (peach leaves), } \\
\text { IRMM BCR } 062 \text { (olive leaves), } \\
\text { and spike recovery }\end{array}$ & 276 \\
\hline $\mathrm{As}, \mathrm{Cd}, \mathrm{Cr}, \mathrm{Pb}, \mathrm{Se}$ & Tea & Open vessel on hot plate & $\begin{array}{l}1 \mathrm{~g} \text { sample, } 10 \mathrm{~mL} \\
\mathrm{HNO}_{3} \text {, overnight at } \\
\text { room } \mathrm{T} \text { then heated } \\
\text { to semi-dryness }\end{array}$ & ETAAS & Spike recovery & 277 \\
\hline $\mathrm{As}, \mathrm{Cr}, \mathrm{Cu}$ & Wood & Closed flask in oven & $\begin{array}{l}\mathrm{HNO}_{3}+\mathrm{H}_{2} \mathrm{O}_{2}, 24 \mathrm{~h}, \\
95^{\circ} \mathrm{C}\end{array}$ & ICP-MS & NIST SRM 1575a (pine needles) & 278 \\
\hline $\mathrm{Au}, \mathrm{Pd}, \mathrm{Pt}$ & Sediment, & Closed PTFE vessel & Aqua regia & ETAAS $(\mathrm{Au})$, & Soil and stream sediment CRMs & 279 \\
\hline
\end{tabular}




\begin{tabular}{|c|c|c|c|c|c|c|}
\hline & soil & & & ICP-MS (Pd, Pt) & & \\
\hline $\mathrm{Ca}, \mathrm{Cu}, \mathrm{Mg}, \mathrm{Mn}$ & $\begin{array}{l}\text { Oilseed } \\
\text { crops }\end{array}$ & UAE & $\begin{array}{l}0.3 \mathrm{~g} \text { sample, } 10 \mathrm{~mL} \\
1.4 \mathrm{M} \mathrm{HNO}_{3}, 10 \mathrm{~min}, \\
25^{\circ} \mathrm{C}\end{array}$ & FAAS & $\begin{array}{l}\text { Brazilian soybean RM PIATV } \\
2 / 2020 \text { and } 5 / 2010\end{array}$ & 281 \\
\hline $\mathrm{Cd}, \mathrm{Cr}, \mathrm{Cu}, \mathrm{Pb}, \mathrm{Zn}$ & Sediment & UAE & & FAAS, ETAAS & CRM and spike recovery & 282 \\
\hline $\begin{array}{l}\mathrm{Co}, \mathrm{Cr}, \mathrm{Cu}, \mathrm{Fe} \\
\mathrm{Mn}, \mathrm{Ni}, \mathrm{Se}, \text { and } \mathrm{Zn}\end{array}$ & $\begin{array}{l}\text { Soil, } \\
\text { vegetable, } \\
\text { nuts, grain }\end{array}$ & MAE & & ICP-AES & $\begin{array}{l}\text { NIST SRM } 7001 \text { (light sandy } \\
\text { soil), NIST SRM } 1515 \text { (apple } \\
\text { leaves) }\end{array}$ & 283 \\
\hline $\mathrm{Hg}$ & $\begin{array}{l}\text { Sediment, } \\
\text { soil }\end{array}$ & Water bath & $\begin{array}{l}0.5 \mathrm{~g} \text { sample, } 1 \mathrm{~mL} \\
40 \%(v / v) \\
\text { Universol }{ }^{\circledR}, 30 \mathrm{~min} \text {, } \\
60^{\circ} \mathrm{C}\end{array}$ & CV-AAS & $\begin{array}{l}\text { IRMM ERM CC580 (estuarine } \\
\text { sediment) }\end{array}$ & 284 \\
\hline $\mathrm{V}$ & Sediment & Open vessel on hotplate & $\begin{array}{l}0.25 \text { g sample, } 25 \\
\mathrm{~mL} 0.1 \mathrm{M} \mathrm{Na}_{2} \mathrm{CO}_{3} \\
10 \mathrm{~min}\end{array}$ & ETAAS & $\begin{array}{l}\text { NRCC PACS-2 and MESS-3 } \\
\text { (sediments) and spike recovery }\end{array}$ & 285 \\
\hline
\end{tabular}


Table 4 Preconcentration methods involving coprecipitation used in the analysis of soils, plants and related materials

\begin{tabular}{|c|c|c|c|c|c|c|}
\hline Analyte(s) & Matrix & Carrier & Detector & $\operatorname{LOD}\left(\mu \mathrm{g} \mathrm{L}^{-1}\right)$ & $\begin{array}{l}\text { CRMs or other } \\
\text { validation }\end{array}$ & Reference \\
\hline $\begin{array}{l}\mathrm{Co}, \mathrm{Cu}, \mathrm{Fe}, \mathrm{Mn} \text {, } \\
\mathrm{Ni}, \mathrm{Pb}\end{array}$ & Spinach, water & Ytterbium hydroxide & FAAS & $2.1-8.2$ & $\begin{array}{l}\text { NIST SRM 1570a } \\
\text { (spinach leaves), } \\
\text { SPS WW2 (waste } \\
\text { water) }\end{array}$ & 286 \\
\hline
\end{tabular}


Table 5 Preconcentration methods involving liquid-phase microextraction used in the analysis of soils, plants and related materials

\begin{tabular}{|c|c|c|c|c|c|c|c|}
\hline Analyte(s) & $\begin{array}{l}\text { Sample } \\
\text { matrix }\end{array}$ & Method & Reagent(s) & Detector & $\operatorname{LOD}\left(\mu \mathrm{g} \mathrm{L}^{-1}\right)$ & CRMs or other validation & Reference \\
\hline $\mathrm{Au}, \mathrm{Pd}$ & $\begin{array}{l}\text { Sediment, } \\
\text { ore, water, }\end{array}$ & DLLME & $\begin{array}{l}\text { N-(6-morpholin-4-ylpyridine-3-yl)- } \\
\text { N'-phenylthiourea }\end{array}$ & FAAS & $\begin{array}{l}1.75 \text { for } \mathrm{Au}, \\
1.65 \text { for } \mathrm{Pd}\end{array}$ & HPS CRM SA-C (sandy soil C) & 287 \\
\hline $\mathrm{Cd}$ & $\begin{array}{l}\text { Fruit, } \\
\text { vegetables, } \\
\text { tobacco, } \\
\text { water }\end{array}$ & LLME & APDC, switchable polarity solvent & FAAS & 0.16 & $\begin{array}{l}\text { NWRI TMDA } 51.3 \text { and } 53.3 \\
\text { (fortified water), SPS WW2 } \\
\text { (waste water), NIST SRM } \\
\text { 1573a (tomato leaves), INCT- } \\
\text { OBTL-5 (tobacco leaves). }\end{array}$ & 288 \\
\hline $\mathrm{Cd}$ & $\begin{array}{l}\text { Fruit, } \\
\text { vegetables, } \\
\text { water }\end{array}$ & LLME & $\begin{array}{l}\text { 1-(2-pyridylazo)-2-naphthol, } \\
\text { "switchable water" }\end{array}$ & ETAAS & 0.0004 & $\begin{array}{l}\text { NRCC SLRS-4 (riverine } \\
\text { water), NIST SRM } 1515 \text { (apple } \\
\text { leaves) }\end{array}$ & 289 \\
\hline $\mathrm{Cd}, \mathrm{Cu}, \mathrm{Ni}$ & Sediment & CPE & $\begin{array}{l}\text { 2-(5-bromo-2-pyridylazo)-5- } \\
\text { (diethylamino)-phenol, Triton X- } \\
114\end{array}$ & ICP-AES & $\begin{array}{l}0.066 \text { for } \mathrm{Cd}, \\
0.15 \text { for } \mathrm{Cu} \\
0.19 \text { for } \mathrm{Ni}\end{array}$ & $\begin{array}{l}\text { NIST SRM 1646a (estuarine } \\
\text { sediment), NIST SRM } 2702 \\
\text { (marine sediment) }\end{array}$ & 290 \\
\hline $\mathrm{Cd}, \mathrm{Pb}$ & $\begin{array}{l}\text { Hair, soil, } \\
\text { water }\end{array}$ & LLME & $\begin{array}{l}\text { Deep eutectic solvent modified } \\
\text { magnetic NPs }\end{array}$ & FAAS & $\begin{array}{l}0.1 \text { for } \mathrm{Cd} \\
0.4 \text { for } \mathrm{Pb}\end{array}$ & $\begin{array}{l}\text { Spike recovery, comparison } \\
\text { with ETAAS }\end{array}$ & 291 \\
\hline $\mathrm{Co}$ & $\begin{array}{l}\text { Cereal, fruit, } \\
\text { lentils }\end{array}$ & LLME & $\begin{array}{l}\text { Diethyldithiocarbamate, } \\
\text { supramolecular solvent (1- } \\
\text { decanol/THF) }\end{array}$ & FAAS & 1.89 & $\begin{array}{l}\text { NWRI TMDA } 53.3 \text { and } 64.2 \\
\text { (water), SPS WW2 (waste } \\
\text { water), INCT-OBTL-5 } \\
\text { (tobacco leaves), NCS } \\
\text { ZC73033 (scallions) }\end{array}$ & 292 \\
\hline $\mathrm{Cu}$ & $\begin{array}{l}\text { Hair, fruit, } \\
\text { vegetables, } \\
\text { spices, water }\end{array}$ & LLME & $\begin{array}{l}\text { 1-(2-pyridylazo)-2-naphthol, } \\
\text { switchable polarity solvent }\end{array}$ & FAAS & 1.8 & $\begin{array}{l}\text { NWRI TMDA 51.3, } 53.3 \text { and } \\
64.2 \text { (water), NIST SRM 1573a } \\
\text { (tomato leaves), INCT-OBTL- } \\
5 \text { (tobacco leaves), NCS } \\
\text { ZC8100 2b (human hair) }\end{array}$ & 293 \\
\hline $\begin{array}{l}\mathrm{Eu}, \mathrm{Nd} \\
\mathrm{Sm} \dagger\end{array}$ & $\begin{array}{l}\text { Sediment, } \\
\text { soil }\end{array}$ & $\mathrm{CPE}$ & $\begin{array}{l}\mathrm{N}, \mathrm{N}, \mathrm{N}^{\prime}, \mathrm{N}^{\prime} \text {-tetraisopropyl } \\
\text { diglycolamide, Triton X-114 }\end{array}$ & $\begin{array}{l}\text { ICP- } \\
\mathrm{MS} / \mathrm{MS} \\
\end{array}$ & $\begin{array}{l}\text { Isotope ratio } \\
\text { measurement }\end{array}$ & $\begin{array}{l}\text { NIST SRM 2709a (San Joaquin } \\
\text { soil) }\end{array}$ & 294 \\
\hline $\mathrm{Hg} \dagger$ & Sediment & $\begin{array}{l}\text { IL- } \\
\text { VALLME }\end{array}$ & $\begin{array}{l}\text { Dithizone, 1-hexyl-3- } \\
\text { methylimidazolium }\end{array}$ & $\begin{array}{l}\text { HPLC- } \\
\text { CV-AFS }\end{array}$ & $\begin{array}{l}0.037-0.061 \\
\mu \mathrm{g} \mathrm{kg}{ }^{-1}\end{array}$ & $\begin{array}{l}\text { IAEA-405 (estuarine } \\
\text { sediment), IRRM ERM CC580 }\end{array}$ & 295 \\
\hline
\end{tabular}




\begin{tabular}{|c|c|c|c|c|c|c|c|}
\hline & & & hexafluorophosphate & & & (estuarine sediment) & \\
\hline Mo & Plants & DLLME & 8-hydroxyquinoline, 1-undecanol & ICP-AES & 0.2 & $\begin{array}{l}\text { NIST 1568a (rice flour), NIST- } \\
8433 \text { (corn bran) and NIST- } \\
1515 \text { (apple leaves) }\end{array}$ & 296 \\
\hline $\mathrm{Pb}$ & Plants, water & LLME & $\begin{array}{l}\text { APDC, dicationic ionic liquid, } \\
\text { magnetic NPs }\end{array}$ & FAAS & 0.7 & Spike recovery & 297 \\
\hline $\mathrm{Se}$ & $\begin{array}{l}\text { Beer, eggs, } \\
\text { fruit, honey, } \\
\text { milk, wine }\end{array}$ & $\begin{array}{l}\text { UA-IL- } \\
\text { DLLME }\end{array}$ & $\begin{array}{l}\text { 1-phenylthiosemicarbazide, 1- } \\
\text { hexyl-3-methylimidazolium bis } \\
\text { (trifluoromethylsulfonyl) imide }\end{array}$ & ETAAS & 0.012 & $\begin{array}{l}\text { LGC } 6010 \text { (water), NIST SRM } \\
1573 \text { a (tomato leaves) }\end{array}$ & 298 \\
\hline
\end{tabular}

$\ddagger^{143 / 145} \mathrm{Nd},{ }^{147 / 149} \mathrm{Sm}$ and ${ }^{151 / 153} \mathrm{Eu}$

$\uparrow$ inorganic $\mathrm{Hg}, \mathrm{MeHg}, \mathrm{EtHg}$ 
Table 6 Preconcentration methods involving solid phase extraction used in the analysis of soils, plants and related materials

\begin{tabular}{|c|c|c|c|c|c|c|c|}
\hline Analyte(s) & Matrix & Substrate & $\begin{array}{l}\text { Substrate coating/modifying } \\
\text { agent or analyte complexing agent }\end{array}$ & Detector & $\operatorname{LOD}\left(\mu \mathrm{g} \mathrm{L}^{-1}\right)$ & $\begin{array}{l}\text { CRMs or other } \\
\text { validation }\end{array}$ & Reference \\
\hline $\mathrm{Ag}$ & Soil, water & $\begin{array}{l}\text { Magnetic halloysite } \\
\text { nanotubes }\end{array}$ & $\begin{array}{l}\text { 5-( } p \text {-dimethylaminobenzylidene) } \\
\text { rhodanine }\end{array}$ & FAAS & 1.6 & Spike recovery & 300 \\
\hline $\mathrm{Au}$ & $\begin{array}{l}\text { Anodic slime, } \\
\text { soil, water }\end{array}$ & MWCNTs & None & FAAS & 1.71 & Spike recovery & 301 \\
\hline $\mathrm{Au}$ & $\begin{array}{l}\text { Anodic slime, } \\
\text { soil, water }\end{array}$ & Diaion SP 207 & 2-aminobenzothiazole & FAAS & 3.8 & $\begin{array}{l}\text { CDN-GS-3D (gold } \\
\text { ore) }\end{array}$ & 302 \\
\hline $\begin{array}{l}\mathrm{Cd}, \mathrm{Co} \\
\mathrm{Cu}\end{array}$ & $\begin{array}{l}\text { Chicken, } \\
\text { honey, water }\end{array}$ & Silica gel & $\begin{array}{l}\text { 2-(N,N'-bis(2,3- } \\
\text { dihydroxybenzaldimin)) } \\
\text { aminoethylamine }\end{array}$ & FAAS & $\begin{array}{l}0.65 \text { for } \mathrm{Cd}, \\
1.42 \text { for } \mathrm{Co} \text {, } \\
0.52 \text { for } \mathrm{Cu}\end{array}$ & $\begin{array}{l}\text { INCT CTA-VLT-2 } \\
\text { (tobacco leaves), } \\
\text { NWRI NWTM-15.2 } \\
\text { (water) }\end{array}$ & 304 \\
\hline $\begin{array}{l}\mathrm{Cd}, \mathrm{Co}, \\
\mathrm{Cu}, \mathrm{Ni}, \mathrm{Pb}\end{array}$ & $\begin{array}{l}\text { Black pepper, } \\
\text { chilli, hemp, } \\
\text { water }\end{array}$ & $\begin{array}{l}\text { Magnetic graphene } \\
\text { oxide- } \\
\text { poly(vinylacetate-co- } \\
\text { divinylbenzene) }\end{array}$ & allylamine & FAAS & $0.37-2.39$ & $\begin{array}{l}\text { NIST SRM 1573a } \\
\text { (tomato leaves), } \\
\text { INCT-OBTL-5 } \\
\text { (tobacco leaves), SPS } \\
\text { WW2 (waste water), } \\
\text { and TMDA } 64.2 \\
\text { (water), }\end{array}$ & 305 \\
\hline $\mathrm{Cd}, \mathrm{Cu}$ & Soil, water & Magnetic zeolite & $\begin{array}{l}\text { 2-(3,4-dihydroxyphenyl)-1,3- } \\
\text { dithiane }\end{array}$ & FAAS & Not reported & $\begin{array}{l}\text { Spike recovery, } \\
\text { comparison with } \\
\text { ETAAS }\end{array}$ & 306 \\
\hline $\begin{array}{l}\mathrm{Cd}, \mathrm{Cu}, \\
\mathrm{Ni}\end{array}$ & $\begin{array}{l}\text { Mushroom, } \\
\text { water }\end{array}$ & Amberlite XAD-4 & Thermophilic bacterial strain KG9 & FAAS & $\begin{array}{l}0.42 \text { for } \mathrm{Cd} \text {, } \\
0.54 \text { for } \mathrm{Cu} \text {, } \\
1.24 \text { for } \mathrm{Ni}\end{array}$ & $\begin{array}{l}\text { NRCC-SLRS4 } \\
\text { (riversine water), } \\
\text { NIST SRM 1570a } \\
\text { (spinach leaves }\end{array}$ & 307 \\
\hline $\mathrm{Cd}, \mathrm{Cu}$, & Fruit, sugar & Magnetic NPs & 2-aminobenzothiazole & FAAS & 0.03 for $\mathrm{Cd}$ & LGC RM 6010 & 308 \\
\hline
\end{tabular}




\begin{tabular}{|c|c|c|c|c|c|c|c|}
\hline $\mathrm{Ni}$ & & & & & $\begin{array}{l}0.009 \text { for } \mathrm{Cu}, \\
0.1 \text { for } \mathrm{Ni}\end{array}$ & $\begin{array}{l}\text { (drinking water), NIST } \\
\text { SRM } 1515 \text { (apple } \\
\text { leaves) }\end{array}$ & \\
\hline $\begin{array}{l}\mathrm{Cd}, \mathrm{Cu} \\
\mathrm{Ni}, \mathrm{Zn}\end{array}$ & Tea, water & $\begin{array}{l}\text { Nanoporous } \\
\text { pumpellyite zeolite }\end{array}$ & $\begin{array}{l}\text { 2-phenyl-4-(1-(2-thienyl) } \\
\text { methylidene)-5-oxazolone }\end{array}$ & FAAS & $1.1-3.2$ & Tea leaf CRM & 309 \\
\hline $\begin{array}{l}\mathrm{Cd}, \mathrm{Cu} \\
\mathrm{Ni}, \mathrm{Pb}, \mathrm{Zn}\end{array}$ & $\begin{array}{l}\text { Cabbage, rice, } \\
\text { tomato, water }\end{array}$ & MWCNTs & 2-(2-benzothiazolylazo)orcinol & FAAS & $0.7-2.6$ & $\begin{array}{l}\text { NIST SRM 1570a } \\
\text { (spinach leaves) }\end{array}$ & 310 \\
\hline $\mathrm{Cd}, \mathrm{Ni}, \mathrm{Zn}$ & $\begin{array}{l}\text { Plants, tea, } \\
\text { water }\end{array}$ & Polyurethane foam & 2-aminothiazole & FAAS & $\begin{array}{l}3.0 \text { for } \mathrm{Cd} \text {, } \\
2.0 \text { for } \mathrm{Ni} \text {, } \\
3.0 \text { for } \mathrm{Zn}\end{array}$ & Spike recovery & 311 \\
\hline $\mathrm{Cd}, \mathrm{Pb}$ & Fruit, water & Benzophenone & dithizone & FAAS & $\begin{array}{l}0.2 \text { for } \mathrm{Cd}, \\
1.2 \text { for } \mathrm{Pb}\end{array}$ & $\begin{array}{l}\text { NCS DC73323 (soil) } \\
\text { for Cd, Zidarovo- } \\
\text { PMZrZ CRM206 BG } \\
326 \text { (polymetallic gold } \\
\text { ore) for Pb }\end{array}$ & 312 \\
\hline $\mathrm{Cd}, \mathrm{Pb}$ & $\begin{array}{l}\text { Honey, } \\
\text { lentils, nuts, } \\
\text { potato, rice, } \\
\text { tea, water }\end{array}$ & Magnetic NPs & $\begin{array}{l}\text { Thermophilic bacteria } \\
\text { Geobacillus galactosidasius }\end{array}$ & ICP-AES & $\begin{array}{l}0.06 \text { for } \mathrm{Cd} \\
0.07 \text { for } \mathrm{Pb}\end{array}$ & $\begin{array}{l}\text { NWRI NWTM-15 } \\
\text { (water), SCP Science } \\
\text { EU-L-2 (wastewater), } \\
\text { NCS DC73350 (poplar } \\
\text { leaves), NIST SRM } \\
\text { 1643e (simulated fresh } \\
\text { water) }\end{array}$ & 313 \\
\hline $\mathrm{Cd}, \mathrm{Pb}$ & $\begin{array}{l}\text { Hair, fruit, } \\
\text { vegetables, } \\
\text { spices, } \\
\text { tobacco, } \\
\text { water }\end{array}$ & $\begin{array}{l}\text { Bovine serum } \\
\text { albumin-Cu }{ }^{\mathrm{II}} \text { hybrid } \\
\text { nanoflowers }\end{array}$ & None & SS-FAAS & $\begin{array}{l}0.37 \text { for } \mathrm{Cd} \\
8.8 \text { for } \mathrm{Pb}\end{array}$ & $\begin{array}{l}\text { NWRI TMDA } 53.3 \\
\text { and } 70 \text { (water), SPS } \\
\text { WW2 (waste water), } \\
\text { NCS DC73349 (bush } \\
\text { branches and leaves) }\end{array}$ & 314 \\
\hline $\begin{array}{l}\text { Cr species } \\
*\end{array}$ & Tea, water & $\begin{array}{l}\text { Cellulose acetate } \\
\text { membrane filter }\end{array}$ & Cochineal red A & FAAS & 1.4 & $\begin{array}{l}\text { NWRI TMDA } 54.4 \\
\text { (lake water) and TM } \\
25.3 \text { (water), NIST } \\
\text { SRM } 2710 \text { (Montana } \\
\text { soil), IRMM BCR } \\
\text { 144R (sewage sludge) }\end{array}$ & 315 \\
\hline $\mathrm{Cr}, \mathrm{Cu}, \mathrm{Pb}$ & Liver, water & magnetite & $\begin{array}{l}\text { Shell 1: Poly(3- } \\
\text { (trimethoxysilyl)propyl }\end{array}$ & ICP-AES & $\begin{array}{l}0.029 \text { for } \mathrm{Cr} \\
0.079 \text { for } \mathrm{Cu}\end{array}$ & $\begin{array}{l}\text { NRCCRM GBW } \\
080001 \text { (tea leaves) }\end{array}$ & 316 \\
\hline
\end{tabular}




\begin{tabular}{|c|c|c|c|c|c|c|c|}
\hline & & & $\begin{array}{l}\text { methacrylate } \\
\text { Shell 2: dithizone grafted onto } \\
\text { poly(allyl chloride) }\end{array}$ & & 0.87 for $\mathrm{Pb}$ & & \\
\hline $\mathrm{Co}, \mathrm{Ni}, \mathrm{Pb}$ & $\begin{array}{l}\text { Fertiliser, } \\
\text { water }\end{array}$ & $\begin{array}{l}\text { Activated carbon } \\
\text { cloth }\end{array}$ & EDTA & FAAS & $\begin{array}{l}0.99 \text { for } \mathrm{Co} \\
0.91 \text { for } \mathrm{Ni} \\
4.4 \text { for } \mathrm{Pb}\end{array}$ & $\begin{array}{l}\text { SRS WW2 (waste } \\
\text { water), IRMM BCR } \\
\text { 146R (sewage sludge } \\
\text { amended soil) }\end{array}$ & 317 \\
\hline $\mathrm{Cu}, \mathrm{Pb}$ & $\begin{array}{l}\text { Cumin, } \\
\text { lentils, } \\
\text { lettuce, } \\
\text { potato, } \\
\text { strawberry }\end{array}$ & $\begin{array}{l}\text { Nanosized } \\
\text { spongelike } \mathrm{Mn}_{3} \mathrm{O}_{4}\end{array}$ & none & FAAS & $\begin{array}{l}2.6 \text { for } \mathrm{Cu} \\
3.0 \text { for } \mathrm{Pb}\end{array}$ & $\begin{array}{l}\text { IRMM BCR } 482 \\
\text { (lichen), NIST SRM } \\
\text { 1573a (tomato leaves) }\end{array}$ & 318 \\
\hline $\mathrm{Ni}$ & Plants, water & $\begin{array}{l}\text { Ion imprinted } \\
\text { polymer }\end{array}$ & none & ICP-AES & 0.38 & NCS ZC73036 (tea) & 319 \\
\hline $\mathrm{Ni}$ & $\begin{array}{l}\text { Plants, soil, } \\
\text { tobacco, } \\
\text { water }\end{array}$ & $\begin{array}{l}\text { Alumina coated } \\
\text { magnetite NPs }\end{array}$ & Dimethylglyoxim/SDS & FAAS & 4.6 & Spike recovery & 320 \\
\hline $\mathrm{Ni}$ & Water & $\begin{array}{l}\mathrm{SiO}_{2} / \mathrm{Al}_{2} \mathrm{O}_{3} / \mathrm{Sb}_{2} \mathrm{O}_{5} \text { sol } \\
\text { gel }\end{array}$ & none & FAAS & 0.48 & $\begin{array}{l}\text { NRCC MESS-3 } \\
\text { (marine sediment) }\end{array}$ & 321 \\
\hline $\mathrm{Pb}$ & Rice & $\begin{array}{l}\text { Mercapto-grafted } \\
\text { silica polymer }\end{array}$ & none & ETAAS & 0.94 & Spike recovery & 322 \\
\hline $\mathrm{Pb}$ & $\begin{array}{l}\text { Plants, serum, } \\
\text { water }\end{array}$ & $\begin{array}{l}\text { Nano-carbon black } \\
\text { particles }\end{array}$ & $\begin{array}{l}\text { 3- } \\
\text { mercaptopropyltrimethoxysilane }\end{array}$ & FAAS & 1.33 & $\begin{array}{l}\text { NRCC MESS-3 } \\
\text { (marine sediment) }\end{array}$ & 323 \\
\hline $\mathrm{Pt}$ & Soil, water & $\begin{array}{l}\mathrm{Fe}_{3} \mathrm{O}_{4} / \text { graphene/poly } \\
\text { pyrrole } \\
\text { nanocomposite }\end{array}$ & none & FAAS & 16 & $\begin{array}{l}\text { NIST SRM } 2556 \text { (used } \\
\text { auto catalyst pellets), } \\
\text { spike recovery }\end{array}$ & 324 \\
\hline $\mathrm{U}$ & Soil, water & $\begin{array}{l}\text { Titanium oxide } \\
\text { nanotubes }\end{array}$ & $\mathrm{CuFe}_{2} \mathrm{O}_{4}$ quantum dots & ICP-AES & 0.12 & Spike recovery & 325 \\
\hline
\end{tabular}

${ }^{*} \mathrm{Cr}{ }^{\mathrm{III}}$, then reduction, measurement of $\mathrm{Cr}$, and estimation of $\mathrm{Cr}^{\mathrm{VI}}$ by difference 


\section{$4 \quad$ Analysis of geoglogical materials}

\subsection{Reference materials and data quality}

With the rapid increase in isotopic analytical facilities worldwide, various approaches have been taken to satisfy the current demand for well-characterised isotopic RMs. One popular strategy has been to take RMs originally prepared for elemental analysis and assess their suitability as matrix-matched isotope RMs. Examples included the analysis of 24 geological $\mathrm{RMs}$ for $\mathrm{Mg}$ isotopes ${ }^{326}$, three Chinese igneous rock $\mathrm{RMs}$ for $\mathrm{Fe}$ and $\mathrm{Hf}$ isotopes $^{327}$ and a variety of RMs including 20 igneous and sedimentary rocks for Mo isotope ratios $^{328}$. Fourny et al. ${ }^{329}$ provided $\mathrm{Hf}-\mathrm{Nd}-\mathrm{Pb}-\mathrm{Sr}$ isotope data on 11 rock RMs covering a wide range of geological compositions, while another study ${ }^{330}$ published long term QC data for the $\mathrm{Hf}-\mathrm{Nd}-\mathrm{Pb}-\mathrm{Sr}$ isotopic composition of USGS RM BCR-2 (Columbia River Basalt). Unfortunately, BCR-2 was not included in the compilation by Fourny et al. ${ }^{329}$, although both papers noted a need to leach basaltic RMs prior to dissolution to obtain reproducible $\mathrm{Pb}$ isotope ratios. In these examples, care was taken to control the accuracy and precision of the analytical data as far as possible and the resulting data were compared with other published values where available. While all these efforts are highly commendable, significant progress in developing well-characterised RMs for the geological isotope community will only be achieved when reliable consensus values are available, rather than just another set of data that generally agrees with previous published values. This goal will require much more rigorous metrological examination of data acquired in a planned exercise to avoid inter-laboratory biases. As an interim measure, Jochum et $a l .{ }^{331}$ calculated new reference values and their uncertainties at the $95 \%$ confidence level for 19 of the most popular geological RMs accessed in the GeoReM database. They took the most reliable published data sets available and followed ISO guidelines as closely as possible. These new reference values, for a wide range of major, minor and trace elements, will be known as the GeoReM preferred values.

A paucity of suitable matrix-matched calibration standards for the microanalysis of manganese nodules prompted Jochum et al. ${ }^{332}$ to prepare a synthetic RM suitable for the analysis of material from a wide range of different Mn-Fe deposits. This new RM, FeMnOx1, was examined with three LA systems (200 nm fs, and $193 \mathrm{~nm}$ and $213 \mathrm{~nm} \mathrm{~ns}$ lasers) using different spot sizes and fluence. It was homogeneous in the $\mathrm{nm}$ to $\mu \mathrm{m}$ range and therefore well suited to microanalytical applications. Repeated measurements of test portion masses of 5-100 ng had an RSD of 2-3\%, comparable to those of reference glasses such as NIST SRM 610. Seven laboratories using five different bulk and microanalytical techniques were 
involved in the characterisation of this RM. A pressed powder pellet and fused bead produced from ultrafine chalcopyrite and pyrite RM powders ${ }^{333}$ (China National Research Centre for Analysis) were homogeneous enough to act as in-house standards for the measurement of Os isotope ratios in sulfides by LA-MC-ICP-MS. The pyrite fused bead showed a greater degree of phase separation than that prepared from chalcopyrite, implying that that the $\mathrm{Fe}-\mathrm{S}$ system may be more suitable than the $\mathrm{Cu}-\mathrm{Fe}-\mathrm{S}$ system for making sulfide fused beads.

With the increased sensitivity of modern analytical instrumentation, the mass of test portion required for quantification has decreased. However, accurate determinations can be compromised by microheterogeneities within a sample or RM. This is often referred to as the 'nugget effect', especially when precious metals such as $\mathrm{Au}, \mathrm{Ir}, \mathrm{Pd}, \mathrm{Pt}$ and $\mathrm{Ru}$ are the target elements. In a novel approach, Bedard et $a l^{334}$ estimated the minimum mass required for a representative sample by mapping the distribution of minerals containing precious metals in relevant RMs, mainly sulfides, by $\mu$-XRFS. The importance of treating RMs and unknowns in exactly the same manner was emphasised.

Several new mineral standards have been characterised and are available on request. A new titanite standard ${ }^{335}$, MKED1, from Queensland, Australia, with relatively high concentrations of REEs, Th and U, was shown to be largely free of inclusions and have a high degree of elemental and isotopic homogeneity, including very low levels of common $\mathrm{Pb}$. Comprehensive bulk sample and in situ microanalysis demonstrated its suitability as an RM for $\mathrm{U}-\mathrm{Pb}$ dating and the $\mathrm{Nd}-\mathrm{Sm}$ isotope composition of titanites. Over 1400 EPMA and 700 ion probe measurements ${ }^{336}$ confirmed homogeneous distributions of $\mathrm{Li}$ and its isotopes in 11 ultramafic mineral separates of olivine, orthopyroxene and clinopyroxene from Cenozoic basalts in northern China. These separates were deemed to be suitable for use as RMs for calibration and measurement by SIMS and LA-MC-ICP-MS. A gem garnet ${ }^{337}$, GA1 from Sri Lanka, characterised for major and trace elements using LA-ICP-MS with a spot size of 35 $\mu \mathrm{m}$, was homogeneous for all the elements determined except V. Reference values for 40 elements were reported.

Fission track dating of apatites by direct measurement of $U$ concentrations using LAICP-MS depends on the availability of homogeneous RMs for accurate calibration. Until recently, no suitable matrix-matched RMs were available. However, Soares et al. ${ }^{338}$ identified two large natural apatite crystals as potential RMs for this purpose: a $1 \mathrm{~cm}^{3}$ fraction of a Durango crystal $\left(7.5 \mu \mathrm{g} \mathrm{g}^{-1} \mathrm{U}\right)$ and a $1 \mathrm{~cm}^{3}$ Mud Tank crystal $\left(6.9 \mu \mathrm{g} \mathrm{g}^{-1} \mathrm{U}\right)$. Major element compositions were determined by EPMA, and a combination of ID-ICP-MS and LA-ICP-MS was used to confirm the homogenous distribution of $U$ in the samples. The overall 
uncertainties on the mean $\mathrm{U}$ concentrations of $\leq 1.5 \% \mathrm{RSD}$ were relatively small compared to the overall precision of the LA-ICP-MS measurements of $c a$. $4 \%$. These results represented an important step in establishing in situ dating routines for fission track analysis by LA-ICPMS and these materials will be shared with the fission-track community.

\subsection{Solid sample introduction}

\subsubsection{Laser ablation inductively coupled plasma mass spectrometry.}

Current thinking on elemental fractionation and matrix effects in laser-based sampling techniques and ways to minimise them were the subject of a tutorial review ${ }^{339}$ (277 references). A series of experiments ${ }^{340}$ using six geological RMs helped to distinguish the influence of the plasma on elemental fractionation from processes occurring at the ablation site and in the mass spectrometer. The thermal state of the plasma was estimated from the ${ }^{38} \mathrm{Ar}^{+} /{ }^{40} \mathrm{Ar}_{2}{ }^{+}$ratio. Element-specific behaviour dominated under cool conditions but vanished under hot plasma conditions. The more robust operating conditions obtained by tuning the ICP for hot plasma conditions improved matrix tolerance, sample decomposition and the degree of ionisation, while also reducing the formation of polyatomic ions. Guidance was given for the rigorous control of low sample and auxiliary gas flows while at the same time maintaining efficient extraction and focussing of the mass spectrometer.

Currently there is much interest in the use of LA-ICP-MS for quantitative elemental imaging of solid samples as it offers several advantages over other techniques. For example, LA-ICP-MS has better LODs than electron beam techniques, it is considerably cheaper than SIMS to operate, and, because the LA is performed at atmospheric pressure, it can handle samples with high moisture content in contrast with other techniques where samples are placed in a high vacuum. However, there are many factors to consider when optimising a LAICP-MS system for this purpose, as exemplified in experiments ${ }^{341}$ performed to optimise LAICP-MS mapping of trace element concentrations in igneous minerals. Maps of clinopyroxene and amphibole macrocrysts were produced using a $193 \mathrm{~nm}$ excimer laser system with a two-volume ablation cell coupled to a quadrupole ICP-MS instrument. Evenly ablated lines were generated from overlapping square laser beam spots of either 12 or $24 \mu \mathrm{m}$ edge length using a square-shaped laser aperture. The final ablated area was either square or rectangular in shape, with side lengths of $200 \mu \mathrm{m}$ to $2 \mathrm{~mm}$, to facilitate production of trace element maps using different data reduction approaches. Because of the excellent reproducibility of the laser stage movement and the limited depth of ablation $(<1 \mu \mathrm{m})$, it was possible to re-ablate the same area many times using different instrument parameters or 
element menus. Spatial variations in samples that appeared to be petrographically homogeneous were resolved at a smaller scale than the beam diameter, e.g. 7-10 $\mu \mathrm{m}$ discontinuities using a $12 \mu \mathrm{m}$ laser beam. A method for quantitative imaging of elements in ferromanganese nodules $^{342}$ by LA-ICP-MS was developed using a $213 \mathrm{~nm} \mathrm{Nd:YAG} \mathrm{laser}$ system with $\mathrm{Mg}$ as an internal standard. To overcome any artefacts from elemental fractionation, several matrix-matched calibration standards were prepared from GSJ RM JMn1 diluted with high-purity $\mathrm{MnO}_{2}$ powder. An area of 5x20 mm was analysed as a series of lines at a scan speed of $100 \mu \mathrm{m} \mathrm{s}^{-1}$ and a total of 5000 peak intensities were obtained for each element. The validity of the imaged data was confirmed by comparison with elemental concentrations obtained by ICP-MS after dissolution of representative chips from the nodules. A 2D plotting system for displaying the images was established in which the colours corresponding to elemental concentration ranges could be easily changed to provide better contrast. These applications demonstrate that LA-ICP-MS imaging is likely to provide new information and insights about many geological processes in the future.

When performing line scans, the crucial parameters are the laser repetition rate and scan speed, both of which will influence the quality of the image of the resulting maps. Bonta et al. $^{343}$ devised a novel method of evaluating the image quality of chemical maps based on squares with edges between 200 and $400 \mu \mathrm{m}$ printed on paper. Copper in the blue ink was mapped by LA-ICP-MS and the elemental distributions compared to optical images taken before ablation. This approach allowed quantitative determination of the image quality under various measurement conditions and was used for method optimisation to obtain a reasonable compromise between image quality and acquisition time.

Although many of the frontier advances in LA-ICP-MS mapping are currently in its application to the imaging of biological materials, some of the recent developments in cell design, aerosol transport and data acquisition reviewed by Van Malderen et al. ${ }^{344}$ (165 references) are relevant to geochemical imaging. An example is a novel two-volume LA cell and integrated ICP torch designed to minimise aerosol dispersion for fast efficient sample transport $^{345}$. Its design incorporated a direct concentric injector consisting of a short, singlediameter fused-silica conduit from the point of ablation, through the ICP torch into the base of the plasma. When NIST SRM glass 612 was ablated with a $5 \mu \mathrm{m}$ spot at a fluence of 22.1 $\mathrm{J} \mathrm{cm}^{-2}$, resolved single-shot peak widths of $1.4,2.9$ and $4.3 \mathrm{~ms}$ were achieved at $50 \%, 10 \%$ and $1 \%$ maximum full width, respectively. The absolute sensitivity was improved 8 - to $14-$ fold compared to that possible with a single-volume ablation cell. This design is subject to a patent and has recently been adopted by a major instrument manufacturer. Another 
authoritative review $^{216}$ (175 references) considered recent advances in quantitative analysis by LA-ICP-MS. Although this article was directed at the life sciences and environmental research, many of the concepts discussed are equally applicable to the analysis of geological materials, not least the concluding remarks about the need for sufficiently homogeneous RMs to enable results to be compared.

Although low dispersion cells are expected to have impact in many fields, it was noted $^{344}$ that their adoption may be hampered by the absence of affordable, fast, sensitive, simultaneous mass spectrometer systems. However, the high speed and quasi-simultaneous detection capabilities of time of flight mass spectrometry (TOF-MS) are well suited to the measurement of short transient LA signals. Gundlach-Graham et al. ${ }^{346}$ demonstrated the performance characteristics of a low dispersion LA cell coupled to a prototype ICP-TOF-MS instrument for 2D imaging of geological materials. An excimer LA system operating at 193 $\mathrm{nm}$ was used to ablate a pyrite-rich region of an Opalinus clay sample and a polished section of a named meteorite. A laser frequency of $20 \mathrm{~Hz}$ was chosen to prevent pulse-to-pulse mixing and minimise image acquisition times. As well as an improved ability to separate hf laser-generated signals, fast-washout LA-ICP-TOF-MS provided better sensitivity because all the ions were contained in a shorter time window, allowing imaging of major and minor elements down to a spot size of $1.5 \mu \mathrm{m}$. The lowest LODs were single digit ppm for a singleshot LA signal from a $10 \mu \mathrm{m}$ diameter spot. A 3x1.5 mm, 45600-pixel, multi-elemental image of the meteorite was acquired in 50 mins, compared to over $12 \mathrm{~h}$ using a conventional LA-ICP-MS system operating with an ablation cell washout of $1 \mathrm{~s}$ and ablation rate of $1 \mathrm{~Hz}$. In a further development ${ }^{347}$, the potential of this technology for rapid, high resolution, quantitative 3D multi-elemental imaging was demonstrated. Quantification of elements ablated from each individual laser pulse was carried out by $100 \%$ mass normalisation. Ablating heterogeneous samples, such as the Opalinus clay, resulted in different ablation yields depending on the target phase. This created a complex surface morphology and posed a problem for adequate 3D representation of the data. Neverthelesss, this study demonstrated the potential of this technique for acquiring 3D multi-element images with high spatial resolution more rapidly than previously reported. The analysis of fluid inclusions is another application that is likely to benefit from the development of LA-ICP-TOF-MS, with its advantages of rapid, quasi-simultaneous acquisition for all isotopes from ${ }^{6} \mathrm{Li}$ to ${ }^{238} \mathrm{U}$ in a very short cycle time down to $30 \mathrm{~ms}$. This exciting prospect was confirmed in an authoritative comparison $^{348}$ of the capabilities SF-ICP-MS and ICP-TOF-MS with those of quadrupole ICP-MS for the analysis of fluid inclusions by LA. Although SF-ICP-MS provided improved 
LODs over quadrupole ICP-MS, its longer acquisition times limited the number of measureable elements and the precision attained. When ICP-TOF-MS was coupled to a fast washout cell, marked improvements in the figures of merit for the analysis of small $(<10 \mu \mathrm{m})$ and multiphase fluid inclusions were observed, making it possible to discriminate signals from different phases (liquids and solids) as well as detect a larger number of isotopes.

It is acknowledged that the use of femtosecond $L A$ minimises elemental fractionation compared to ablation with ns lasers because of the shorter interaction with the sample, decreased thermal effects and the production of very small aerosol particles. In a study ${ }^{349}$ to examine whether fractionation occurs during fs LA, several different sulfide minerals were ablated with three different LA systems $(213 \mathrm{~nm}$ ns solid state, $193 \mathrm{~nm}$ ns excimer and 200 $\mathrm{nm}$ fs) coupled to quadrupole or SF-ICP-MS instruments. No melting of any of the sulfides was observed with the fs laser, in contrast to the use of ns LA which produced large amounts of melt at both laser wavelengths. In spite of these different melting characteristics, no downhole fractionation was observed for any of the LA systems even at the highest melt production. Sulfur proved to be an appropriate internal standard for ns LA-ICP-MS of sulfides, as long as the instrument was tuned for low oxide production. However, Fe was the recommended internal standard for the $200 \mathrm{~ns}$ fs LA system because of variations in $\mathrm{S}$ sensitivity when ablating different minerals with this system. Although matrix effects using fs LA were shown to be negligible, the case was made for more sulfide RMs because these are still required for the best measurement accuracy and precision.

Femtosecond LA has been used for analysis of a variety of isotope systems. Lazarov and Horn $^{350}$ demonstrated that by using a low fluence it was possible to measure $\mathrm{Cu}$ isotope ratios in native copper and $\mathrm{Cu}$-bearing sulfides, carbonate and oxides by fs LA (194 nm) MCICP-MS with a precision of better than $0.1 \%$ ( 2 SD) without using a matrix-matched standard. A new analytical protocol ${ }^{351}$ for determining stable $\mathrm{Cl}$ isotopes in halite and igneous rocks employed a fs laser operating at $266 \mathrm{~nm}$ coupled to MC-ICP-MS. Chlorine was extracted from igneous rocks by pyrohydrolysis and then precipitated as $\mathrm{AgCl}$ from which pellets were prepared. Argon isotopes $\left({ }^{36} \mathrm{Ar} /{ }^{38} \mathrm{Ar}\right)$ were used to correct for mass fractionation. Complex theoretical overlap calculations were performed to correct for isobaric interferences from $\mathrm{ArH}^{+}, \mathrm{K}^{+}$and $\mathrm{S}^{+}$on $\mathrm{Ar}$ and $\mathrm{Cl}$ isotopes. The external $\delta^{37} \mathrm{Cl}$ reproducibilities of $\pm 0.18 \%$ o (2 SD) for halite and $\pm 0.05 \%$ ( $2 \mathrm{SD}$ ) for the $\mathrm{AgCl}$ precipitates compared favourably with the precision obtainable by gas source IRMS. The use of fs LA was important in this study because ablation with a ns $193 \mathrm{~nm}$ excimer laser partially melted the $\mathrm{AgCl}$ pellets, releasing $\mathrm{Cl}$ in the process. A fs laser was also chosen to minimise any fractionation in the 
determination $^{352}$ of $\mathrm{Mg}$ isotopes in basalt glasses by LA-MC-ICP-MS. The results revealed that the $\mathrm{Mg}$ isotopic ratios were affected by changes in the mass discrimination caused by different mass loadings in the plasma. The amount of ablated aerosol was greatly influenced by LA parameters such as spot size, laser frequency and scanning speed. To obtain reliable $\mathrm{Mg}$ isotope data it was important that the difference in $\mathrm{Mg}$ concentrations between the sample and standard was no more than a factor of 3 . The measurement precision of $\delta^{26} \mathrm{Mg}$ was better than $\pm 0.17 \%$ o (2 SD).

Several studies of the use of fs LA for the bulk analysis of fused rock powders have been reported. Kon and Hirata ${ }^{353}$ determined ten major and 34 trace elements in 34 GSJ geological RMs by fs LA ICP-MS. The rock powders were prepared as fused glass beads using a lithium tetraborate flux and ${ }^{6} \mathrm{Li}$ was monitored as an internal standard. Precisions were better than $5 \%$ for most elements. Bao et al. ${ }^{354}$ fused powdered-rock RMs without a flux in a small $\left(450 \mathrm{~mm}^{3}\right)$ sealed boron nitride crucible at $1400{ }^{\circ} \mathrm{C}$ for $1 \mathrm{~min}$ before rapid immersion in liquid $\mathrm{N}_{2}$; the resulting glasses were mounted in resin and polished to obtain an even surface before analysis. Loss of volatile elements was negligible due to the rapid and hermetic nature of the melting process. Data were generally within $15 \%$ of the preferred values for the geological RMs. Kimura et al. ${ }^{355}$ determined $\mathrm{Pb}$ isotopes by fs LA-MC-ICPMS using multiple Faraday cups equipped with state-of-the-art high gain $10^{13} \Omega$ amplifiers. Because of the slow response of these amplifiers, a correction based on a linear correlation between the rate of change of the signal intensity and that of the $\mathrm{Pb}$ isotope ratios was applied. This improved the intermediate precisions and repeatability of the measurements, which were approximately 2-3 times better than those obtained using MICs or FCs with $10^{12}$ $\Omega$ amplifiers. The increased sensitivity of the system with $10^{13} \Omega$ amplifiers resulted in analytical performance comparable with that of SIMS (2-0.5\%, 2 SE) from the same sample mass. In spite of claims to the contrary, it is difficult to envisage the rapid adoption of bulk analysis by fs LA given the cost of such systems and it could be considered inappropriate use of such facilities.

A primary application of laser ablation split-stream (LASS) ICP-MS is zircon and monazite petrochronology. In this technique the laser aerosol is split between two ICP-MS instruments to obtain $\mathrm{U}-\mathrm{Pb}$ ages (or other geochronometers) and trace element compositions simultaneously from very small sample volumes. Single shot LASS-ICP-MS depth profiling ${ }^{356}$ was used to sample thin metamorphic zircon overgrowths at a spatial resolution of $<1 \mu \mathrm{m}$ per analysis. Ages of RMs measured by this technique were accurate to within $1.5 \%$ of published values. The analysis only took 3-6 mins per grain allowing the collection 
of the large datasets required to resolve short-duration $\left(<10^{6}\right.$ years $)$ zircon growth events with confidence. Thus the high spatial and temporal resolution of single shot LASS shows great promise as a tool to decipher petrochronological events on this timescale. The LASS depth profiling technique was also used to obtain a continuous rim-to-core record ${ }^{357}$ of $\mathrm{U}-\mathrm{Pb}$ ages and trace element composition preserved within variably recrystallised zircon from different rock types within a well-studied granulite domain in Canada. Distinct homogeneous domains and heterogeneous intervening zones could be correlated with textural features observed by CL. The response of monazite and its host rocks during the subduction of continental crust to mantle depths was studied ${ }^{358}$ using $\mathrm{U}-\mathrm{Pb}$ isotope ratios and elemental abundances measured simultaneously by LASS ICP-MS in rocks from the Scandinavian Caledonides. All the samples were analysed in thin section so that the $\mathrm{U}-\mathrm{Pb}$ dates and trace element data could be tied to metamorphic textures and parageneses. A tectonic history of the region was inferred from the analysis of 69 samples.

Several different strategies have been deployed to avoid or mitigate isobaric interference from ${ }^{87} \mathrm{Rb}$ and other spectral interferences during the measurement of Sr isotope ratios by LA-ICP-MS. Bolea-Fernandez et $a l^{359}$ explored the capabilities of an ICP-MS/MS instrument for obtaining direct isotopic information from solid samples with high $(>0.2)$ $\mathrm{Rb} / \mathrm{Sr}$ ratios. This instrument has an additional quadrupole located before the octopole collision-reaction cell, providing greater control over the ions entering the cell. A mixture of $\mathrm{CH}_{3} \mathrm{~F}-\mathrm{He}(1+9)$ in the collision-reaction cell converted $\mathrm{Sr}^{+}$ions to the corresponding $\mathrm{SrF}^{+}$ ions, whereas $\mathrm{Rb}^{+}$ions did not react. Instrumental mass bias was corrected by a combination of internal correction using the Russell law, followed by external correction in a SSB approach. Reference glass NIST SRM 610 was used as the external standard for the seven silicate rock RMs analysed. No closer matrix-matching or additional correction was required. Under wet plasma conditions, precisions of $0.02-0.05 \%$ RSD for ${ }^{87} \mathrm{Sr} /{ }^{86} \mathrm{Sr}$ ratios were obtained irrespective of the matrix composition or $\mathrm{Rb} / \mathrm{Sr}$ ratio of the materials examined. Zack and Hogmalm ${ }^{360}$ also employed LA-ICP-MS/MS for on-line separation of $\mathrm{Rb}$ and $\mathrm{Sr}$ but used $\mathrm{O}_{2}$ as the reaction gas. The precision for ${ }^{87} \mathrm{Sr} /{ }^{86} \mathrm{Sr}$ was $<0.5 \%$ for a single spot. The procedure was applied to in situ dating of micas and feldspars. Systematic investigations ${ }^{361}$ of factors affecting the accuracy of Sr isotope determinations in apatite by LA-MC-ICP-MS found no evidence of significant polyatomic interferences from $\mathrm{Ca}$ argides or dimers or any significant interference on $m / z 87$ from ${ }^{40} \mathrm{Ca}^{31} \mathrm{P}^{16} \mathrm{O}^{+}$. However, fractionation of elemental $\mathrm{Rb} / \mathrm{Sr}$ during ablation of apatite with a $193 \mathrm{~nm}$ excimer laser was shown to be significant ( $c a$. $15 \%)$ and the accuracy of the ${ }^{87} \mathrm{Rb}$ correction was called into question. In the revised 
procedure, aliquots of concentrated Ca-P solutions with varying ${ }^{85} \mathrm{Rb} /{ }^{86} \mathrm{Sr}$ ratios were used to improve the accuracy of the ${ }^{87} \mathrm{Rb}$ correction and matrix-matched phosphate glasses were incorporated to correct for $\mathrm{Rb} / \mathrm{Sr}$ fractionation.

Other novel approaches to the analysis of geological materials by LA-ICP-MS included an unusual method ${ }^{362}$ for the determination of trace amounts of Os. Samples were digested using aqua regia in Carius tubes and the Os converted to $\mathrm{OsO}_{4}$, which was distilled and trapped in $2 \mathrm{~mL}$ of $\mathrm{HBr}$ solution to convert the Os to a non-volatile $\mathrm{Br}$ species. The purified Os was dissolved in $10 \mu \mathrm{L}$ of a $0.02 \%$ sucrose- $-0.005 \% \mathrm{H}_{3} \mathrm{PO}_{4}$ solution and evaporated on a small piece of PFA film, resulting in the formation of a tiny residue. When analysed by LA-ICP-MS, the residue provided Os signals at least 100 times greater than those from solution ICP-MS while successfully avoiding any memory effect. The procedural blank was $3.0 \mathrm{pg}$ and the LOD $1.8 \mathrm{pg}$ Os when $1 \mathrm{~g}$ of sample was processed by this method; the precision was 0.6 to $9.4 \%$ RSD ( $\mathrm{n}=5$ ) depending on the RM analysed.

Instrumental developments in ICP-MS are covered in our sister $\mathrm{ASU}^{3}$ on advances in atomic spectrometry and related techniques. It will be interesting to see whether zoom TOF$\mathrm{MS}^{363}$ and distance-of-flight mass spectrometry ${ }^{364}$ techniques, which are in their early stages of development, will advance sufficiently to impact on LA measurements of geological materials in future.

\subsubsection{Laser induced breakdown spectroscopy and related techniques.}

An exciting new development is Laser Ablation Molecular Isotopic Spectrometry (LAMIS) which utilises optical emission from laser-induced plasmas for isotopic analysis. An excellent tutorial review ${ }^{365}$ (49 references) is invaluable for those unfamiliar with the technique. The advantages of fs ablation over ns ablation in LAMIS, such as significantly stronger molecular emissions with lower backgrounds and fewer matrix effects because of the lower energies of fs laser pulses, result in improved precision and accuracy. In spite of this, the majority of published LAMIS studies used ns lasers operating at a wavelength of 1064 nm. Both LIBS and LAMIS probe the optical spectra produced in ablation plumes, so potentially it should be possible to build a portable device incorporating both techniques for direct measurements in the field. So far, studies of LAMIS have been limited to a few elements and isotopes, i.e. $\mathrm{B}, \mathrm{C}, \mathrm{Cl}, \mathrm{H}, \mathrm{N}, \mathrm{O}, \mathrm{Sr}$ and $\mathrm{Zr}$, of which $\mathrm{B}$ and $\mathrm{C}$ have been examined in the greatest detail. The current sensitivity and precision of LAMIS requires 
further improvement for most practical applications and several possibilities for such improvements were discussed.

Several recent applications of LIBS to geological materials involved the assessment of hydrocarbon source rocks. In a multi-elemental surface mapping of carbonaceous shale rocks $^{366}$ by LIBS, a drill core was sliced in half vertically, one half polished for LIBS scanning and the other divided into small sections that were reduced to a powder for analysis by XRFS and ICP-AES to validate the measurements. Local thermal equilibrium conditions were verified for the induced plasma for a point-by-point line profile. Matrix effects were negligible. Concentration maps for $\mathrm{Al}, \mathrm{Ca}, \mathrm{Fe}, \mathrm{K}, \mathrm{Mg}, \mathrm{Na}$ and $\mathrm{Si}$ were constructed with a 2D spatial resolution of $300 \times 300 \mu \mathrm{m}^{2}$. A new approach ${ }^{367}$ to measuring kerogen $\mathrm{H}: \mathrm{C}$ elemental ratios in shales and mudrocks by LIBS provided a rapid means of assessing kerogen quality and thermal maturity with minimal sample processing. Predicted kerogen $\mathrm{H}: \mathrm{C}$ ratio from the LIBS measurements of whole rock samples were well correlated $\left(R^{2}=0.99\right)$ with values determined from the elemental analysis of kerogen isolates. A study ${ }^{368}$ of different methods of processing data acquired from LIBS measurements of sedimentary rocks concluded that better accuracy and precision were obtained using algorithms based on support vector regression compared to PLSR. A selection of sandstones, limestones and mudstones were analysed for $\mathrm{Al}, \mathrm{Ca}, \mathrm{Fe}, \mathrm{Mg}$ and $\mathrm{Si}$. Mapping ${ }^{369}$ the 2D distribution of $\mathrm{Li}$ and other light elements $(Z<10)$ in pegmatite minerals by LIBS was carried out using a grid of laser spots of $125 \mu \mathrm{m}$ diameter, spaced at $200 \mu \mathrm{m}$ intervals, on the surface of a core sample cut with a diamond saw blade without any additional preparation. The Li maps effectively discriminated between the ore mineral spodumene $\left(\mathrm{LiAlSi}_{2} \mathrm{O}_{6}\right)$, its alteration mineralogy and matrix silicate minerals. However, full quantification of the results using Li-doped borosilicate glasses as standards was limited by self-absorption effects that were evident when the $\mathrm{Li}_{2} \mathrm{O}$ content was $>2 \mathrm{wt} \%$ and especially at values $>6 \mathrm{wt} \%$. This demonstrated that LIBS could be a useful complementary mapping technique to others, such as EDXRFS, because of its ability to measure the light elements effectively. A pilot study ${ }^{370}$ showed that LIBS has potential in the provenancing of gem stones. Nearly 570 ruby and sapphire specimens from 21 localities in 11 countries were analysed for the main database. The method utilised PLSR to build a series of models to compare spectra. Each specimen was analysed at 30 spots and averaged to create one spectrum per sample. Several Al peaks were removed from the spectra to allow multivariate analysis to focus on trace element distributions. The overall success rate of identifying the correct deposit of origin for unknown samples was $>95 \%$. 
Many of the developments in LIBS over the last few years have been driven by the requirements of space research. A comprehensive review ${ }^{371}$ (107 references) of the scientific achievements of ChemCam on Mars highlighted the lessons learned from the first use of LIBS in space. New tools were developed for data processing and element detection to take account of the unique nature of the Mars data. ChemCam was shown to be a very versatile instrument and its ability to survey quickly the geochemistry of several targets to facilitate rapid understanding of an environment was a great boon for efficient use of mission time. The experience gained on this mission will be incorporated in the instrumentation that is scheduled to fly on board the NASA Mars2020 rover. A prototype multispectral instrument ${ }^{372}$ based on Raman, laser-induced fluorescence, LIBS and a lidar system has already been designed and tested by NASA scientists in relation to missions to the icy moons of Mars and Jupiter. Its ability to identify water, water-ice, dry ice and samples of hydrous minerals at distances from 1 to $50 \mathrm{~m}$ were demonstrated. It could also characterise chemicals and minerals up to $15 \mathrm{~m}$ away and conduct atmospheric aerosol and cloud profiling from up to 10 $\mathrm{km}$ distance. The ultimate aim was to use this instrument to detect chemical signatures of life through biogenic molecules (biomarkers) and small bio-organic precursors of life.

A related innovation is a miniature LA ionisation TOF mass spectrometer developed at the University of Bern for quantitative measurements of the elemental and mineralogical composition of planetary surfaces. Its capability for quantitative measurements of geological materials was assessed ${ }^{373}$ using four rock RMs (andesite, shale, clay and quartz latite) to determine the RSFs for the instrument. These factors were close to 1 for all elements determined and their consistency between matrices provided a sound basis for in situ standardless measurements. Another study $^{374}$ investigated the instrument's ability to determine stable isotope abundances and produce chemical maps of rock samples at the $\mu \mathrm{m}$ scale. Test samples consisted of $\mu \mathrm{m}$-size filaments of fossilised micro-organisms embedded in aragonite veins from a harburgite. Results indicated that accurate chemical mapping of heterogeneous rock samples could be achieved but that the isotope ratios were not sufficiently accurate for biomarker identification. Improvements to the $\mathrm{S} / \mathrm{N}$ were required.

\subsection{Sample dissolution, separation and preconcentration}

All geoanalysts need to be mindful of potential sources of contamination from equipment used to produce rock powders of a suitable size fraction for dissolution. In a recent study ${ }^{375}$ of primary and cross contamination, quartz crystals were crushed using conventional steel alloy and tungsten carbide jaw crushers, followed by milling in agate, tungsten carbide or 
chromium steel ring planetary ring mills. Semi-quantitative ICP-MS data for 75 elements confirmed the accepted wisdom that for many applications a combination of crushing with a steel jaw crusher, followed by milling in agate afforded the least contamination.

The literature is littered with investigations into suitable methods of effecting a complete dissolution of geological materials prior to analysis. In a recent example ${ }^{186}$, four different acid attacks were assessed for the dissolution of geological RMs prior to the determination of $\mathrm{Nd}$ and $\mathrm{Sr}$ isotope ratios by MC-ICP-MS and trace elements by HR-ICPMS. A method based on microwave-assisted digestion using a mixture of $\mathrm{HCl}, \mathrm{HNO}_{3}$ and $\mathrm{HF}$ followed by evaporation of excess HF provided the best figures of merit. It should be noted, however, that the assessment of accuracy was based on recoveries from two Chinese stream sediments and USGS RM BCR-2 (basalt) but no values for Zr were reported. Basaltic rocks are relatively easy to dissolve and the $\mathrm{Zr}$ contents, which are often associated with the presence of resistant minerals, can be a good indicator of the effectiveness of dissolution. The digestion of bauxite, with $\mathrm{Al}_{2} \mathrm{O}_{3}$ as its major component, is particularly prone to the formation of insoluble $\mathrm{AlF}_{3}$ precipitates when a mixed $\mathrm{HF}-\mathrm{HNO}_{3}$ attack is used. For this reason, Zhang et al. ${ }^{376}$ investigated four alternative approaches and recommended open vessel methods based on $\mathrm{NH}_{4} \mathrm{HF}_{2}$ or $\mathrm{NH}_{4} \mathrm{~F}$ for multi-elemental analysis of bauxite samples by ICP-MS.

In spite of the wealth of information available on appropriate digestion methods, there was evidence from the GeoPT proficiency testing scheme ${ }^{377}$ that a significant number of geochemical laboratories using acid attack dissolutions reported low results for elements such as $\mathrm{Y}, \mathrm{Yb}$ (representing the HREEs) and $\mathrm{Zr}$. This was not observed in results obtained using a fusion or sintering approach, XRFS or INAA. A detailed evaluation of the acid attack procedures used by laboratories indicated that quantitative recoveries could be obtained using $2 \mathrm{ml} \mathrm{HF}$ per $100 \mathrm{~g}$ of test material, heated to $180{ }^{\circ} \mathrm{C}$ for 48 hour in a pressure bomb. It was likely that the less rigorous conditions of acid attack used by many laboratories on a routine basis resulted in an incomplete dissolution of resistant minerals such as zircon. It was therefore incumbent on laboratories to identify test materials that fall outside the scope of validation of their dissolution procedure and take appropriate action.

Several methods for the production of glasses for LA by flux-free fusion techniques have been advocated. An iridium-strip heater was used to melt rock powders directly ${ }^{378}$. The temperature was controlled manually by monitoring the current; the samples melted within 30 $s$ and were then air cooled. The homogeneity of fused glasses prepared from 11 USGS and GSJ RMs was $<5 \%$ RSD $(1 \sigma, n=3)$ for most elements. However, in common with previous 
studies employing this fusion technique, $\mathrm{Pb}$ was lost on heating, $\mathrm{Cr}$ was less homogeneously distributed than the other elements, particularly when present at $>150 \mu \mathrm{g} \mathrm{g}^{-1}$, and $\mathrm{Hf}$, Lu and Ta were occasionally enriched by contamination. Retention of volatile elements and reduced contamination were achieved ${ }^{379}$ by melting rock powders without a flux in a molybdenum capsule sealed in a graphite tube in a temperature-controlled furnace. After water cooling, the quenched glasses were mounted in epoxy resin and polished for microscopic examination and LA-ICP-MS analysis. Major and trace element data for a series of USGS RMs containing 47 to $73 \% \mathrm{SiO}_{2}(\mathrm{~m} / \mathrm{m})$ were mostly within $5-10 \%$ of recommended values with a precision generally better than 5-10\%. Any heterogeneity of $\mathrm{Cr}$ and $\mathrm{Ni}$ caused by the fusion process was smaller than the analytical uncertainties of LA-ICP-MS. This approach was similar to that of Bao et al. ${ }^{354}$ in which $500 \mathrm{mg}$ of silicate rock powders was fused in a small boron nitride vessel before measurement of 34 trace elements and $\mathrm{Pb}$ isotope ratios by fs LA-MCICP-MS (see section 4.2.2). The sealed melting process ensured that $\mathrm{Pb}$ volatilisation was negligible so that in situ determinations of $\mathrm{Pb}$ isotope ratios for geological $\mathrm{RMs}$ with a range of compositions were in good agreement (within $2 \mathrm{~s}$ ) with published data or values obtained by solution MC-ICP-MS.

Aqua regia is often preferred as the digestion medium in the determination of $\mathrm{Ag}$ and $A u$ in geological samples even though low recoveries of Au have been reported by several researchers. An experiment ${ }^{380}$ to monitor the effect of varying the ratios $(v / v)$ from the usual $\mathrm{HCl}: \mathrm{HNO}_{3}$ ratio of 3:1 to 1:3 (reverse aqua regia) revealed that the recoveries of $\mathrm{Ag}$ and $\mathrm{Au}$ exhibited inverse trends. Complete recovery of $\mathrm{Au}$ with excellent reproducibility was achieved with a $\mathrm{HCl}: \mathrm{HNO}_{3}$ ratio of 1:3. The low recoveries for samples with high $\mathrm{Ag}$ contents were improved by the addition of a small volume of concentrated $\mathrm{HCl}$ to the cooled digests to resolubilise the $\mathrm{AgCl}$ precipitate. Based on these observations, a rapid (10-15 mins) method using reverse aqua regia digestion with IR heating was proposed for determinations by ICP-MS. The strong memory effect of $\mathrm{Au}$ was overcome by preparing standards and samples in a solution of L-cysteine in $1 \%(v / v) \mathrm{HCl}$.

Over the years, a wide range of absorbants and ion-exchangers have been proposed for the separation and preconcentration of $A u$. Xue et al. ${ }^{381}$ synthesised a modified polyurethane foam incorporating a cytosine ligand to extract Au from aqua regia digests of geological samples prior to measurement by ICP-AES. They reported a LOD of $6 \mathrm{ng} \mathrm{L}^{-1}(3 \sigma$, $\mathrm{n}=6$ ) with an enrichment factor of 480. Other procedures for SPE of Au from environmental samples involved the use of $\mathrm{MWCNTs}^{301}$ or extraction of its 2-aminobenzothiazole complex $^{302}$ on Diaion SP-207 resin, a brominated styrene-divinylbenzene polymer, prior to 
FAAS detection. Preconcentration factors and LODs were 150 and $1.71 \mu \mathrm{g} \mathrm{L}^{-1}$, respectively, for the MWCNT method and 250 and $3.8 \mu \mathrm{g} \mathrm{L}{ }^{-1}$, respectively, using Diaion SP-207 resin.

\subsection{Instrumental analysis}

\subsubsection{Atomic absorption and atomic emission spectrometry.}

For determinations of trace amounts of $\mathrm{Cd}$ in complex matrices, ETAAS offers several advantages over ICP-MS including relatively few spectral interferences, good LODs and low cost. In a procedure ${ }^{382}$ for the determination of $\mathrm{Cd}$ in geological materials, samples were digested in $\mathrm{HF}-\mathrm{HNO}_{3}$ in a sealed bomb and $\mathrm{Pd}\left(\mathrm{NO}_{3}\right)_{2}$ solution added as a matrix modifier to increase the thermal stability of $\mathrm{Cd}$ and allow higher pyrolysis temperatures. A LOQ of 0.75 $\mathrm{ng} \mathrm{g}^{-1}$ and characteristic mass of $0.8 \pm 0.1 \mathrm{pg}$ for $\mathrm{Cd}$ demonstrated sufficient sensitivity for the analysis of soil, sediment and rock samples for which the Cd content was 0.02-0.5 $\mu \mathrm{g} \mathrm{g}^{-1}$. Method accuracy was assessed by the determination of Cd in 51 geological RMs. To improve throughput, Cui et al. ${ }^{383}$ developed a method using slurry sample introduction for trace Cd determinations by ETAAS. Solid samples were ground to a particle size of $62 \mu \mathrm{m}$ and a slurry prepared in $0.5 \%(v / v) \mathrm{HNO}_{3}$ containing $0.6 \%(v / v)$ Triton X-100. After the addition of $\mathrm{Pd}\left(\mathrm{NO}_{3}\right)_{2}$ as a chemical modifier, the slurry was homogenised in an ultrasonic bath before delivery to a graphite tube for analysis.

A novel adsorbant ${ }^{384}$ composed of cellulose fibre, activated carbon and Dowex $1 \times 8$ anion-exchange resin was devised for the separation and preconcentration of $\mathrm{Au}, \mathrm{Pd}$ and Pt prior to determination by GF-AAS. Geological CRMs were digested in aqua regia and transferred to a column containing a homogenised mixture of $5.0 \mathrm{~g}$ Dowex 1x8 resin, $3.5 \mathrm{~g}$ activated carbon and $100 \mathrm{~mL}$ of cellulose fibre pulp. The precious metals were eluted with $0.25 \mathrm{M} \mathrm{HCl}$ and the resulting solution digested in a microwave oven to liberate the analytes and reduce the sample volume to $5 \mathrm{~mL}$. The LODs were $0.008 \mathrm{ng} \mathrm{mL}^{-1}(\mathrm{Au}), 0.017 \mathrm{ng} \mathrm{mL}^{-1}$ (Pd) and $0.014 \mathrm{ng} \mathrm{mL}^{-1}(\mathrm{Pt})$ and maximum throughput was 30 samples every $8 \mathrm{~h}$.

Two new optical methods were assessed ${ }^{385}$ for the detection of $A u$ NPS in soils and vegetation in the vicinity of gold deposits. The first was based on localised SPR, in which electrons on the surface of the metal are excited by photons, resulting in a peak in the absorption spectrum of a sample. The second property explored was the ability of Au NPs to catalyse the conversion of the non-fluorescent compound I-BODIPY to its fluorescent derivative H-BODIPY. For both methods, the LOQ was dependent on the size of the NPs, i.e. $71 \mathrm{ppb}$ for $5 \mathrm{~nm}$ and $24.5 \mathrm{ppb}$ for $50 \mathrm{~nm}$ NPs using the absorption method, and $74 \mathrm{ppb}$ for 5 $\mathrm{nm}$ and $1200 \mathrm{ppb}$ for $50 \mathrm{~nm}$ NPs with the fluorescence procedure. These LOQs demonstrated 
a potential for deployment in the field, although the size of the target NPs would need to be taken into account as fluorescence would be the better option for the analysis of small NPs whereas the absorption measurements would give lower LOQs for larger NPs.

\subsubsection{Inductively coupled plasma mass spectrometry.}

The relatively recent introduction of an $I C P-M S / M S$ instrument onto the market has spawned research papers on its application in many fields. The main feature of this instrument (often referred to - incorrectly - as a triple quadrupole system) is the insertion of an additional quadrupole before the collision-reaction cell. This acts as a mass filter allowing ions with only one $\mathrm{m} / \mathrm{z}$ ratio to enter the cell, providing better control over reactions taking place in the cell and thus offering new approaches to avoiding isobaric overlaps. An excellent tutorial review ${ }^{13}$ (55 references) describing the operating principles and procedures available for advanced method development is essential reading for those new to this technique. Whitty-Léveillé et al. ${ }^{386}$ explored the potential of this instrument to determine Sc (monoisotopic at $\mathrm{m} / \mathrm{z} 45$ ) at low concentrations in silicate minerals. Discrimination from Sibased ions was achieved using $\mathrm{O}_{2}$ as the reaction gas and monitoring $\mathrm{ScO}^{+}$ions at $\mathrm{m} / z 61$. The LOD of $3 \mathrm{ng} \mathrm{L}^{-1}$ in solution was sufficient to provide accurate results in the low $\mathrm{mg} \mathrm{kg}^{-1}$ Sc range for a variety of RMs. Fernández et $a l .{ }^{387}$ advocated ICP-MS/MS for the determination of very low B:Ca ratios in biogenic carbonates. By introducing $\mathrm{O}_{2}$ into the collision-reaction cell, $\mathrm{P}, \mathrm{S}$ and $\mathrm{Ti}$ were converted to their corresponding oxides while ${ }^{11} \mathrm{~B}$ and ${ }^{46} \mathrm{Ca}$, which did not react with $\mathrm{O}_{2}$, were monitored as elemental ions. In addition, some of the carbon present reacted with the $\mathrm{O}_{2}$ enabling resolution of the large ${ }^{12} \mathrm{C}$ peak from the ${ }^{11} \mathrm{~B}$ signal. The ability to make interference-free measurements of ${ }^{46} \mathrm{Ca}^{+}$, which is only $0.004 \%$ abundant, meant that ${ }^{11} \mathrm{~B}$ and ${ }^{46} \mathrm{Ca}$ could both be measured in counting mode, thereby improving the ratio precision. As noted in section 4.2.1, ICP-MS/MS coupled to LA has been exploited for the determination of $\mathrm{Sr}$ isotope ratios $^{359,}{ }^{360}$. Bolea-Fernandez et al. ${ }^{388}$ demonstrated an external precision of $0.05 \%$ when determining ${ }^{87} \mathrm{Sr} /{ }^{86} \mathrm{Sr}$ in digested rock RMs using a similar methodology, i.e. a mixture of $\mathrm{CH}_{3} \mathrm{~F}-\mathrm{He}(1+9)$ as the reaction gas and monitoring the $\mathrm{SrF}^{+}$reaction products. Corrections for mass discrimination using a combination of Russell's law and SSB with NIST SRM $987\left(\mathrm{SrCO}_{3}\right)$ were applied. Because matrix elements were removed before they entered the reaction cell, matrix-matched standards were not required to correct for mass bias. It is likely that many more relevant applications will be published in the near future when the benefits of ICP-MS/MS are realised. 
Additional data for established and relatively new geological RMs have emerged from several studies. The performances ${ }^{389}$ of three ICP-MS instruments (two SF and one quadrupole system) were assessed through the trace element characterisation of six USGS RMs. The agreement between data from this study and previously published values was best for the RMs of mafic to intermediate compositions, i.e. BHVO-2 (basalt), BCR-2 (basalt) and AGV-2 (andesite) for which there is a large volume of comparative data. Published data were relatively sparse for the felsic RMs, RGM-2 (rhyolite) and G-3 (granite), and completely unavailable for STM-2 (syenite), making the data from this study valuable for a more complete characterisation of these RMs. A method ${ }^{390}$ for the determination of trace amounts of $\mathrm{Cd}$ in geological samples used argon aerosol dilution ICP-MS to overcome polyatomic interferences from Mo and $\mathrm{Zr}$ oxides and hydroxides. In this technique, the sample aerosol from the spray chamber was diluted with argon before it reached the plasma, resulting in less water in the plasma and reduced oxide formation. Over $90 \%$ of the sample $\mathrm{Zr}$ content was eliminated during extraction of $\mathrm{Cd}$ by boiling with inverse aqua regia. Aerosol dilution reduced the residual interfering oxides and hydroxides by up to $90 \%$ compared to conventional ICP-MS without argon addition. The LOD for ${ }^{111} \mathrm{Cd}$ was $1.6 \mathrm{ng} \mathrm{g}$ and the proposed method was applied to the determination of $\mathrm{Cd}$ in 81 soil, sediment and rock RMs. Boron concentrations in nine geochemical RMs were measured ${ }^{391}$ on three different ICP-MS instruments after extraction by a modified pyrohydrolysis technique. Blanks for the whole procedure were $14 \pm 5 \mathrm{ng} \mathrm{B}$ and precisions were $<10 \%$ for samples containing $>2 \mu \mathrm{g} \mathrm{g}^{-1} \mathrm{~B}$. A procedure $^{392}$ for the determination of chalcophile and siderophile elements in crustal rocks using SF-ICP-MS with standard addition reported new values for $\mathrm{Bi}, \mathrm{Cd}, \mathrm{Ga}, \mathrm{Ge}, \mathrm{In}, \mathrm{Mo}, \mathrm{Sb}$, Sn, Tl and W abundances in six USGS RMs (AGV-2, BHVO-2, BIR-1, G-2, GSP-1 and W2). Poor precisions for $\mathrm{Cd}$ and Mo concentrations in GSP-1 were ascribed to powder heterogeneity at the test portion size caused by a sulfide nugget effect whereas the RSDs of $>10 \%$ for Mo and $\mathrm{W}$ in several RMs were attributed to high analytical blanks.

A summary of newly published methods for the determination of isotope ratios by $M C-I C P-M S$ is given in Table 7. Many of these involve new or modified separation schemes, including the incorporation of a low pressure, fully automated fluoropolymer chromatography system ( $\operatorname{prep} F A S T^{\mathrm{TM}}$ ) capable of purifying $\mathrm{Ca}$ and $\mathrm{Sr}$ for isotope analysis ${ }^{393}$. The equipment was able to process over 200 samples on the same column at a rate of over 30 samples per day for a wide range of sample matrices (rocks, bone ash, seawater). Automated chromatographic methods based on this system are under development for a range of other 
isotope systems and it will be interesting to see whether it has an impact on future applications.

A review ${ }^{394}$ (177 references) examined the application of stable isotope systems such as $\mathrm{Cu}, \mathrm{Li}$ and $\mathrm{Zn}$, often referred to as non-traditional isotopes, to the emerging field of analytical ecogeochemistry. It stressed the importance of metrologically sound analytical protocols, data-processing strategies and uncertainty considerations for the successful detection and interpretation of small isotopic shifts. Mass spectrometric techniques for determining ${ }^{135} \mathrm{Cs} /{ }^{137} \mathrm{Cs}$ in environmental samples were reviewed ${ }^{168}$ (123 references). Critical issues affecting the accuracy and LODs were the effectiveness of procedures to remove isobaric $\mathrm{Ba}$ interferences and eliminate peak tailing from ${ }^{133} \mathrm{Cs}$ on ${ }^{135} \mathrm{Cs}$. A state-of-the-art review $^{395}$ (97 references) of isotope ratio measurements by solution MC-ICP-MS presented guidelines for data reduction strategies and uncertainty assessments using $\mathrm{Sr}$ isotope ratios as an example. Although the data set presented was based on the analysis of wood cores from trees in Austria, many of the principles are applicable to geochemical samples.

In an interlaboratory comparison ${ }^{396}$ of $\mathrm{Mg}$ isotopic data, 12 Chinese rock RMs were analysed in five laboratories using various sample dissolution and chromatography schemes and three types of MC-ICP-MS instrument. Although ${ }^{25} \mathrm{Mg} /{ }^{24} \mathrm{Mg}$ and ${ }^{26} \mathrm{Mg} /{ }^{24} \mathrm{Mg}$ compositions from all laboratories were in agreement within quoted uncertainties for most rocks, there were some significant differences of up to $0.3 \%$ in ${ }^{26} \mathrm{Mg} /{ }^{24} \mathrm{Mg}$ for some mafic samples. The source of these discrepancies was thought most likely to arise from the column chemistry employed, although incomplete sample dissolution may have been another factor. It was concluded that well characterised RMs with a range of matrices were required to reduce such interlaboratory mass bias. In their quest for a new absolute Mg isotope RM, Vogl et al $^{397}$ characterised three candidate solutions by sending them to three partner laboratories for analysis, together with calibration solutions prepared from isotopically enriched and purified Mg materials. The project's target uncertainty of $<0.5 \%$ relative $(k=2)$ was achieved and a set of Mg isotope RMs, including ERM-AE143, which is nearly identical to NIST SRM 980 in terms of its $\mathrm{Mg}$ isotopic composition, will be made available.

Differences in sulfur isotope ratios were found ${ }^{398}$ in well-characterised sulfate RMs when determined by both solution and LA-MC-ICP-MS but not in sulfide samples when analysed by LA-MC-ICP-MS. The interference of ${ }^{16} \mathrm{O}_{2}{ }^{+}$on ${ }^{32} \mathrm{~S}^{+}$and complex matrix effects were investigated but the cause was actually vaporisation-induced plasma fractionation associated with the $\mathrm{S}$ valence state. Accurate data were obtained in both solution and LA modes by application of an external isotope calibration, constructed using in-house and NIST 
$\mathrm{S}$ isotope RMs, in combination with SSB. Matrix effects from Ca during the measurement of $\mathrm{S}$ isotopes in gypsum ${ }^{399}$ were found to depend on the absolute $\mathrm{Ca}$ concentration rather than the Ca:S ratio. Gypsum samples were dissolved in water at $40{ }^{\circ} \mathrm{C}$, diluted to $0.30 \mathrm{mM} \mathrm{S}$ and measured directly by MC-ICP-MS using a SSB procedure. An ammonium sulfate solution of known $\mathrm{S}$ isotopic composition and matched $\mathrm{S}$ concentration was employed as the standard.

In a new protocol ${ }^{400}$ for the measurement of $V$ isotopes by $M C-I C P-M S$, the instrument was operated in medium mass resolution mode $(\Delta M / M c a$. 4000) to separate $\mathrm{Cr}$, $\mathrm{Ti}$ and $\mathrm{V}$ isotopes from polyatomic ions of $\mathrm{Ar}, \mathrm{C}, \mathrm{Cl}, \mathrm{N}, \mathrm{O}$ and $\mathrm{S}$. The method, based on the analysis of synthetic solutions, achieved a precision of $\pm 0.12 \%$ o (comparable to that of low resolution methods) while consuming as little as $260 \mathrm{ng} \mathrm{V}$. When combined with ionexchange chromatographic separation procedures, this approach should facilitate the determination of $\mathrm{V}$ isotope ratios in samples with low $\mathrm{V}$ contents, such as depleted peridotites, iron meteorites and carbonates. Wu et al. ${ }^{401}$ used a similar FC configuration in medium mass resolution mode $(\Delta M / M>5500)$ for $\mathrm{V}$ isotope measurements of 12 geological RMs including igneous rocks and manganese nodules. Based on replicate analysis of solution and rocks standards, the long-term external reproducibility for $\delta^{51} \mathrm{~V}$ was better than $\pm 0.1 \%$ ( 2 $\mathrm{SD})$.

High precision $\mathrm{Br}$ isotope measurements by MC-ICP-MS represent a considerable challenge because of isobaric interferences from ${ }^{40} \mathrm{Ar}^{38} \mathrm{ArH}^{+}$and ${ }^{40} \mathrm{Ar}^{40} \mathrm{ArH}^{+}$. Wei et al. ${ }^{402}$ reported that it was possible to resolve these argides from ${ }^{79} \mathrm{Br}$ and ${ }^{81} \mathrm{Br}$ by using high mass resolution and appropriate settings of the instrument's Zoom Optics. The external precision of ${ }^{81} \mathrm{Br} /{ }^{79} \mathrm{Br}$ in selected RMs ranged from \pm 0.03 to $\pm 0.14 \%$. Solutions of NIST SRM 977 (bromine isotope solution) prepared in the $\mathrm{NaBr}$-form produced larger signals and better precisions than solutions prepared as $\mathrm{HBr}$, reflecting loss of $\mathrm{HBr}$ in the nebuliser and potential diffusive isotope fractionations in the plasma.

\subsubsection{Other mass spectrometric techniques}

4.4.3.1 Thermal ionisation mass spectrometry. This is still a popular technique for determining $S r$ isotope ratios, especially in samples with low Sr contents. A useful review ${ }^{403}$ (79 references) summarised methods of obtaining very low blanks and high precision $\mathrm{Sr}$ isotope measurements on ng samples. A new system for microsampling ${ }^{404}$ by laser cutting followed by conventional Rb-Sr isotopic analysis of $\mu$ g-sized samples by TIMS was used for extracting calcite and white-mica domains from samples of granitic mylonites. The 
automated cutting process minimised loss of material and the risk of handling errors while facilitating sampling of complex shapes of almost any size.

Several studies sought to improve the double-spike technique for determining $\mathrm{Ca}$ isotope ratios by MC-TIMS. Feng et al. ${ }^{405}$ investigated three double spike pairs, ${ }^{42} \mathrm{Ca}-{ }^{48} \mathrm{Ca}$, ${ }^{43} \mathrm{Ca}-{ }^{48} \mathrm{Ca}$ and ${ }^{44} \mathrm{Ca}-{ }^{48} \mathrm{Ca}$, using the Monte Carlo simulation technique to predict the internal precision in peak jumping mode. Theoretical precisions were confirmed by repeat measurements of NIST SRMs $915 \mathrm{a}$ and $915 \mathrm{~b}$ (calcium carbonate) for $\delta^{44} \mathrm{Ca}$, thus validating the simulation as an effective method of predicting optimal FC configurations, ratio combinations and integration times. However, the observed external precisions were 8-9 times poorer than the internal precisions; these were ascribed to an additional, yet unknown, source of uncertainty. Lehn et al. ${ }^{406}$ also used a Monte Carlo error model to optimise a ${ }^{43} \mathrm{Ca}-$ ${ }^{48} \mathrm{Ca}$ double spike method for measuring $\delta{ }^{44} \mathrm{Ca} /{ }^{40} \mathrm{Ca}$ and $\delta{ }^{44} \mathrm{Ca} /{ }^{42} \mathrm{Ca}$. Whilst the measured internal precisions generally agreed with model predictions, external reproducibility for a range of RMs including NIST SRMs 915a and 915b (calcium carbonate) was much worse than expected. This was attributed to filament reservoir effects causing deviation from ideal exponential mass fractionation during ionisation. They concluded that a ${ }^{42} \mathrm{Ca}-{ }^{43} \mathrm{Ca}$ double spike should provide the most precise $\delta^{44} \mathrm{Ca} /{ }^{40} \mathrm{Ca}$ values because the average mass difference between the spike pair of isotopes and the measured isotopes is only $0.5 \mathrm{amu}$. In contrast to these peak jumping methodologies, Naumenko-Dèzes et al. ${ }^{407}$ measured all $\mathrm{Ca}$ isotopes simultaneously using a MC-TIMS instrument with a specially developed collector geometry. Sample masses were kept to $<1 \mu \mathrm{g} \mathrm{Ca}$ and measurement uncertainties were $0.06 \%$ o for ${ }^{40} \mathrm{Ca} /{ }^{44} \mathrm{Ca}$ and $0.12 \%$ for ${ }^{48} \mathrm{Ca} /{ }^{40} \mathrm{Ca}$. Deficiencies in the exponential law used to correct instrumental mass fractionation were highlighted and the accuracy of an improved exponential law confirmed with NIST SRMs 915a and 915b (calcium carbonate). The laser microsampling technique described previously ${ }^{404}$ was employed to extract $\mu \mathrm{g}$ fragments of calcite and apatite for $\mathrm{Ca}$ isotopic analysis ${ }^{408}$. Samples were dissolved in $\mathrm{HNO}_{3}$ with the addition of a ${ }^{42} \mathrm{Ca}^{44} \mathrm{Ca}$ spike and loaded onto a Re filament using a parafilm dam technique to minimise in-run fractionation. Measurements of ${ }^{40} \mathrm{Ca},{ }^{42} \mathrm{Ca},{ }^{43} \mathrm{Ca},{ }^{44} \mathrm{Ca}$ and ${ }^{48} \mathrm{Ca}$ by TIMS and MC-ICP-MS were reported after mass fractionation correction using the double-spike and a Matlab model. Accurate TIMS data were achieved without chemical purification whereas analysis by MC-ICP-MS was challenging without separation from matrix elements.

The determination of $\mathrm{Pb}$ isotope ratios in ng-size samples by TIMS is hampered by the low abundance of ${ }^{204} \mathrm{~Pb}$. This limitation was overcome ${ }^{409}$ by the use of an FC with a $10^{13}$ $\Omega$ resistor in the amplifier feedback loop for the collection of ${ }^{204} \mathrm{~Pb}$. This resulted in a 10 -fold 
improvement in the $\mathrm{S} / \mathrm{N}$ but necessitated an external gain correction using a secondary standard and careful monitoring of the ion beam stability. Using a ${ }^{207} \mathrm{~Pb}-{ }^{204} \mathrm{~Pb}$ spike to correct for instrumental mass fractionation, results for $5 \mathrm{ng}$ aliquots of NIST SRM $982(\mathrm{~Pb}$ isotopic standard) had a reproducibility of $90 \mathrm{ppm}(2 \mathrm{SD})$ for ${ }^{206} \mathrm{~Pb} /{ }^{204} \mathrm{~Pb}$. Similar precision was achieved for $5 \mathrm{ng}$ portions of USGS RMs AGV-1 (andesite) and BCR-1 (basalt) indicating that the ion-exchange procedure had no adverse effect on data quality and the blank contribution was negligible. A different strategy was adopted by von Quadt et al. ${ }^{410}$ for high precision zircon U-Pb geochronology by ID-TIMS in samples containing small amounts of radiogenic $\mathrm{Pb}(<1-700 \mathrm{pg})$. The instrument was configured with FCs fitted with $10^{13} \Omega$ resistors for static collection of all the $\mathrm{Pb}$ isotopes except ${ }^{204} \mathrm{~Pb}$, which was measured with the axial secondary electron multiplier. Gain calibration factors for the $10^{13} \Omega$ resistors determined using the GSJ Nd standard JNdi-1 were crucial for the accuracy of subsequent isotope ratio determinations. Accuracy was demonstrated by analysis of synthetic and natural $\mathrm{U}-\mathrm{Pb}$ standards and by comparison with conventional dynamic ion counting data. Although the static FC measurements were more reproducible by a factor of 2-5, the uncertainties on the final $\mathrm{U}-\mathrm{Pb}$ ratios and derived $\mathrm{U}-\mathrm{Pb}$ dates were only slightly reduced due to external sources of uncertainty. These would need to be eliminated to fully realise the benefit of the improved precision of the FC measurements.

Other newly published methods for the determination of isotope ratios by TIMS are included in Table 7.

4.4.3.2 Secondary ion mass spectrometry. Detailed mapping by SIMS, in combination with other techniques, has been employed to elucidate the origins of accessory minerals. Elemental and isotope ratio imaging of monazite ${ }^{411}$ by NanoSIMS provided high quality sub- $\mu \mathrm{m}$ scale images that revealed chemical domains not distinguishable by EPMA mapping, especially for $\mathrm{Pb}$ and $\mathrm{U}$. It also enabled accurate dating of domains that were too small for reliable measurements by LA-ICP-MS. Maps of ${ }^{208} \mathrm{~Pb} /{ }^{232} \mathrm{Th}$ offered the opportunity to correlate ages with distinct chemical domains. Trace element data obtained by LA-ICP-MS provided important evidence in reconstructing the petrological history of the monazite. Three zircon RMs (Plešovice, Qinghu and Temora) were mapped for their Li abundance and isotopic composition by SIMS in a study ${ }^{412}$ designed to understand the behaviour of Li in zircon. All the RMs had rims 5-20 $\mu$ m wide in which the Li concentration was 5 to 20 times higher than in the zircon core. The $\mathrm{Li}$ contents and $\delta^{7} \mathrm{Li}$ values were very variable in the rims but relatively homogenous in the cores. From rim to core, the Li concentrations decreased rapidly 
while $\delta^{7} \mathrm{Li}$ values increased, suggesting that the large $\mathrm{Li}$ isotopic variation in the zircons could be caused by diffusion. A tutorial review ${ }^{413}$ ( 215 references) on the use of isotope ratios in cosmochemistry compared the performance of MC-ICP-MS, SIMS and TIMS for this purpose. Because of its high spatial resolution and sensitivity for many key elements, SIMS has proved to be indispensable for the in situ characterisation of extraterrestial materials.

Other examples of geological applications of nanoSIMS included the measurement of stable $\mathrm{C}$ and $\mathrm{O}$ isotope compositions of methane-derived carbonates ${ }^{414}$ in rocks from Poland. The fine spatial resolution $(5 \mu \mathrm{m})$ of the nanoSIMS analyses revealed a very high variability in $\delta^{13} \mathrm{C}$, even in individual crystals, from very negative $(-54 \%$ o) to positive $(+7 \%)$. This indicated that these carbonates were predominately formed by the anaerobic oxidation of biogenic methane. The $\mathrm{C}$ and $\mathrm{O}$ stable isotope compositions of these microcrystalline cements could be used to reconstruct the diagenetic evolution of porewaters in this region. Hauri et al. ${ }^{415}$ demonstrated that nanoSIMS was capable of high precision $\mathrm{S}$ isotope measurements $\left({ }^{32} \mathrm{~S},{ }^{33} \mathrm{~S}\right.$ and $\left.{ }^{34} \mathrm{~S}\right)$ with a precision capable of resolving variations in $\Delta^{33} \mathrm{~S}$ of $c a$. $0.4 \%$ o $(2 \sigma)$ with a spatial resolution of $15 \mu \mathrm{m}$. Pyrite grains from metasedimentary rocks in Ontario, Canada had $\delta^{34} \mathrm{~S}$ values of between -9.6 and $+6.3 \%$ and corresponding $\Delta^{33} \mathrm{~S}$ values of between -0.8 and $+1.5 \%$. These results indicated that microbial sulfate reduction was widespread in the Neoarchean era. Figures of merit obtained in this study by nanoSIMS were comparable to those of large radius SIMS instruments, indicating the potential of these smaller instruments.

In a study ${ }^{416,417}$ of carbonate $\delta^{13} C$ and $\delta^{18} O$ records for reconstructing past climatic conditions throughout the evolution of the Earth, a suite of $\mathrm{Ca}-\mathrm{Fe}-\mathrm{Mg}$ carbonate $\mathrm{RMs}$ for calibrating $\delta^{13} \mathrm{C}$ and $\delta^{18} \mathrm{O}$ SIMS measurements was developed. The highly systematic, nonlinear nature of SIMS instrumental bias was demonstrated for minerals with compositions along the dolomite-ankerite solid solution series.

4.4.3.3 Accelerator mass spectrometry. This technique is often used to measure cosmogenic isotopes because of its great sensitivity. Cosmogenic ${ }^{10} \mathrm{Be}$ forms in situ when high-energy cosmic rays bombard rocks in the upper few metres of the Earth's surface. Sample preparation procedures to extract ${ }^{10} \mathrm{Be}$ from quartz mineral separates ${ }^{418}$ were reassessed to maximise the yield of ${ }^{10} \mathrm{Be}$ for AMS while minimising contamination and background levels of ${ }^{10} \mathrm{~B}$. By using a beryl carrier and dedicated equipment to process samples with low $\mathrm{Be}$ content, the optimised method routinely achieved blanks with ${ }^{10} \mathrm{Be} /{ }^{9} \mathrm{Be}$ ratios in the mid $10^{-16}$ level, an improvement of almost two orders of magnitude compared with blanks obtained 
with commercial carriers. A study ${ }^{419}$ to extend the dating of sediments using the cosmogenic isotope ${ }^{32} \mathrm{Si}$ demonstrated the potential benefits of making modest improvements in detector background levels. The design and performance of new low-background, gas-proportional beta counters to measure ${ }^{32} \mathrm{Si}\left(\right.$ via $\left.^{32} \mathrm{P}\right)$ were presented.

4.4.3.4 Noble gas mass spectrometry. In an interlaboratory comparison ${ }^{420}$ to determine the accuracy of cosmogenic ${ }^{21} \mathrm{Ne}$ measurements in quartz, the five participating laboratories employed their own measurement routines to analyse CREU-1, a natural quartz standard prepared from amalgamated vein clasts. Although the reported analytical precision for each laboratory was as low as $2 \%$, the $7.1 \%$ dispersion of results between laboratories was considered to be a more realistic estimate of the accuracy of the ${ }^{21} \mathrm{Ne}$ method at the present time. During the development of a new analytical procedure ${ }^{421}$ for the determination of $\mathrm{Ne}$ in rocks, the contribution of isobaric ions on the three $\mathrm{Ne}$ isotopes were studied in detail, particularly the major interference from ${ }^{40} \mathrm{Ar}^{2+}$ on ${ }^{20} \mathrm{Ne}^{+}$; strategies for interference corrections were modified accordingly. Method accuracy and precision were assessed by measuring ${ }^{21} \mathrm{Ne}$ in three aliquots of CREU-1; the average value was within $0.3 \%$ of the published value with a $2.2 \%$ uncertainty.

The main advantage of the ${ }^{40} \mathrm{Ar}-{ }^{39} \mathrm{Ar}$ method over conventional $\mathrm{K}-\mathrm{Ar}$ dating is that it only relies on the ratios between five isotopes of the same element. A completely revised workflow ${ }^{422}$ for generating accurate ${ }^{40} \mathrm{Ar}-{ }^{39} \mathrm{Ar}$ ages from raw mass spectrometer data accounted for all sources of analytical uncertainty, including those associated with decay constants and the air ratio. The programme can be downloaded free of charge.

\subsubsection{X-ray spectrometry.}

For a comprehensive review of recent advances in XRF instrumentation and geological applications, the reader is advised to consult the ASU on XRFS ${ }^{5}$.

Advances in detector technologies and associated data processing software now means that synchrotron XRF microscopy can be used for trace element mapping at the $\mu \mathrm{m}$ scale with ppm LODs. Li et al. ${ }^{423}$ demonstrated the application of megapixel SXRFS to ore petrology by imaging six samples representative of different ore deposits related to the extraction of $\mathrm{Cu}, \mathrm{Ge}, \mathrm{Pt}$ and $\mathrm{U}$. Millisecond dwell times allowed collection of maps the size of a thin section at resolutions of a few $\mu \mathrm{m}$ in just a few hours. It was particularly efficient at revealing the distribution of precious metals such as $\mathrm{Au}$ and $\mathrm{Pt}$, which tend to occur as small inclusions of native metals and alloys, and trace contaminants that form distinct micro- 
minerals, as well as providing information on metal speciation. All the samples analysed revealed new features that had not been reported previously. Fisher et al. ${ }^{424}$ presented three case studies from orogenic gold deposits in which all phases in a thin section were mapped by SXRFS at high resolution (2-4 $\mu$ m pixels) with LODs comparable to, or exceeding, EMPA LODs for most elements. The system employed full spectral data collection so elements did not have to be selected prior to measurement, in contrast to other imaging techniques, such as EPMA and SIMS. The first two examples examined the variation in sulfide phases round high-grade gold veins, while the third considered the fine-scale alternation of sulfides, in order to shed light on the source of and deposition mechanisms of gold in such deposits. Although megapixel SXRFS mapping is still in its infancy, it should open up new horizons in the study of trace and major element distributions and speciation in geological materials and offer a complementary method to other imaging techniques.

The performance of a laboratory $\mu X R F$ system was assessed for $2 \mathrm{D}$ elemental mapping ${ }^{425}$ of petrographic thin sections for studies of argillaceous rocks from a potential radioactive waste repository. Different options of X-ray sources and detectors were tested to find the optimal configuration of this system in terms of sensitivities and LODs for Cs and $\mathrm{Ni}$, which acted as surrogates for fission and corrosion products. Although laboratory $\mu$ XRFS was an excellent tool for identifying the key minerals for the uptake of Cs, careful corrections were required for $\mathrm{Ni}$ because of the relatively high $\mathrm{Ca}$ content of the samples. The capabilities of a semi-portable $\mu$ XRF instrument were demonstrated ${ }^{426}$ through the determination of $\mathrm{Sr}$ in speleothems. A smooth, highly-polished sample surface was required together with a strategy to account for the observed matrix effects. This type of analysis would be a suitable way of preselecting samples prior to more detailed geochemical analysis.

Over the last decade, XRF core scanning has become increasingly popular for a variety of applications. A prototype LIBS system was compared with a commercially available EDXRF core scanner for rapid detection ${ }^{427}$ of metalliferous zones in cores from a tailings deposit in a former $\mathrm{Pb}-\mathrm{Zn}$ mine. Both methods suffered from matrix effects; the application of PLSR improved the results in both cases. Distributions of element concentrations obtained by the two techniques were similar and well correlated with bulk concentrations obtained by WDXRFS. Although both systems could detect metal-rich layers not visible to the naked eye up to concentrations of $2.2 \% \mathrm{Cu}+\mathrm{Pb}+\mathrm{Zn}$, the LIBS core scanner had the advantage of high spatial resolution and an ability to create $2 \mathrm{D}$ elemental images. A study ${ }^{428}$ of XRF core scanning to measure palaeoenvironmental markers in cores of organicrich lake sediments and peat investigated the influence of organic matter, water content and 
sample porosity. The importance of careful evaluation of the data through corroborative evidence from other techniques was stressed.

Other, more unusual, examples of the application of XRF techniques to geological samples included: the determination of Mn valence state and speciation in Mn ores ${ }^{429}$ by WDXRFS; using XANES to identify the forms of $\mathrm{Cu}$ extracted ${ }^{191}$ from geochemical RMs by the $\mathrm{BCR}$ sequential extraction scheme; and the determination of $\mathrm{Br}, \mathrm{Cl}, \mathrm{F}$ and $\mathrm{I}$ in marine sediments ${ }^{430}$ by WDXRFS directly on pressed pellets without binder. Reported LODs for the halogens were $0.5,5,100$, and $10 \mu \mathrm{g} \mathrm{g}^{-1}$ for $\mathrm{Br}, \mathrm{Cl}, \mathrm{F}$ and I respectively for a counting time of 100 s. Quye-Sawyer et $a l .{ }^{431}$ showed that handheld EDXRF instruments were capable of rapid and quantitative determination of $\mathrm{Al}, \mathrm{Ba}, \mathrm{Ca}, \mathrm{Fe}, \mathrm{K}, \mathrm{Mg}, \mathrm{Mn}, \mathrm{Rb}, \mathrm{Si}, \mathrm{Sr}, \mathrm{Ti}$ and $\mathrm{Zn}$ in carbonate rocks provided appropriate corrections, based on a set of carbonate standards, were applied to the manufacturer's calibration. Grain size in powdered samples and the roughness of hand samples had no impact on measured concentrations except for $\mathrm{Mg}$. However, weathering posed a significant challenge for in situ measurements of carbonate outcrops and the use of fresh rock chips hammered from the outcrop was advised for reliable quantitative results.

Traditionally, XRD devices have largely been restricted to laboratories but advances in XRD sample holders and X-ray sources have contributed to the recent development of portable XRD instruments. A study ${ }^{432}$ of the capabilities of portable XRD for mineralogical analysis of hydrothermal systems demonstrated that although laboratory-based systems delivered superior results compared to the field portable unit, there was good correlation between data from the two systems for major mineral phases; some minor and trace phases were also detectable. Portable XRD was shown to have the potential to provide the exploration geologist with a tool for the rapid acquisition of mineralogical data on which to make more informed decisions during drilling programmes. The ultimate remote field location for operating such devices is Mars, where the miniaturised XRD/XRF instrument CheMin aboard the Curiosity rover analysed four different samples ${ }^{433}$. The primary on-board XRD standards were mixtures of beryl and quartz. By a happy coincidence, the first XRD measurements on Mars coincided with the $100^{\text {th }}$ anniversary of the discovery of the technique. 
Table 7 Methods used in the determination of isotope ratios in geological materials by ICP-MS and TIMS 


\begin{tabular}{|c|c|c|c|c|c|}
\hline Analyte & Matrix & Sample treatment & Technique & Analysis and figures of merit & Ref \\
\hline $\mathrm{Ba}$ & $\begin{array}{l}\text { Geological } \\
\text { materials }\end{array}$ & $\begin{array}{l}\text { Decomposition in } \mathrm{HNO}_{3}-\mathrm{HF} \text {, take up in } \mathrm{HCl} \text {. Two- } \\
\text { column purification with AG50W-X12 cation- } \\
\text { exchange resin. }\end{array}$ & $\begin{array}{l}\text { MC-ICP- } \\
\text { MS }\end{array}$ & $\begin{array}{l}\text { SSB using NIST SRM } 3104 \mathrm{a}\left(\mathrm{Ba}\left(\mathrm{NO}_{3}\right)_{2} \text { solution }\right) \text {. } \\
\text { Long-term precision for } \delta^{137} \mathrm{Ba} /{ }^{134} \mathrm{Ba} \text { better than } \\
\pm 0.05 \% \text { (2SD); new data for } 8 \text { USGS and GSJ } \\
\text { geological RMs. }\end{array}$ & 434 \\
\hline $\mathrm{Ca}$ & Basalt and bone & $\begin{array}{l}\text { Purification using a low pressure, fully automated } \\
\text { fluoropolymer chromatography system (prep } F A S T \\
\text { MC) with a proprietary Sr-Ca column designed for } \\
\text { wide range of sample types. }\end{array}$ & $\begin{array}{l}\text { MC-ICP- } \\
\text { MS }\end{array}$ & $\begin{array}{l}\mathrm{Ca} \text { isotopes measured in medium resolution } \\
\text { mode, with SSB using in-house Ca solution and } \\
\text { conversion to SRM } 915 \text { a scale. Typical precision } \\
\delta^{44} \mathrm{Ca} /{ }^{42} \mathrm{Ca} 0.06 \% \text { o }(2 \sigma) \text {. }\end{array}$ & 393 \\
\hline $\mathrm{Cd}$ & FeMn nodule & $\begin{array}{l}\text { Dissolution in } 6 \mathrm{M} \mathrm{HCl} \text {, addition of Cd double spike } \\
\text { before anion-exchange chromatography with } \\
\text { Eichrom TRU resin. Liquid-liquid extraction with n- } \\
\text { heptane used to remove organic resin residues eluted } \\
\text { with Cd. }\end{array}$ & $\begin{array}{l}\text { MC-ICP- } \\
\text { MS }\end{array}$ & $\begin{array}{l}\text { Changes in instrumental mass bias calculated } \\
\text { from }{ }^{111} \mathrm{Cd}-{ }^{114} \mathrm{Cd} \text { double spike. Typical } \\
\text { procedural blanks contained }<20 \mathrm{pg} \text { Cd. Repeat } \\
\text { measurements of Cd isotope RM BAM-I012 gave } \\
\epsilon^{114} \mathrm{Cd} /{ }^{111} \mathrm{Cd} \text { of }-13.2 \pm 0.7(2 \mathrm{SD}, \mathrm{n}=15), c f \\
\text { literature value of }-13.3 \pm 0.4\end{array}$ & 435 \\
\hline $\mathrm{Cr}$ & Lunar basalts & $\begin{array}{l}\text { Dissolution in } \mathrm{HNO}_{3}-\mathrm{HF}-\mathrm{HCl} \text {, addition of }{ }^{50} \mathrm{Cr}^{54}{ }^{54} \mathrm{Cr} \\
\text { double spike and separation from matrix via a two } \\
\text { column chemistry utilising AG50 X8 resin }\end{array}$ & $\begin{array}{l}\text { MC-ICP- } \\
\text { MS }\end{array}$ & $\begin{array}{l}\text { Medium resolution mode, Cr double spike used to } \\
\text { correct for mass bias. Accuracy confirmed with } \\
\text { NIST SRM } 979 \text { (hydrated chromium nitrate) }\end{array}$ & 436 \\
\hline $\mathrm{Cr}$ & Meteorites & $\begin{array}{l}\text { For silicate samples, preparation was same as in ref. } \\
437 \text {. For Fe-rich samples, an extra column containing } \\
\text { AG1 X8 resin was employed to remove Fe from } \\
\text { sample before continuing as for silicates. }\end{array}$ & MC-TIMS & $\begin{array}{l}\text { Mass-independent and mass-dependent Cr isotope } \\
\text { compositions reported. Two methodologies used } \\
\text { to correct for mass fractionation because } \\
\text { assumptions made for terrestrial samples do not } \\
\text { hold for extra-terrestrial samples. }\end{array}$ & 437 \\
\hline $\mathrm{Cu}, \mathrm{Zn}$ & $\begin{array}{l}\text { Geological } \\
\text { materials }\end{array}$ & $\begin{array}{l}\text { Digestion in } \mathrm{HF}-\mathrm{HNO}_{3}-\mathrm{HClO}_{4} \text {. Simplified } \\
\text { purification procedure using BioRad AG MP-1 resin } \\
\text { reduced handling time, amount of } \mathrm{HCl} \text { used and } \\
\text { eliminated need for treatment with } \mathrm{H}_{2} \mathrm{O}_{2} \text {. }\end{array}$ & $\begin{array}{l}\text { MC-ICP- } \\
\text { MS }\end{array}$ & $\begin{array}{l}\text { Procedure blanks of } 2 \mathrm{ng} \mathrm{Cu} \text { and } 23 \mathrm{ng} \mathrm{Zn} \text {, with } \\
\text { yield of nearly } 100 \% \text {. Potential polyatomic } \\
\text { interferences from } \mathrm{ArN}_{2}^{+} \text {and } \mathrm{ArNO}^{+} \text {studied. } \\
\text { Use of desolvating nebuliser recommended to } \\
\text { enhance ionisation of } \mathrm{Zn} \text {. }\end{array}$ & 438 \\
\hline $\mathrm{Cu}$ & Geological RMs & $\begin{array}{l}\text { Dissolution in } \mathrm{HNO}_{3}-\mathrm{HF} \text { and take up in } \mathrm{HCl} \text {. } \\
\text { Separation on anion-exchange resin BioRad AG MP- } \\
\text { 1M. Purified } \mathrm{Cu} \text { fraction spiked with Ga prior to } \\
\text { analysis. Blank } 2 \mathrm{ng} \mathrm{Cu}\end{array}$ & $\begin{array}{l}\text { MC-ICP- } \\
\text { MS }\end{array}$ & $\begin{array}{l}\text { Mass bias correction using combined SSB and Ga } \\
\text { internal standard resulting in a } 5 \text {-fold } \\
\text { improvement in precision of } \delta^{65} \mathrm{Cu} \text { compared with } \\
\text { SSB alone. }\end{array}$ & 439 \\
\hline $\mathrm{Fe}$ & Geological RMs & $\begin{array}{l}\text { Digestion in } \mathrm{HF}-\mathrm{HNO}_{3}-\mathrm{HCl}-\mathrm{HClO}_{4} \text { and purified } \\
\text { using a } 2 \text { column procedure with anion-exchange } \\
\text { resin AG1X-8. Blanks }<10 \mathrm{ng} \mathrm{Fe} \text {. }\end{array}$ & $\begin{array}{l}\text { HR-MC- } \\
\text { ICP-MS }\end{array}$ & $\begin{array}{l}\text { Medium to high resolution mode. SSB with in- } \\
\text { house high purity Fe solution; data reported } \\
\text { relative to IRMM-014. Long-term reproducibility }\end{array}$ & 440 \\
\hline
\end{tabular}




\begin{tabular}{|c|c|c|c|c|c|}
\hline & & & & $\begin{array}{l}\text { and accuracy of }<0.03 \% \text { ( } 2 \mathrm{~s}) \text { for }{ }^{56} \mathrm{Fe} /{ }^{54} \mathrm{Fe} \text {. Data } \\
\text { reported for } 22 \text { geological RMs. }\end{array}$ & \\
\hline $\mathrm{Fe}$ & $\begin{array}{l}\text { Ultramafic } \\
\text { minerals }\end{array}$ & $\begin{array}{l}\text { Digestion in } \mathrm{HF}-\mathrm{HNO}_{3} \text {, take up with } \mathrm{HCl} \text { and } \\
\text { separation on } \mathrm{AG} 1-\mathrm{X} 4 \text { column with quantitative } \\
\text { recoveries. Addition of }{ }^{57} \mathrm{Fe}^{58} \mathrm{Fe} \text { double spike, dried } \\
\text { down and redissolved in } \mathrm{HNO}_{3} \text {. Blanks }<10 \mathrm{ng} \text {. }\end{array}$ & $\begin{array}{l}\text { MC-ICP- } \\
\text { MS }\end{array}$ & $\begin{array}{l}\text { Mass bias corrections using Fe double spike. }{ }^{60} \mathrm{Ni} \\
\text { monitored and used to correct for }{ }^{58} \mathrm{Ni} \\
\text { interference on }{ }^{58} \mathrm{Fe} \text {. Ion counter rather than } \\
\text { Faraday detector for }{ }^{60} \mathrm{Ni} \text { signal improved } \delta^{56} \mathrm{Fe} \\
\text { reproducibility from } \pm 0.145 \% \text { to } \pm 0.052 \% 0 .\end{array}$ & 441 \\
\hline $\mathrm{Hf}$ & $\begin{array}{l}\text { Zircon, } \\
\text { baddeleyite }\end{array}$ & $\begin{array}{l}\text { Dissolution of ng quantities of material but no } \\
\text { separation from matrix elements. Method can be used } \\
\text { for minerals as small as } c a .24 \mathrm{ng} \text {. }\end{array}$ & $\begin{array}{l}\text { MC-ICP- } \\
\text { MS }\end{array}$ & $\begin{array}{l}\text { Study of isobaric interferences on }{ }^{176} \mathrm{Hf} /{ }^{177} \mathrm{Hf} \text { and } \\
\text { methods proposed to account for them. SSB } \\
\text { approach with matrix-matched standards. LOQ } \\
<2 \mathrm{ng} \mathrm{g}^{-1} \mathrm{Hf}\end{array}$ & 442 \\
\hline $\mathrm{Hf}$ & $\begin{array}{l}\text { Terrestrial rocks } \\
\text { and meteorites }\end{array}$ & $\begin{array}{l}\text { Basalt samples digested in } \mathrm{HF}^{-} \mathrm{HNO}_{3} \text {, chondrites in } \\
\mathrm{HF}^{-} \mathrm{HNO}_{3}-\mathrm{HClO}_{4}\left(\mathrm{HF}-\mathrm{HNO}_{3} \text { only for some types of }\right. \\
\text { chrondrite) and iron meteorites in aqua regia. Two- } \\
\text { stage chemistry using Eichrom }{ }^{\mathrm{TM}} \mathrm{Ln} \text { resin to separate } \\
\mathrm{Hf} \text { from matrix elements and then } \mathrm{AG} 1-\mathrm{X} 8 \text { anion- } \\
\text { exchange resin to minimise interference from }{ }^{174} \mathrm{Yb} \text {. } \\
\text { Blanks were }<30 \mathrm{pg} \mathrm{Hf} \text {. }\end{array}$ & $\begin{array}{l}\text { MC-ICP- } \\
\text { MS }\end{array}$ & $\begin{array}{l}\text { For isotope ratios involving low abundance } \\
\text { isotopes }{ }^{174} \mathrm{Hf},{ }^{180} \mathrm{~W} \text { and }{ }^{190} \mathrm{Pt} \text {, uncertainties of } \\
<100 \mathrm{ppm} \text { were typically achieved, by use of } \\
\text { Faraday amplifiers with } 10^{12} \Omega \text { resistors and } \\
\text { improved separation procedures. }\end{array}$ & 443 \\
\hline Hf & $\begin{array}{l}\text { Rocks and } \\
\text { mineral grains }\end{array}$ & $\begin{array}{l}\text { Modified procedure suitable for Lu-Hf, Sm-Nd and } \\
\text { Rb-Sr geochronology. Mixed spikes of }{ }^{176} \mathrm{Lu}{ }^{180} \mathrm{Hf} \text {, } \\
\text { (also }{ }^{149} \mathrm{Sm}^{150}-{ }^{150} \text { and }{ }^{87} \mathrm{Rb}-{ }^{84} \mathrm{Sr} \text { if required) added } \\
\text { before digestion with } \mathrm{HF}-\mathrm{HNO}_{3} \text { and take up in } \mathrm{HCl} \text {. } \\
\text { To improve the purification of Hf, HFSEs were } \\
\text { separated from REEs and then purified on Ln Spec } \\
\text { column. Sm-Nd and Rb-Sr separations could be } \\
\text { added easily. Blank }<10 \mathrm{pg} \text { Hf. }\end{array}$ & $\begin{array}{l}\text { MC-ICP- } \\
\text { MS }\end{array}$ & $\begin{array}{l}\text { Instrument equipped with three FCs fitted with } \\
10^{12} \Omega \text { resistors for improved precision and an X- } \\
\text { skimmer and Jet sample cone to enhance } \\
\text { sensitivity. }{ }^{176} \mathrm{Hf} /{ }^{177} \mathrm{Hf} \text { measurements on } \\
\text { geological RMs gave precisions of } 5-20 \mathrm{ppm} \text { for } \\
\text { solutions containing } 40 \mathrm{ppb} \mathrm{Hf} \text { and } 50-180 \mathrm{ppm} \\
\text { for } 1 \mathrm{ppb} \text { solutions. }\end{array}$ & 444 \\
\hline $\mathrm{K}$ & Igneous rocks & $\begin{array}{l}\text { Digestion with } \mathrm{HNO}_{3}-\mathrm{HF} \text { and take-up in } \mathrm{HCl} \text {. } \\
\text { Separation from matrix elements in two-column } \\
\text { procedure using BioRad AG50W-X12 and then } \\
\text { BioRad AG50W-X* resin to achieve }>99 \% \text { recovery } \\
\text { with blanks 3-8 ng K. }\end{array}$ & $\begin{array}{l}\text { MC-ICP- } \\
\text { MS }\end{array}$ & $\begin{array}{l}\text { Single focusing instrument with hexapole } \\
\text { collision cell used to suppress } \mathrm{ArH}^{+} \text {isobaric } \\
\text { interferences. Better precision } \mathrm{K} \text { isotope ratios } \\
\text { achieved using } \mathrm{D}_{2} \text { rather than } \mathrm{H}_{2} \text { as the reaction } \\
\text { gas. External reproducibility of better than } \\
\pm 0.21 \% \text { (2SD) for }{ }^{41} \mathrm{~K}{ }^{39} \mathrm{~K} \text {. }\end{array}$ & 222 \\
\hline $\mathrm{Li}$ & Geological RMs & $\begin{array}{l}\text { Digestion with } \mathrm{HNO}_{3}-\mathrm{HF} \text {, final solution in } 0.67 \mathrm{M} \\
\mathrm{HNO} / 30 \% \text { methanol }(v / v) \text {. Separation on AG50W- } \\
\text { X8 cation-exchange resin achieved full recovery. }\end{array}$ & $\begin{array}{l}\text { MC-ICP- } \\
\text { MS }\end{array}$ & $\begin{array}{l}5 \% \mathrm{NaCl} \text { rinse solution used to reduce } \mathrm{Li} \\
\text { instrumental background and memory effect. } \\
\text { With } \mathrm{NaCl} \text { washing, no significant mass bias }\end{array}$ & 445 \\
\hline
\end{tabular}




\begin{tabular}{|c|c|c|c|c|c|}
\hline & & & & $\begin{array}{l}\text { observed when measuring Li isotope ratios } \\
\text { making it unnecessary for strict matching of } \mathrm{Li} \\
\text { concentrations in samples and standards. External } \\
\text { precision } \pm 0.25 \% \text { (2SD) for } \delta^{7} \mathrm{Li} \text {. }\end{array}$ & \\
\hline $\mathrm{Li}$ & $\begin{array}{l}\text { Carbonates and } \\
\text { clays }\end{array}$ & $\begin{array}{l}\text { Fine tuning of different digestion and column } \\
\text { separation procedures for carbonates and clay } \\
\text { matrices. Separation on BioRad AG } 50 \mathrm{~W}-\mathrm{X} 8 \text { cation- } \\
\text { exchange resin gave }>99 \% \text { recovery of } 10-20 \mathrm{ng} \mathrm{Li} \text {. }\end{array}$ & $\begin{array}{l}\text { MC-ICP- } \\
\text { MS }\end{array}$ & $\begin{array}{l}\text { SSB approach for correcting instrumental mass } \\
\text { bias, with same Li concentrations in all standard } \\
\text { and sample solutions. External precision } \pm 0.2 \% 0 \\
(2 \mathrm{SE}, \mathrm{n}=15) \text { for } \delta^{7} \mathrm{Li} \text {. }\end{array}$ & 446 \\
\hline $\mathrm{Mg}$ & Geological RMs & $\begin{array}{l}12 \text { geological RMs analysed in } 5 \text { labs using various } \\
\text { sample dissolution and chromatography schemes. }\end{array}$ & $\begin{array}{l}\text { MC-ICP- } \\
\text { MS }\end{array}$ & $\begin{array}{l}\text { Comparison of }{ }^{26} \mathrm{Mg} /{ }^{24} \mathrm{Mg} \text { data and interlab mass } \\
\text { bias using } 3 \text { types of MC-ICP-MS instrument. } \\
\text { Mass bias determined by SSB using a pure } \mathrm{Mg} \\
\text { metal standard with matched Mg concentrations. }\end{array}$ & 396 \\
\hline Mo & $\begin{array}{l}\text { Geological (and } \\
\text { U-rich samples) }\end{array}$ & $\begin{array}{l}\text { Digestion in } \mathrm{HF}-\mathrm{HNO}_{3}-\mathrm{HCl}-\mathrm{HClO}_{4} \text { with take up in } \\
\mathrm{HCl} \text {. Addition of Mo double spike before three-stage } \\
\text { ion chromatography procedure based on AG1-X8, } \\
\text { TRU Spec and another AG1-X8 column to obtain } \\
\text { high degree of purification; recoveries } 42-80 \% \text {. }\end{array}$ & $\begin{array}{l}\text { MC-ICP- } \\
\text { MS }\end{array}$ & $\begin{array}{l}\text { Instrument equipped with Jet cones; solutions } \\
\text { analysed contained } c a .30 \mathrm{ng} \mathrm{ml}^{-1} \text { Mo. Chemical } \\
\text { and instrumental mass bias corrected using }{ }^{97} \mathrm{Mo}- \\
\left.{ }^{100} \text { Mo double spike. Precision } 0.02 \% \text { (2SE, } \mathrm{n}=8\right) \\
\text { for } \delta^{98} \text { Mo. }\end{array}$ & 447 \\
\hline Mo & $\begin{array}{l}\text { Rocks and iron } \\
\text { meteorites }\end{array}$ & 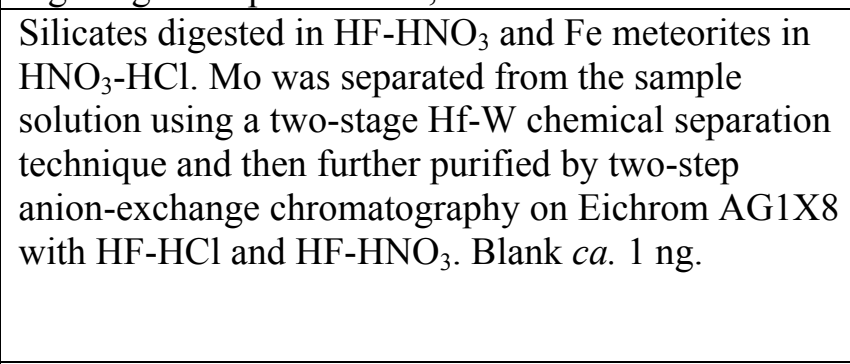 & NTIMS & $\begin{array}{l}\text { For most efficient ionisation to } \mathrm{MoO}_{3}{ }^{-} \text {, sample } \\
\text { loaded onto Re filament and covered with } \\
\mathrm{La}\left(\mathrm{NO}_{3}\right)_{2} \text {. Mo trioxide ions at masses } 149 \text { and } \\
150 \text { used to correct for oxide interferences and } \\
\text { mass dependent fractionation. Precisions }(2 \mathrm{SD}) \\
\text { for }{ }^{92} \mathrm{Mo} /{ }^{96} \mathrm{Mo},{ }^{94} \mathrm{Mo} /{ }^{96} \mathrm{Mo},{ }^{95} \mathrm{Mo} /{ }^{96} \mathrm{Mo},{ }^{97} \mathrm{Mo} /{ }^{96} \mathrm{Mo} \\
\text { and }{ }^{100} \mathrm{Mo} /{ }^{96} \mathrm{Mo} \text { were } 47,16,10,13 \text { and } 33 \mathrm{ppm} \\
\text { respectively. }\end{array}$ & 448 \\
\hline $\mathrm{Ni}$ & $\begin{array}{l}\text { Iron meteorites } \\
\text { and geological } \\
\text { RMs }\end{array}$ & $\begin{array}{l}\text { Aqua regia digestion for meteorites, } \mathrm{HF}-\mathrm{HNO}_{3} \text { attack } \\
\text { followed by aqua regia digestion for silicate samples. } \\
\text { Three-step ion-exchange chromatographic } \\
\text { purification: Dowex } 50 \mathrm{WX} 4 \text { resin to separate } \mathrm{Ni} \\
\text { from matrix followed by two columns containing } \\
\text { Eichrom } 1 \mathrm{X} 8 \text { resin to separate } \mathrm{Ni} \text { from } \mathrm{Fe}, \mathrm{Ti} \text { and } \mathrm{Zn} \text {. }\end{array}$ & $\begin{array}{l}\text { MC-ICP- } \\
\text { MS }\end{array}$ & $\begin{array}{l}\text { Medium resolution mode employed. Instrumental } \\
\text { mass bias corrected using }{ }^{63} \mathrm{Cu} /{ }^{65} \mathrm{Cu} \text { internal } \\
\text { normalisation or }{ }^{62} \mathrm{Ni} /{ }^{58} \mathrm{Ni} \text { of sample and } \mathrm{SSB} \\
\text { used to correct for instrumental drift. } \\
\text { Mathematical correction for }{ }^{56} \mathrm{Fe} \text { and }{ }^{66} \mathrm{Zn} \text { isobars } \\
\text { a critical aspect of method. Precisions for four Ni } \\
\text { isotope ratios equal or better than other reported } \\
\text { methods. }\end{array}$ & 449 \\
\hline $\mathrm{Nd}$ & $\begin{array}{l}\text { Geological } \\
\text { materials }\end{array}$ & $\begin{array}{l}\text { Digestion in } \mathrm{HF}-\mathrm{HNO}_{3} \text { and take up in } \mathrm{HCl} \text {. Improved } \\
\text { four-step separation and purification scheme: (i) REE }\end{array}$ & $\begin{array}{l}\text { MC-ICP- } \\
\text { MS }\end{array}$ & $\begin{array}{l}{ }^{148} \mathrm{Nd} /{ }^{144} \mathrm{Nd} \text { used for internal normalisation plus } \\
\mathrm{SSB} \text { with GSJ RM JNdi-1 (Nd oxide) as the }\end{array}$ & 450 \\
\hline
\end{tabular}




\begin{tabular}{|c|c|c|c|c|c|}
\hline & & $\begin{array}{l}\text { separation on AG50W-X8; (ii) Ce clean up on Ln } \\
\text { Spec; (iii) automated separation of LREE and Sm on } \\
\text { Ln Spec; and (iv) AG50W-X8 to remove any } \\
\text { organics and phosphates discharged from previous } \\
\text { columns. Nd recovery }>99 \% \text {. }\end{array}$ & & $\begin{array}{l}\text { reference standard. Iolite software package used } \\
\text { for all data reduction off-line. External precision } \\
\text { of } 0.20 \text { on } \epsilon^{145} \mathrm{Nd} \text { was comparable to that obtained } \\
\text { by double spike techniques. }\end{array}$ & \\
\hline $\begin{array}{l}\mathrm{Nd}, \mathrm{Th} \\
\text { and } \mathrm{U}\end{array}$ & Carbonates & $\begin{array}{l}\text { Combined separation procedure for } \mathrm{Nd} \text {, Th and } \mathrm{U} \text {. } \\
\text { Sample dissolution in } \mathrm{HNO}_{3} \text { with addition of }{ }^{236} \mathrm{U}_{-} \\
{ }^{229} \mathrm{Th} \text { spike. Trace metals coprecipitated with } \mathrm{FeCl}_{3} \text {, } \\
\text { redissolved in } 8 \mathrm{M} \mathrm{HNO}_{3} \text { before anion } \\
\text { chromatography to obtain separate fractions of REE, } \\
\text { Th and } \mathrm{U} \text {, followed by a two-stage separation and } \\
\text { purification of Nd. Average blank } 11 \mathrm{pg} \mathrm{Nd} \text {. }\end{array}$ & TIMS & $\begin{array}{l}\mathrm{Nd} \text { measured as } \mathrm{NdO}^{+} \text {with GSJ RM JNdi-1 (Nd } \\
\text { oxide) used to monitor instrumental offset and } \\
\text { correct for mass bias. Accuracy of }{ }^{143} \mathrm{Nd} /{ }^{144} \mathrm{Nd} \\
\text { ratios confirmed using USGS RM BCR-2 (basalt) } \\
\text { and in-house coral RM. }\end{array}$ & 451 \\
\hline Os & Geological RMs & $\begin{array}{l}\text { Digestion in Carius tubes with reverse aqua regia, Os } \\
\text { extracted into } \mathrm{CCl}_{4} \text { and back-extracted into } \mathrm{HBr} \\
\text { before purification by microdistillation. Blanks were } \\
0 .-0.3 \text { pg Os. }\end{array}$ & TIMS & $\begin{array}{l}\text { Static collection involving in-run measurement of } \\
\text { oxygen isotope ratios to correct for isobaric oxide } \\
\text { interferences on }{ }^{186} \mathrm{Os} /{ }^{188} \mathrm{Os} \text { and }{ }^{187} \mathrm{Os} /{ }^{188} \mathrm{Os} \text {. Main } \\
\mathrm{Os}^{16} \mathrm{O}_{3}{ }^{-} \text {ion beam collected with FCs fitted with } \\
10^{11} \Omega \text { amplifiers and }{ }^{192} \mathrm{Os}^{16} \mathrm{O}_{2}{ }^{17} \mathrm{O}^{-} \text {and } \\
{ }^{192} \mathrm{Os}^{16} \mathrm{O}_{2}{ }^{18} \mathrm{O}^{-} \text {ion beams with FCs fitted with } \\
10^{12} \Omega \text { amplifiers. }\end{array}$ & 452 \\
\hline $\mathrm{Pt}$ & $\begin{array}{l}\text { Terrestrial rocks } \\
\text { and meteorites }\end{array}$ & $\begin{array}{l}\text { Basalt samples digested in } \mathrm{HF}-\mathrm{HNO}_{3} \text {, chondrites in } \\
\mathrm{HF}-\mathrm{HNO}_{3}-\mathrm{HClO}_{4}\left(\mathrm{HF}-\mathrm{HNO} \mathrm{O}_{3} \text { only for some types of }\right. \\
\text { chondrite) and iron meteorites in aqua regia. One } \\
\text { column purification procedure based on BioRad AG } \\
1-\mathrm{X} 8 \text { resin. Blanks were }<370 \mathrm{pg} \text { Pt. }\end{array}$ & $\begin{array}{l}\text { MC-ICP- } \\
\text { MS }\end{array}$ & See Hf ref. ${ }^{443}$ & 443 \\
\hline $\mathrm{S}$ & Gypsum & $\begin{array}{l}\text { Dissolution in water at } 40{ }^{\circ} \mathrm{C} \text { (maximum solubility at } \\
\text { this temperature) and dilution to } \mathrm{S} \text { concentration of } \\
0.30 \mathrm{mM} \text {. }\end{array}$ & $\begin{array}{l}\text { MC-ICP- } \\
\text { MS }\end{array}$ & $\begin{array}{l}\text { Evaluation of Ca matrix effects on S isotope ratio } \\
\text { measurements. Medium mass resolution mode } \\
\text { with SSB using Vienna Canon Diablo Troilite. Ca } \\
\text { matrix effects were found to depend on absolute } \\
\text { Ca concentration rather } \mathrm{Ca} \text { :S ratio and were more } \\
\text { significant under dry compared to wet plasma } \\
\text { conditions. }\end{array}$ & 399 \\
\hline $\mathrm{S}$ & $\begin{array}{l}\text { Sulfates and } \\
\text { sulfides }\end{array}$ & $\begin{array}{l}\text { Powdered samples either pressed into a powder } \\
\text { without binder or leached in } 2 \% \mathrm{HNO}_{3} \text { to give a final } \\
\text { sulphate concentration of } c a .3 \mathrm{mg} \mathrm{L}^{-1} \text {. }\end{array}$ & $\begin{array}{l}\text { MC-ICP- } \\
\text { MS and } \\
\text { LA-MC- } \\
\text { ICP-MS }\end{array}$ & $\begin{array}{l}\text { Because of large range of } \delta^{34} \mathrm{~S} \text { in nature, SSB } \\
\text { with a single isotope standard not able to provide } \\
\text { accurate corrections for mass bias. Likely cause } \\
\text { was thought to be fractionation in ICP associated }\end{array}$ & 398 \\
\hline
\end{tabular}




\begin{tabular}{|c|c|c|c|c|c|}
\hline & & & & $\begin{array}{l}\text { with valence state. Proposed procedure for mass } \\
\text { bias correction based on external calibration } \\
\text { provided accurate data for LA and solution } \\
\text { analysis. }\end{array}$ & \\
\hline $\mathrm{Sr}$ & Basalt and bone & See Ca, ref ${ }^{393}$ & $\begin{array}{l}\text { MC-ICP- } \\
\text { MS }\end{array}$ & $\begin{array}{l}\text { Radiogenic and stable } \mathrm{Sr} \text { isotopes measured in } \\
\text { low resolution mode, with SSB using NIST SRM } \\
987\left(\mathrm{SrCO}_{3}\right) \text { and } \mathrm{Zr} \text { doping. Typical precisions } \\
\left.{ }^{87} \mathrm{Sr} /{ }^{42} \mathrm{Sr} 0.00001(2 \sigma) \text { and } \delta^{88} \mathrm{Sr} /{ }^{86} \mathrm{Sr} 0.04 \% \text { ( } 2 \sigma\right)\end{array}$ & 393 \\
\hline Th & Silicate RMs & 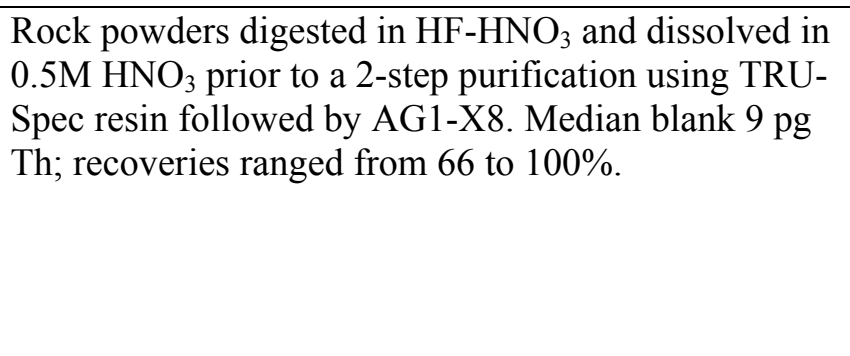 & $\begin{array}{l}\text { MC-ICP- } \\
\text { MS }\end{array}$ & $\begin{array}{l}\text { Two-step wash procedure after every sample to } \\
\text { reduce Th backgrounds to acceptable levels. } \\
\text { Measurement of }{ }^{232} \mathrm{Th} \text { tail and its contribution at } \\
\text { mass } 230 \text { subtracted. SSB procedure with in- } \\
\text { house Th standard solution to correct for mass } \\
\text { bias. Intermediate precisions for }{ }^{230} \mathrm{Th} /{ }^{232} \mathrm{Th} \text { in } \\
\text { rock samples }(0.24-0.49 \%, 2 \mathrm{RSD}) \text { were similar to } \\
\text { those achieved for synthetic solutions. }\end{array}$ & 453 \\
\hline$\overline{\mathrm{V}}$ & Terrestrial rocks & 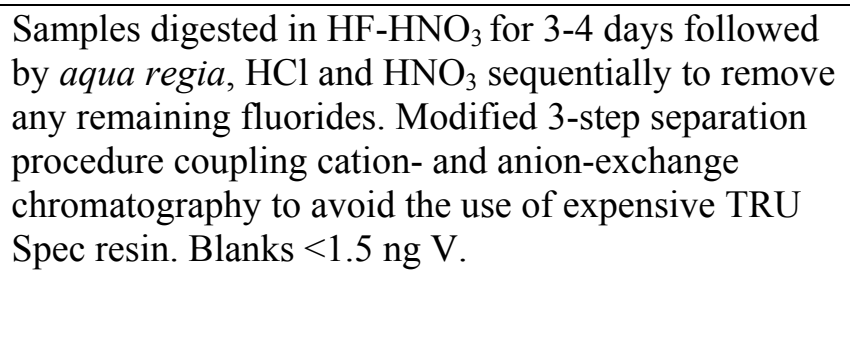 & $\begin{array}{l}\text { MC-ICP- } \\
\text { MS }\end{array}$ & $\begin{array}{l}\text { Instrument run in medium mass resolution mode } \\
\text { with SSB protocol using in-house V solution as } \\
\text { standard. Cup configuration and instrument set } \\
\text { up provided improved instrument sensitivity and } \\
\text { so reduced amount of V required for }{ }^{51} \mathrm{~V}^{50} \mathrm{~V} \\
\text { measurements. V isotope ratios of } 12 \mathrm{RMs} \\
\text { reported, with long term precision of } \pm 0.1 \% 0 \\
\text { (2SD). }\end{array}$ & 401 \\
\hline$\overline{\mathrm{W}}$ & $\begin{array}{l}\text { Terrestrial rocks } \\
\text { and meteorites }\end{array}$ & 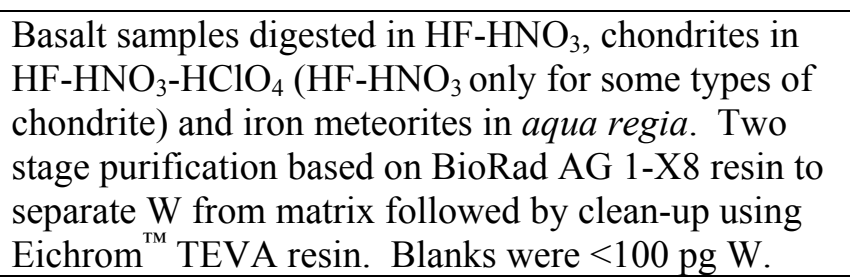 & $\begin{array}{l}\text { MC-ICP- } \\
\text { MS }\end{array}$ & See Hf ref. ${ }^{443}$ & 443 \\
\hline W & Geological RMs & $\begin{array}{l}\text { Tungsten double spike added prior to sample } \\
\text { dissolution in } \mathrm{HF}^{-} \mathrm{HNO}_{3}-\mathrm{H}_{2} \mathrm{O}_{2} \text {. Three-step anion- } \\
\text { exchange chromatography on AG10X8 resin to } \\
\text { purify samples. Yield typically } 50-80 \% \text {; blanks } 100- \\
500 \text { pg W. }\end{array}$ & $\begin{array}{l}\text { MC-ICP- } \\
\text { MS }\end{array}$ & $\begin{array}{l}\text { Double spike of }{ }^{180} \mathrm{~W}-{ }^{183} \mathrm{~W} \text { used to correct for } \\
\text { mass bias and fractionation effects. External } \\
\text { precision of } \pm 0.05 \% 0(2 \mathrm{SD}, \mathrm{N}=171) .{ }^{186} \mathrm{~W} /{ }^{184} \mathrm{~W} \\
\text { ratios for } 5 \text { USGS RMs reported. }\end{array}$ & 454 \\
\hline
\end{tabular}




\section{Glossary of terms}

2D

3D

AAS

AEC

AES

AFS

amu

AMS

APDC

APDG

ASU

ASV

BAM

BCR

$\mathrm{C}_{18}$

CARIBIC

$\mathrm{CDN}$

$\mathrm{CE}$

CI

CL

CPE

CRDS

CRM

CS

CV

CVG

DA

DBD two-dimensional

three-dimensional

atomic absorption spectrometry

anion exchange chromatography

atomic emission spectrometry

atomic fluorescence spectrometry

atomic mass unit

accelerator mass spectrometry

ammonium pyrrolidine dithiocarbamate

atmospheric pressure glow discharge

Atomic Spectrometry Update

anodic stripping voltammetry

Federal Institute for Materials Research and Testing (Germany)

Community Bureau of Reference (of the European Community) now IRMM

octadecyl bonded silica

Civil Aircraft for the Regular Investigation of the Atmosphere Based on an Instrumented Container

CDN Resources Laboratories Ltd (Canada)

capillary electrophoresis

confidence interval

cathode luminsecence

cloud point extraction

cavity ring-down spectroscopy

certified reference material

continuum source

cold vapour

chemical vapour generation

discriminant analysis

dielectric barrier discharge 
DBT

DCI

DDTC

DGT

DLLME

DMA

DMSO

DOC

DP

DPhT

DRS

EBS

EDTA

EDX

EDXRF

EDXRFS

EN

EPA

EPMA

ERM

ETAAS

EtHg

ETV

EU

FAAS

FC

FFF

FI

FP

fs

FT

FTIR

GBW dibutyl tin

direct concentric injector

diethyldithiocarbamate, sodium salt

diffusion gradient in thin films

dispersive liquid liquid microextraction

dimethylarsenic acid

dimethylsulfoxide

dissolved organic carbon

dual pulse

diphenyl tin

diffuse reflectance spectrometry

elastic back scattering

ethyldiaminetetraacetic acid

energy dispersive X-ray spectroscopy

energy dispersive X-ray fluorescence

energy dispersive X-ray fluorescence spectrometry

European Committee for Standardisation

Environmental Protection Agency (USA)

electron probe microanalysis

European Reference Material

electrothermal atomic absorption spectrometry

ethyl mercury

electrothermal vaporisation

European Union

flame atomic absorption spectrometry

faraday cup

field flow fractionation

flow injection

fundamental parameter

femtosecond

Fourier transform

Fourier transform infrared

CRMs of the National Research Centre for Certified Reference

Materials (China) 


\begin{tabular}{|c|c|}
\hline GC & gas chromatography \\
\hline GF & graphite furnace \\
\hline \multirow[t]{2}{*}{ GSB } & CRMs of the Institute for Environmental Reference Materials (of \\
\hline & Ministry of Environmental Protection, China) \\
\hline GSJ & Geological Survey of Japan \\
\hline HFSE & high field strength element \\
\hline HG & hydride generation \\
\hline HILIC & hydrophobic interaction liquid chromatography \\
\hline HPIC & high performance ion chromatography \\
\hline HPLC & high performance liquid chromatography \\
\hline HPS & High Purity Standards (USA) \\
\hline HR & high resolution \\
\hline HREE & heavy rare earth element \\
\hline IAEA & International Atomic Energy Agency \\
\hline $\mathrm{IC}$ & ion chromatography \\
\hline ICP & inductively coupled plasma \\
\hline ICP-AES & inductively coupled plasma atomic emission spectrometry \\
\hline ICP-MS & inductively coupled plasma mass spectrometry \\
\hline ICP-MS/MS & $\begin{array}{l}\text { inductively coupled plasma mass spectrometry with a quadrupole-cell- } \\
\text { quadrupole design }\end{array}$ \\
\hline id & internal diameter \\
\hline ID & isotope dilution \\
\hline IDA & isotope dilution analysis \\
\hline IERM & Institute for Environmental Reference Materials (of Ministry of \\
\hline & Environmental Protection, China) \\
\hline IL & ionic liquid \\
\hline INAA & instrumental neutron activation analysis \\
\hline INCT & Institute of Nuclear Chemistry and Technology (Poland) \\
\hline IOM & Institute of Occupational Medicine (Scotland) \\
\hline IR & infrared \\
\hline IRMM & Institute for Reference Materials and Measurements \\
\hline IRMS & isotope ratio mass spectrometry \\
\hline IS & internal standard \\
\hline LA & laser ablation \\
\hline
\end{tabular}


LAMIS

LASS

LC

LGC

LIBS

LLME

LOD

LOQ

LPME

LREE

MAE

MBT

$\mathrm{MC}$

MCE

$\mathrm{MeHg}$

MIC

$\mathrm{M}_{0}$

MMA

$\mathrm{MPhT}$

MS

MSIS

MWCNT

$\mathrm{m} / \mathrm{z}$

NASA

NBL

NCS

Nd:YAG

NIES

$\mathrm{NIOSH}$

NIR

NIST

NP

NRCC

NRCCRM laser ablation molecular isotopic spectrometry

laser ablation split stream

liquid chromatography

Laboratory of the Government Chemist (UK)

laser induced breakdown spectroscopy

liquid liquid microextraction

limit of detection

limit of quantification

liquid phase microextraction

light rare earth element

microwave assisted extraction

monobutyl tin

multicollector

mixed cellulose ester

methyl mercury

multiple ion counter

characteristic mass

monomethylarsenic acid

monophenyltin

mass spectrometry

multimode sample introduction system

multiwalled carbon nanotube

mass to charge ratio

National Aeronautics and Space Administration (USA)

New Brunswick Laboratories (USA)

National Analysis Centre for Iron and Steel (China)

neodymium doped:yttrium aluminum garnet

National Institute for Environmental Studies (Japan)

National Institute of Occupational Safety and Health

near infrared

National Institute of Standards and Technology (USA)

nanoparticle

National Research Council (of Canada)

National Research Centre for Certified Reference Materials (China) 
$n s$

NTIMS

NWRI

o.d.

PCA

PESA

PFA

PGE

PIXE

PLS

PLSR

$\mathrm{PM}_{1}$

$\mathrm{PM}_{2.5}$

$\mathrm{PM}_{10}$

ppb

ppm

PTE

PTFE

PVC

PVG

pXRF

pXRFS

QA

QC

REA

REE

RM

RMSEP

RSD

RSE

RSF

SARM

SD nanosecond

negative thermal ionisation mass spectrometry

National Water Research Institute (Canada)

outer diameter

principal component analysis

proton electric scattering

perfluoroalkyl

platinum group element

particle induced X-ray emission

partial least squares

partial least squares regression

particulate matter (with an aerodynamic diameter of up to $1 \mu \mathrm{m}$ )

particulate matter (with an aerodynamic diameter of up to $2.5 \mu \mathrm{m}$ )

particulate matter (with an aerodynamic diameter of up to $10 \mu \mathrm{m}$ )

parts per billion

parts per million

potentially toxic element

poly(tetrafluoroethylene)

polyvinylchloride

photochemical vapour generation

portable x-ray fluorescence

portable x-ray fluorescence spectrometry

quality assurance

quality control

relaxed eddy accumulation

rare earth element

reference material

root mean square eror of prediction

relative standard deviation

relative standard error

relative sensitivity factor

South African producers of Metallurgical and Geological Certified

Reference Materials

standard deviation 
SDS

SE

SEC

SEM

SF

SIMS

SMPS

$\mathrm{S} / \mathrm{N}$

$\mathrm{Sp}$

SPE

SPME

SPR

SPS

SR

SRM

SS

SSB

SVM

SXRFS

TBT

TD

TEM

THF

TIMS

TMAO

TOF

TPhT

TXRF

TXRFS

UAE

USGS

USA

USN

UV sodium dodecyl sulfate

standard error

size exclusion chromatography

scanning electron microscopy

sector field

secondary ion mass spectrometry

scanning mobility particle sizer

signal-to-noise ratio

single particle

solid phase extraction

solid phase microextraction

surface plasma resonance

Spectrapure Standards (Norway)

synchrotron radiation

standard reference material (of NIST)

solid sampling

sample-standard bracketing

support vector machine

synchrotron X-ray fluorescence spectrometry

tributyl tin

thermal desorption

transmission electron microscopy

tetrahydrofuran

thermal ionisation mass spectrometry

trimethylarsenic oxide

time of flight

Triphenyltin

total reflection X-ray fluorescence

total reflection X-ray fluorescence spectrometry

ultrasonic extraction

United States Geological Survey

United States of America

ultrasonic nebulisation

ultra violet 
VALLME

VG

VIS

VOC

WDXRF

WDXRFS

WMO

XANES

XAS

XRD

$\mathrm{XRF}$

XRFS vortex assisted liquid liquid microextraction

vapour generation

visible

volatile organic carbon

wavelength dispersive X-ray fluorescence

wavelength dispersive X-ray fluorescence spectrometry

World Meteorological Organisation

$\mathrm{X}$-ray absorption near edge structure

X-ray absorption spectrometry

X-ray diffraction

$\mathrm{X}$-ray fluorescence

$\mathrm{X}$-ray fluorescence spectrometry 
1 O. T. Butler, W. R. L. Cairns, J. M. Cook and C. M. Davidson, J. Anal. At. Spectrom., 2016, 31(1), 35-89.

2 A. Taylor, N. Barlow, M. P. Day, S. Hill, M. Patriarca and M. White, J. Anal. At. Spectrom., 2016, 31(3), 554-596.

3 E. H. Evans, J. Pisonero, C. M. M. Smith and R. N. Taylor, J. Anal. At. Spectrom., 2016, 31(5), 1057-1077.

4 R. Clough, C. F. Harrington, S. J. Hill, Y. Madrid and J. F. Tyson, J. Anal. At. Spectrom., 2016, 31(7), 1330-1373.

5 M. West, A. T. Ellis, P. J. Potts, C. Streli, C. Vanhoof and P. Wobrauschek, J. Anal. At. Spectrom., 2016, 31(9), 1706-1755.

6 S. Carter, A. Fisher, R. Garcia, B. Gibson, J. Marshall and I. Whiteside, J. Anal. At. Spectrom., 2016, 31(11), 2114-2164.

7 F. Laborda, E. Bolea, G. Cepria, M. T. Gomez, M. S. Jimenez, J. Perez-Arantegui and J. R. Castillo, Anal. Chim. Acta, 2016, 904, 10-32.

$8 \quad$ S. M. Majedi and H. K. Lee, Trac-Trends Anal. Chem., 2016, 75, 183-196.

9 T. Dreier and C. Schulz, Powder Technol., 2016, 287, 226-238.

10 A. Malysheva, E. Lombi and N. H. Voelcker, Nat. Nanotechnol., 2015, 10(10), 835844.

11 R. Tantra, H. Bouwmeester, E. Bolea, C. Rey-Castro, C. A. David, J. M. Dogne, J. Jarman, F. Laborda, J. Laloy, K. N. Robinson, A. K. Undas and M. van der Zande, Nanotoxicology, 2016, 10(2), 173-184.

12 K. Tirez, C. Vanhoof, J. Bronders, P. Seuntjens, N. Bleux, P. Berghmans, N. De Brucker and F. Vanhaecke, Env. Sci. Processes Impact., 2015, 17(12), 2034-2050.

13 L. Balcaen, E. Bolea-Fernandez, M. Resano and F. Vanhaecke, Anal. Chim. Acta, 2015, 894, 7-19.

14 W. Maenhaut, Nucl. Instr. Meth. Phys. Res. B., 2015, 363, 86-91.

15 D. Sanchez-Rodas, A. M. S. de la Campa and L. Alsioufi, Anal. Chim. Acta, 2015, 898, 1-18.

16 C. Cardell and I. Guerra, Trac-Trends Anal. Chem., 2016, 77, 156-166.

17 A. Galuszka, Z. M. Migaszewski and J. Namiesnik, Environ. Res., 2015, 140, 593603.

18 J. C. Soo, K. Monaghan, T. Lee, M. Kashon and M. Harper, Aerosol Sci. Technol., 2016, 50(1), 76-87.

19 L. W. D. Mines, J. H. Park, I. A. Mudunkotuwa, T. R. Anthony, V. H. Grassian and T. M. Peters, Aerosol Sci. Technol., 2016, 50(5), 497-506.

20 K. R. Anderson, D. Leith, M. Ndonga and J. Volckens, Aerosol Sci. Technol., 2015, 49(12), 1195-1209.

21 M. Wada, M. Tsukada, N. Namiki, W. W. Szymanski, N. Noda, H. Makino, C. Kanaoka and H. Kamiya, Aerosol Air Qual. Res., 2016, 16(1), 36-45.

22 A. Kumar and T. Gupta, Aerosol Air Qual. Res., 2015, 15(4), 1188-1200.

23 T. Okuda, R. Isobe, Y. Nagai, S. Okahisa, K. Funato and K. Inoue, Aerosol Air Qual. Res., 2015, 15(3), 759-767.

24 A. Kumar and T. Gupta, Aerosol Air Qual. Res., 2015, 15(3), 768-775.

25 F. X. Li, J. Schnelle-Kreis, E. Karg, J. Cyrys, J. W. Gu, J. Orasche, G. Abbaszade, A. Peters and R. Zimmermann, Environ. Sci. Pollut. Res., 2016, 23(8), 7278-7287.

26 A. Hecobian, A. Evanoski-Cole, A. Eiguren-Fernandez, A. P. Sullivan, G. S. Lewis, S. V. Hering and J. L. Collett, Atmos. Meas. Tech., 2016, 9(2), 525-533. 
27 F. Rueda-Holgado, L. Calvo-Blazquez, F. Cereceda-Balic and E. Pinilla-Gil, Microchem. J., 2016, 124, 20-25.

28 S. Osterwalder, J. Fritsche, C. Alewell, M. Schmutz, M. B. Nilsson, G. Jocher, J. Sommar, J. Rinne and K. Bishop, Atmos. Meas. Tech., 2016, 9(2), 509-524.

29 M. Aliste and L. G. Chavez, Forensic Sci. Int., 2016, 261, 14-18.

30 T. J. Shepherd, W. Dirks, N. M. W. Roberts, J. G. Patel, S. Hodgson, T. PlessMulloli, P. Walton and R. R. Parrish, Environ. Res., 2016, 146, 145-153.

31 E. Leese, J. Morton, P. H. E. Gardiner and V. A. Carolan, J. Anal. At. Spectrom., 2016, 31(4), 924-933.

32 S. Yatkin, H. S. Amin, K. Trzepla and A. M. Dillner, Aerosol Sci. Technol., 2016, 50(4), 309-320.

33 P. Moravec, J. Smolik, J. Ondracek, P. Vodicka and R. Fajgar, Aerosol Sci. Technol., 2015, 49(8), 655-665.

34 M. D. Minarro, P. J. Brewer, R. J. C. Brown, S. Persijn, J. van Wijk, G. Nieuwenkamp, A. Baldan, C. Kaiser, C. Sutour, T. Mace, N. Skundric and T. Tarhan, Anal. Methods, 2016, 8(15), 3014-3022.

35 M. C. Leuenberger, M. F. Schibig and P. Nyfeler, Atmos. Meas. Tech., 2015, 8(12), 5289-5299.

36 L. AlSioufi, A. M. S. de la Campa and D. Sanchez-Rodas, Microchem. J., 2016, 124, 256-260.

37 I. A. Mudunkotuwa, T. R. Anthony, V. H. Grassian and T. M. Peters, J. Occup. Env. Hyg., 2016, 13(1), 30-39.

38 R. N. Andrews, M. Keane, K. W. Hanley, H. A. Feng and K. Ashley, Anal. Methods, 2015, 7(15), 6403-6410.

39 E. Grygo-Szymanko, A. Tobiasz and S. Walas, Trac-Trends Anal. Chem., 2016, 80, 112-124.

40 A. Ellis, R. Edwards, M. Saunders, R. K. Chakrabarty, R. Subramanian, A. van Riessen, A. M. Smith, D. Lambrinidis, L. J. Nunes, P. Vallelonga, I. D. Goodwin, A. D. Moy, M. A. J. Curran and T. D. van Ommen, Atmos. Meas. Tech., 2015, 8(9), 3959-3969.

41 C. Solis, E. Chavez, M. E. Ortiz, E. Andrade, E. Ortiz, S. Szidat and L.Wacker, Nucl. Instr. Meth. Phys. Res. B., 2015, 361, 419-422.

42 S. C. Jantzi, V. Motto-Ros, F. Trichard, Y. Markushin, N. Melikechi and A. De Giacomo, Spectrochim. Acta Pt. B-Atom. Spectrosc., 2016, 115, 52-63.

43 P. G. Martin, I. Griffiths, C. P. Jones, C. A. Stitt, M. Davies-Milner, J. F. W. Mosselmans, Y. Yamashiki, D. A. Richards and T. B. Scott, Spectrochim. Acta Pt. BAtom. Spectrosc., 2016, 117, 1-7.

44 E. R. Pereira, L. M. Rocha, H. R. Cadorim, V. D. Silva, B. Welz, E. Carasek and J. B. de Andrade, Spectrochim. Acta Pt. B-Atom. Spectrosc., 2015, 114, 46-50.

45 K. Nakata, Y. Okamoto, S. Ishizaka and T. Fujiwara, Talanta, 2016, 150, 434-439.

46 F. Slemr, A. Weigelt, R. Ebinghaus, H. H. Kock, J. Bodewadt, C. A. M. Brenninkmeijer, A. Rauthe-Schoch, S. Weber, M. Hermann, J. Becker, A. Zahn and B. Martinsson, Atmos. Meas. Tech., 2016, 9(5), 2291-2302.

47 M. E. Asgill, S. Groh, K. Niemax and D. W. Hahn, Spectrochim. Acta Pt. B-Atom. Spectrosc., 2015, 109, 1-7.

48 M. Boudhib, J. Hermann and C. Dutouquet, Anal. Chem., 2016, 88(7), 4029-4035.

49 S. C. Yao, J. L. Xu, X. Dong, B. Zhang, J. P. Zheng and J. D. Lu, Spectrochim. Acta Pt. B-Atom. Spectrosc., 2015, 110, 146-150.

50 M. Y. Chen, T. B. Yuan, Z. Y. Hou, Z. Wang and Y. Wang, Spectrochim. Acta Pt. BAtom. Spectrosc., 2015, 112, 23-33. 
51 R. S. Pappas, N. Martone, N. Gonzalez-Jimenez, M. R. Fresquez and C. H. Watson, J. Anal. Toxicol., 2015, 39(5), 347-352.

52 Q. He, Z. Xing, S. C. Zhang and X. R. Zhang, J. Anal. At. Spectrom., 2015, 30(9), 1997-2002.

53 J. Scancar, B. Berlinger, Y. Thomassen and R. Milacic, Talanta, 2015, 142, 164-169.

54 T. Tziaras, S. A. Pergantis and E. G. Stephanou, Environ. Sci. Technol., 2015, 49(19), 11640-11648.

55 K. Tirez, C. Vanhoof, J. Peters, L. Geerts, N. Bleux, E. Adriaenssens, E. Roekens, S. Smolek, A. Maderitsch, R. Steininger, J. Gottlicher, F. Meirer, C. Streli and P. Berghmans, J. Anal. At. Spectrom., 2015, 30(10), 2074-2088.

56 W. Wang, Z. M. Li, J. Xu, G. Q. Zhou, X. P. Shen and L. H. Zhai, Chin. J. Anal. Chem., 2015, 43(5), 703-708.

57 G. Bauer and A. Limbeck, Spectrochim. Acta Pt. B-Atom. Spectrosc., 2015, 113, 6369.

58 P. Sommersacher, N. Kienzl, T. Brunner and I. Obernberger, Energy \& Fuels, 2015, 29(10), 6734-6746.

59 P. Sommersacher, N. Kienzl, T. Brunner and I. Obernberger, Energy \& Fuels, 2016, 30(4), 3428-3440.

60 F. P. Zhao, E. Repo, Y. Meng, X. T. Wang, D. L. Yin and M. Sillanpaa, J. Colloid Interface Sci., 2016, 465, 215-224.

61 I. Benesova, K. Dlabkova, F. Zelenak, T. Vaculovic, V. Kanicky and J. Preisler, Anal. Chem., 2016, 88(5), 2576-2582.

62 J. A. Hubbard and J. A. Zigmond, Spectrochim. Acta Pt. B-Atom. Spectrosc., 2016, 119, 50-64.

63 C. P. Jones, S. N. Lyman, D. A. Jaffe, T. Allen and T. L. O'Neil, Atmos. Meas. Tech., 2016, 9(5), 2195-2205.

64 Z. Y. Chen, S. J. Liu, J. L. Wang and Y. Z. Chang, Chin. J. Anal. Chem., 2016, 44(3), 468-473.

65 S. L. Pathirana, C. van der Veen, M. E. Popa and T. Rockmann, Atmos. Meas. Tech., 2015, 8(12), 5315-5324.

66 L. A. Sobrado, M. R. Fernandez, S. C. Diaz, J. R. Encinar and J. I. G. Alonso, J. Chromatogr., 2015, 1419, 99-108.

67 S. Toyoda and N. Yoshida, Atmos. Meas. Tech., 2016, 9(5), 2093-2101.

68 R. Gemayel, S. Hellebust, B. Temime-Roussel, N. Hayeck, J. T. Van Elteren, H. Wortham and S. Gligorovski, Atmos. Meas. Tech., 2016, 9(4), 1947-1959.

69 Y. Ozawa, N. Takeda, T. Miyakawa, M. Takei, N. Hirayama and N. Takegawa, Aerosol Sci. Technol., 2016, 50(2), 173-186.

70 F. Drewnick, J. M. Diesch, P. Faber and S. Borrmann, Atmos. Meas. Tech., 2015, 8(9), 3811-3830.

71 J. C. Corbin, A. Othman, J. D. Allan, D. R. Worsnop, J. D. Haskins, B. Sierau, U. Lohmann and A. A. Mensah, Atmos. Meas. Tech., 2015, 8(11), 4615-4636.

72 S. Carbone, T. Onasch, S. Saarikoski, H. Timonen, K. Saarnio, D. Sueper, T. Ronkko, L. Pirjola, A. Hayrinen, D. Worsnop and R. Hillamo, Atmos. Meas. Tech., 2015, 8(11), 4803-4815.

73 M. Giannoni, G. Calzolai, M. Chiari, F. Lucarelli, A. Mazzinghi, S. Nava and C. Ruberto, X-Ray Spectrom., 2015, 44(4), 282-288.

74 J. P. Gorce and M. Roff, J. Occup. Env. Hyg., 2016, 13(2), 102-111.

75 K. G. McIntosh, N. L. Cordes, B. M. Patterson and G. J. Havrilla, J. Anal. At. Spectrom., 2015, 30(7), 1511-1517. 
76 K. Shiota, M. Takaoka, T. Fujimori, K. Oshita and Y. Terada, Anal. Chem., 2015, 87(22), 11249-11254.

77 A. D. Jew, E. C. Rupp, D. L. Geatches, J. E. Jung, G. Farfan, L. Bahet, J. C. Hower, G. E. Brown and J. Wilcox, Energy \& Fuels, 2015, 29(9), 6025-6038.

78 J. D. Ward, M. Bowden, C. T. Resch, S. Smith, B. K. McNamara, E. C. Buck, G. C. Eiden and A. M. Duffin, Geostand. Geoanal. Res., 2016, 40(1), 135-148.

79 S. Beccaceci, E. A. McGhee, R. J. C. Brown and D. C. Green, Aerosol Sci. Technol., 2015, 49(9), 793-801.

80 A. Malaguti, M. Mircea, T. M. G. La Torretta, C. Telloli, E. Petralia, M. Stracquadanio and M. Berico, Aerosol Air Qual. Res., 2015, 15(7), 2641-2653.

81 C. Perrino, M. Catrambone, C. Farao, R. Salzano, G. Esposito, M. Giusto, M. Montagnoli, A. Marini, M. Brinoni, G. Simonetti and S. Canepari, Aerosol Sci. Technol., 2015, 49(7), 521-530.

82 D. S. Kaul, Z. Ning, D. Westerdahl, X. J. Yin and R. A. Cary, Aerosol Air Qual. Res., 2016, 16(6), 1345-1355.

83 B. Galfond, D. Riemer and P. Swart, Int. J. Greenh. Gas Control, 2015, 42, 307-318.

84 K. Malowany, J. Stix, A. Van Pelt and G. Lucic, Atmos. Meas. Tech., 2015, 8(10), 4075-4082.

85 L. C. Brent, W. J. Thorn, M. Gupta, B. Leen, J. W. Stehr, H. He, H. L. Arkinson, A. Weinheimer, C. Garland, S. E. Pusede, P. J. Wooldridge, R. C. Cohen and R. R. Dickerson, J. Atmos. Chem., 2015, 72(3-4), 503-521.

86 S. Eyer, B. Tuzson, M. E. Popa, C. van der Veen, T. Rockmann, M. Rothe, W. A. Brand, R. Fisher, D. Lowry, E. G. Nisbet, M. S. Brennwald, E. Harris, C. Zellweger, L. Emmenegger, H. Fischer and J. Mohn, Atmos. Meas. Tech., 2016, 9(1), 263-280.

87 J. R. Pitt, M. Le Breton, G. Allen, C. J. Percival, M. W. Gallagher, S. J. B. Bauguitte, S. J. O'Shea, J. B. A. Muller, M. S. Zahniser, J. Pyle and P. I. Palmer, Atmos. Meas. Tech., 2016, 9(1), 63-77.

88 J. C. Chow, X. L. Wang, B. J. Sumlin, S. B. Gronstal, L. W. A. Chen, D. L. Trimble, S. D. Kohl, S. R. Mayorga, G. Riggio, P. R. Hurbain, M. Johnson, R. Zimmermann and J. G. Watson, Aerosol Air Qual. Res., 2015, 15(4), 1145-1159.

89 N. Zikova, P. Vodicka, W. Ludwig, R. Hitzenberger and J. Schwarz, Aerosol Sci. Technol., 2016, 50(3), 284-296.

90 J. S. Ma, X. Li, P. S. Gu, T. R. Dallmann, A. A. Presto and N. M. Donahue, Aerosol Sci. Technol., 2016, 50(6), 638-651.

91 G. Baccolo, M. Clemenza, B. Delmonte, N. Maffezzoli, M. Nastasi, E. Previtali, M. Prata, A. Salvini and V. Maggi, Anal. Chim. Acta, 2016, 922, 11-18.

92 M. Grafen, K. Nalpantidis, F. Platte, C. Monz and A. Ostendorf, Aerosol Sci. Technol., 2015, 49(10), 997-1008.

93 M. Chiari, G. Calzolai, M. Giannoni, F. Lucarelli, S. Nava and S. Becagli, J. Aerosol Sci, 2015, 89, 85-95.

94 A. M. Dillner and S. Takahama, Atmos. Meas. Tech., 2015, 8(10), 4013-4023.

95 M. Reggente, A. M. Dillner and S. Takahama, Atmos. Meas. Tech., 2016, 9(2), 441454.

96 F. Esaka, D. Suzuki, T. Yomogida and M. Magara, Anal. Methods, 2016, 8(7), 15431548.

97 R. N. Andrews, H. A. Feng and K. Ashley, J. Occup. Env. Hyg., 2016, 13(1), 40-47.

98 S. Yatkin, C. A. Belis, M. Gerboles, G. Calzolai, F. Lucarelli, F. Cavalli and K. Trzepla, Atmos. Environ., 2016, 125, 61-68. 
99 C. Y. Kwok, O. Laurent, A. Guemri, C. Philippon, B. Wastine, C. W. Rella, C. Vuillemin, F. Truong, M. Delmotte, V. Kazan, M. Darding, B. Lebegue, C. Kaiser, I. Xueref-Remy and M. Ramonet, Atmos. Meas. Tech., 2015, 8(9), 3867-3892.

100 V. Crenn, J. Sciare, P. L. Croteau, S. Verlhac, R. Frohlich, C. A. Belis, W. Aas, M. Auml;ijala, A. Alastuey, B. Artinano, D. Baisnee, N. Bonnaire, M. Bressi, M. Canagaratna, F. Canonaco, C. Carbone, F. Cavalli, E. Coz, M. J. Cubison, J. K. EsserGietl, D. C. Green, V. Gros, L. Heikkinen, H. Herrmann, C. Lunder, M. C. Minguillon, G. Mocnik, C. D. O'Dowd, J. Ovadnevaite, J. E. Petit, E. Petralia, L. Poulain, M. Priestman, V. Riffault, A. Ripoll, R. Sarda-Esteve, J. G. Slowik, A. Setyan, A. Wiedensohler, U. Baltensperger, A. S. H. Prevot, J. T. Jayne and O. Favez, Atmos. Meas. Tech., 2015, 8(12), 5063-5087.

101 L. Du and J. Turner, Sci. Total Environ., 2015, 529, 65-71.

102 A. Font, K. de Hoogh, M. Leal-Sanchez, D. C. Ashworth, R. J. C. Brown, A. L. Hansell and G. W. Fuller, Atmos. Environ., 2015, 113, 177-186.

103 L. Cotte, M. Waeles, B. Pernet-Coudrier, P. M. Sarradin, C. Cathalot and R. D. Riso, Deep-Sea Res. Pt. I, , 2015, 105, 186-194.

104 M. Strok, P. A. Baya and H. Hintelmann, CR. Geosci., 2015, 347(7-8), 368-376.

105 A. Rodriguez-Cea, P. Rodriguez-Gonzalez and J. I. G. Alonso, Environ. Sci. Pollut. Res., 2016, 23(5), 4876-4885.

106 L. Pillay and A. Kindness, South Afr. J. Chem.-Suid-Afr. Tydskr. Chem., 2016, 69, 914.

107 D. Y. Deng, C. B. Zheng, X. D. Hou and L. Wu, Appl. Spectrosc., Rev., 2016, 50(8), 678-705.

108 L. Okenicova, M. Zemberyova and S. Prochazkova, Environ. Chem. Lett., 2016, 14(1), 67-77.

109 I. Hagarova and M. Urik, Curr. Anal. Chem., 2016, 12(2), 87-93.

110 S. Sindern, J. Schwarzbauer, L. Gronen, A. Gortz, S. Heister and M. Bruchmann, Int. J. Environ. Anal. Chem., 2015, 95(9), 790-807.

111 C. Bendicho, C. Bendicho-Lavilla and I. Lavilla, Trac-Trends Anal. Chem., 2016, 77, 109-121.

112 M. Amde, Y. G. Yin, D. Zhang and J. F. Liu, Chem. Spec. Bioavail., 2016, 28(1-4), 51-65.

113 L. N. Suvarapu and S. O. Baek, J. Anal. Chem. Methods, 2015, Article ID 372459.

114 C. F. Harrington, R. Clough, S. J. Hill, Y. Madrid and J. F. Tyson, J. Anal. At. Spectrom., 2015, 30(7), 1427-1468.

115 J. Gorny, D. Dumoulin, L. Lesven, C. Noiriel, B. Made and G. Billon, J. Anal. At. Spectrom., 2015, 30(7), 1562-1570.

116 M. Marcinkowska, I. Komorowicz and D. Baralkiewicz, Talanta, 2015, 144, 233-240.

117 M. Marcinkowska, I. Komorowicz and D. Baralkiewicz, Anal. Chim. Acta, 2016, 920, 102-111.

118 K. M. Diniz and C. R. T. Tarley, Microchem. J., 2015, 123, 185-195.

119 M. Birka, C. A. Wehe, O. Hachmoller, M. Sperling and U. Karst, J. Chromatogr., 2016, 1440, 105-111.

120 I. Lopez-Garcia, Y. Vicente-Martinez and M. Hernandez-Cordoba, J. Anal. At. Spectrom., 2015, 30(9), 1980-1987.

121 Y. Q. Chen, X. Cheng, F. Mo, L. M. Huang, Z. J. Wu, Y. N. Wu, L. J. Xu and F. F. $\mathrm{Fu}$, Electrophoresis, 2016, 37(7-8), 1055-1062.

122 G. J. Peng, X. Y. Zhu, J. G. Chen, X. Z. Jin, S. H. Chen and D. Y. Wei, Anal. Lett., 2015, 48(16), 2639-2649. 
123 D. P. Bishop, D. J. Hare, A. de Grazia, F. Fryer and P. A. Doble, Anal. Methods, 2015, 7(12), 5012-5018.

124 P. Paydary and P. Larese-Casanova, Int. J. Environ. Anal. Chem., 2015, 95(15), 14501470.

125 C. K. Su, M. H. Hsieh and Y. C. Sun, Anal. Chim. Acta, 2016, 914, 110-116.

126 T. K. Mudalige, H. O. Qu and S. W. Linder, Anal. Chem., 2015, 87(14), 7395-7401.

127 Z. Q. Tan, J. F. Liu, X. R. Guo, Y. G. Yin, S. K. Byeon, M. H. Moon and G. B. Jiang, Anal. Chem., 2015, 87(16), 8441-8447.

128 F. V. Nakadi, M. da Veiga, M. Aramendia, E. Garcia-Ruiz and M. Resano, J. Anal. At. Spectrom., 2015, 30(7), 1531-1540.

129 E. Pena-Vazquez, M. C. Barciela-Alonso, C. Pita-Calvo, R. Dominguez-Gonzalez and P. Bermejo-Barrera, J. Appl. Spectrosc., 2015, 82(4), 681-686.

130 C. A. Martins, G. L. Scheffler and D. Pozebon, Anal. Methods, 2016, 8(3), 504-509.

131 G. G. Vasile, N. M. Marin, J. Petre and L. V. Cruceru, J. Environ. Prot. Ecol., 2016, 17(1), 31-41.

132 L. G. Cao, W. T. Bu, J. Zheng, S. M. Pan, Z. T. Wang and S. G. Uchida, Talanta, 2016, 151, 30-41.

133 T. Yang, X. P. Bian, B. Zhu, S. Y. Jiang, X. Yan and H. Z. Wei, Anal. Methods, 2016, 8(7), 1721-1727.

134 J. S. de Gois, P. Vallelonga, A. Spolaor, V. Devulder, D. L. G. Borges and F. Vanhaecke, Anal. Bioanal. Chem., 2016, 408(2), 409-416.

135 J. S. de Gois, M. Costas-Rodriguez, P. Vallelonga, D. L. G. Borges and F. Vanhaecke, J. Anal. At. Spectrom., 2016, 31(2), 537-542.

136 O. Hanousek, T. W. Berger and T. Prohaska, Anal. Bioanal. Chem., 2016, 408(2), 399-407.

137 Y. T. Li, W. Guo, Z. W. Wu, L. L. Jin, Y. Q. Ke, Q. H. Guo and S. H. Hu, Microchem. J., 2016, 126, 194-199.

138 S. L. Zhong, R. E. Zheng, Y. Lu, K. Cheng and J. S. Xiu, Plasma Sci. Technol., 2015, 17(11), 979-984.

139 N. Aras and S. Yalcin, Talanta, 2016, 149, 53-61.

140 Y. Gao, R. E. Sturgeon, Z. Mester, X. D. Hou and L. Yang, Anal. Chim. Acta, 2015, 901, 34-40.

141 Y. Gao, R. E. Sturgeon, Z. Mester, X. D. Hon, C. B. Zheng and L. Yang, Anal. Chem., 2015, 87(15), 7996-8004.

142 B. B. A. Francisco, A. A. Rocha, P. Grinberg, R. E. Sturgeon and R. J. Cassella, J. Anal. At. Spectrom., 2016, 31(3), 751-758.

143 M. M. L. Guerrero, E. V. Alonso, J. M. C. Pavon, M. T. S. Cordero and A. G. de Torres, J. Anal. At. Spectrom., 2016, 31(4), 975-984.

144 M. L. Lopez, S. A. Ceppi, M. L. Asar, R. E. Burgesser and E. E. Avila, Spectrochim. Acta Pt. B-Atom. Spectrosc., 2015, 113, 100-105.

145 X. F. Lin, S. X. Li and F. Y. Zheng, RSC Adv., 2016, 6(11), 9002-9006.

146 J. Gorny, L. Lesven, G. Billon, D. Dumoulin, C. Noiriel, C. Pirovano and B. Made, Talanta, 2015, 144, 890-898.

147 H. Y. Peng, N. Zhang, M. He, B. B. Chen and B. Hu, Int. J. Environ. Anal. Chem., 2016, 96(3), 212-224.

148 E. Kazemi, S. Dadfarnia and A. M. H. Shabani, Talanta, 2015, 141, 273-278.

149 B. Parodi, A. Londonio, G. Polla and P. Smichowski, Microchem. J., 2015, 122, 70 75.

150 Z. A. Alothman, E. Yilmaz, M. A. Habila, I. H. Alsohaimi, A. M. Aldawsari, N. M. Al-Harbi and M. Soylak, RSC Adv., 2015, 5(129), 106905-106911. 
151 M. Krawczyk and M. Jeszka-Skowron, Microchem. J., 2016, 126, 296-301.

152 M. Soylak, A. Aydin and N. Kizil, J. AOAC Int., 2016, 99(1), 273-278.

153 S. Taguchi, M. Asaoka, E. Hirokami, N. Hata, H. Kuramitz, T. Kawakami and R. Miyatake, Anal. Methods, 2015, 7(16), 6545-6551.

154 K. Pytlakowska, Microchim. Acta, 2016, 183(1), 91-99.

155 V. Romero, I. Costas-Mora, I. Lavilla and C. Bendicho, RSC Adv., 2016, 6(1), 669676.

156 J. Huber, L. E. Heimburger, J. E. Sonke, S. Ziller, M. Linden and K. Leopold, Anal. Chem., 2015, 87(21), 11122-11129.

157 M. Krawczyk and E. Stanisz, J. Anal. At. Spectrom., 2015, 30(11), 2353-2358.

158 J. Lee, J. An, J. A. Kim and H. O. Yoon, Chemosphere, 2016, 142, 72-76.

159 L. Nyaba, J. M. Matong and P. N. Nomngongo, Microchim. Acta, 2016, 183(4), 12891297.

160 S. Chen, Y. J. Sun, J. B. Chao, L. P. Cheng, Y. Chen and J. F. Liu, J. Environ. Sci., 2016, 41, 211-217.

161 G. L. Peng, Q. He, G. M. Zhou, Y. Li, X. X. Su, M. Z. Liu and L. L. Fan, Anal. Methods, 2015, 7(16), 6732-6739.

162 Naeemullah, T. G. Kazi, H. I. Afridi, F. Shah, S. S. Arain, K. D. Brahman, J. Ali and M. S. Arain, Arabian J. Chem., 2016, 9(1), 105-113.

163 Y. Liu, M. He, B. B. Chen and B. Hu, Talanta, 2015, 142, 213-220.

164 S. M. Sorouraddin and S. Nouri, Anal. Methods, 2016, 8(6), 1396-1404.

165 I. Gaubeur, M. A. Aguirre, N. Kovachev, M. Hidalgo and A. Canals, J. Anal. At. Spectrom., 2015, 30(12), 2541-2547.

166 M. I. Leybourne, K. H. Johannesson and A. Asfaw, Arsenic: Environmental Geochemistry, Mineralogy, and Microbiology, 2014, 79, 371-390.

167 W. A. Maher, M. J. Ellwood, F. Krikowa, G. Raber and S. Foster, J. Anal. At. Spectrom., 2015, 30(10), 2129-2183.

168 B. C. Russell, I. W. Croudace and P. E. Warwick, Anal. Chim. Acta, 2016, 890, 7-20.

169 M. Jablonska-Czapla, J. Elem., 2015, 20(4), 1061-1075.

170 N. Belzile and Y. W. Chen, Appl. Geochem., 2015, 63, 83-92.

171 B. E. S. Costa, L. M. Coelho, C. S. T. Araujo, H. C. Rezende and N. M. M. Coelho, J. Chem., 2016, 11, Article No. 1427154.

172 M. Bodnar, M. Szczyglowska, P. Konieczka and J. Namiesnik, Crit. Rev. Food Sci. Nutr., 2016, 56(1), 36-55.

173 E. M. Kroukamp, T. Wondimu and P. B. C. Forbes, Trac-Trends Anal. Chem., 2016, 77, 87-99.

174 N. Serrano, J. M. Diaz-Cruz, C. Arino and M. Esteban, Trac-Trends Anal. Chem., 2015, 73, 129-145.

175 A. Gredilla, S. F. O. de Vallejuelo, N. Elejoste, A. de Diego and J. M. Madariaga, Trac-Trends Anal. Chem., 2016, 76, 30-39.

176 A. Rabajczyk, Desalin. Water Treat., 2016, 57(3), 1598-1610.

177 J. Cmelik, Z. Nainarova and P. Rysanek, Int. J. Environ. Anal. Chem., 2015, 95(12), 1090-1098.

178 Z. T. Wang, G. S. Yang, J. Zheng, L. G. Cao, H. J. Yu, Y. Zhu, K. Tagami and S. Uchida, Anal. Chem., 2015, 87(11), 5511-5515.

179 S. Yamasaki, A. Takeda, K. Kimura and N. Tsuchiya, Soil Sci. Plant Nutr., 2016, 62(2), 121-126.

180 R. Tisarum, J. H. Ren, X. L. Dong, H. Chen, J. T. Lessl and L. N. Q. Ma, Talanta, 2015, 144, 1171-1175. 
181 P. Roux, D. Lemarchand, H. J. Hughes and M. P. Turpault, Geostand. Geoanal. Res., 2015, 39(4), 453-466.

182 I. Rodushkin, N. Pallavicini, E. Engstrom, D. Sorlin, B. Ohlander, J. Ingri and D. C. Baxter, J. Anal. At. Spectrom., 2016, 31(1), 220-233.

183 L. Husakova, I. Urbanova, T. Sidova, T. Cahova, T. Faltys and J. Sramkova, Int. J. Environ. Anal. Chem., 2015, 95(10), 922-935.

184 J. H. Zhao, X. Yan, T. Y. Zhou, J. Wang, H. Y. Li, P. Zhang, H. Ding and L. Ding, J. Anal. At. Spectrom., 2015, 30(9), 1920-1926.

185 T. L. Marques, H. Wiltsche, H. Motter, J. A. Nobrega and G. Knapp, J. Anal. At. Spectrom., 2015, 30(9), 1898-1905.

186 S. Pradhan, J. Zhang, J. G. Qu and X. Yun, Anal. Lett., 2015, 48(13), 2136-2158.

187 B. A. Sadee, M. E. Foulkes and S. J. Hill, Food Addit. Contam. Part A-Chem., 2016, 33(3), 433-441.

188 M. Sadowska, E. Biadun and B. Krasnodebska-Ostrega, Chemosphere, 2016, 144, 1216-1223.

189 L. Guidotti, S. Q. Abad, P. Rodriguez-Gonzalez, J. I. G. Alonso and G. M. Beone, Environ. Sci. Pollut. Res., 2015, 22(22), 17569-17576.

190 Y. W. Chen, A. Alzahrani, T. L. Deng and N. Belzile, Anal. Chim. Acta, 2016, 905, $42-50$.

191 A. Ohta and R. Kubota, Geostand. Geoanal. Res., 2016, 40(1), 117-134.

192 M. Mittermuller, J. Saatz and B. Daus, Chemosphere, 2016, 147, 155-162.

193 B. Lesniewska, K. Kisielewska, J. Wiater and B. Godlewska-Zylkiewicz, Environ. Monit. Assess., 2016, 188(1), 13.

194 C. A. C. do Nascimento, P. H. Pagliari, D. Schmitt, Z. Q. He and H. Waldrip, Scientific Reports, 2015, 5, Article No. 17967.

195 A. M. S. Lima, D. Araujo and S. L. C. Ferreira, Microchem. J., 2016, 126, 368-372.

196 P. Coufalik, O. Zverina and J. Komarek, Spectrochim. Acta Pt. B-Atom. Spectrosc., 2016, 118, 1-5.

197 L. C. Soares, F. B. Egreja, C. C. Windmoller and M. I. Yoshida, Rev. Bras. Cienc. Solo, 2015, 39(4), 1100-1111.

198 J. Ordones, L. Fernandez, H. Romero, P. Carrera and J. Alvarado, Talanta, 2015, 141, 259-266.

199 M. Schneider, E. R. Pereira, I. N. B. Castilho, E. Carasek, B. Welz and I. B. G. Martens, Microchem. J., 2016, 125, 50-55.

200 A. T. Duarte, A. R. Borges, A. V. Zmozinski, M. B. Dessuy, B. Welz, J. B. de Andrade and M. G. R. Vale, Talanta, 2016, 146, 166-174.

201 A. S. Silva, G. C. Brandao, G. D. Matos and S. L. C. Ferreira, Talanta, 2015, 144, 3943.

202 A. Virgilio, J. F. Rego, A. I. Barros and J. A. G. Neto, J. Braz. Chem. Soc., 2015, 26(10), 1988-1993.

203 S. D. Souza, L. L. Francois, A. R. Borges, M. G. R. Vale and R. G. O. Araujo, Spectrochim. Acta Pt. B-Atom. Spectrosc., 2015, 114, 58-64.

204 W. Boschetti, L. M. G. Dalagnol, M. Dullius, A. V. Zmozinski, E. M. Becker, M. G. R. Vale and J. B. de Andrade, Microchem. J., 2016, 124, 380-385.

205 J. S. de Gois, T. S. Almeida, R. M. de Andrade, I. M. Toaldo, M. T. Bordignon-Luiz and D. L. G. Borges, Microchem. J., 2016, 124, 283-289.

206 D. V. de Babos, M. A. Bechlin, A. I. Barros, E. C. Ferreira, J. A. G. Neto and S. R. de Oliveira, Talanta, 2016, 152, 457-462.

207 K. Greda, K. Kurcbach, K. Ochromowicz, T. Lesniewicz, P. Jamroz and P. Pohl, J. Anal. At. Spectrom., 2015, 30(8), 1743-1751. 
208 Y. Lin, Y. Yang, Y. X. Li, L. Yang, X. D. Hou, X. B. Feng and C. B. Zheng, Environ. Sci. Technol., 2016, 50(5), 2468-2476.

209 M. H. Gonzalez and L. N. Santos, Anal. Lett., 2015, 48(15), 2434-2445.

210 X. C. Duan, J. Y. Zhang and F. L. Bu, Spectrochim. Acta Pt. B-Atom. Spectrosc., 2015, 111, 87-91.

211 X. D. Wen, Y. Gao, P. Wu, Z. Q. Tan, C. B. Zheng and X. D. Hou, J. Anal. At. Spectrom., 2016, 31(2), 415-422.

212 C. C. Brombach, M. F. Ezzeldin, B. Chen, W. T. Corns, J. Feldmann and E. M. Krupp, Anal. Methods, 2015, 7(20), 8584-8589.

213 K. Tirez, C. Vanhoof, J. Bronders, P. Seuntjens, N. Bleux, P. Berghmans, N. De Brucker and F. Vanhaecke, Env. Sci. Processes Impact., 2015, 17(12), 2034-2050.

214 D. D. Bussan, R. F. Sessums and J. V. Cizdziel, J. Anal. At. Spectrom., 2015, 30(7), 1668-1672.

215 C. Y. Tai, S. J. Jiang and A. C. Sahayam, Food Chem., 2016, 192, 274-279.

216 A. Limbeck, P. Galler, M. Bonta, G. Bauer, W. Nischkauer and F. Vanhaecke, Anal. Bioanal. Chem., 2015, 407(22), 6593-6617.

217 G. O. Duodu, A. Goonetilleke, C. Allen and G. A. Ayoko, Anal. Chim. Acta, 2016, 898, 19-27.

218 M. A. G. Nunes, M. Voss, G. Corazza, E. M. M. Flores and V. L. Dressler, Anal. Chim. Acta, 2016, 905, 51-57.

219 R. B. Georg and K. Newman, J. Anal. At. Spectrom., 2015, 30(9), 1935-1944.

220 H. C. Liu, C. H. Chung, C. F. You and Y. H. Chiang, Anal. Bioanal. Chem., 2016, 408(2), 387-397.

221 S. Konegger-Kappel and T. Prohaska, Anal. Bioanal. Chem., 2016, 408(2), 431-440.

222 W. Q. Li, B. L. Beard and S. L. Li, J. Anal. At. Spectrom., 2016, 31(4), 1023-1029.

223 S. E. Janssen, M. W. Johnson, J. D. Blum, T. Barkay and J. R. Reinfelder, Chem Geol., 2015, 411, 19-25.

224 G. S. Yang, H. Tazoe and M. Yamada, Anal. Chim. Acta, 2016, 908, 177-184.

225 M. A. Amr, A. F. I. Helal, A. T. Al-Kinani and P. Balakrishnan, J. Environ. Radioact., 2016, 153, 73-87.

226 C. D. B. Amaral, R. S. Amais, L. L. Fialho, D. Schiavo, A. R. A. Nogueira and J. A. Nobrega, Microchem. J., 2015, 122, 29-32.

227 G. Z. Fang, Q. H. Lv, C. C. Liu, M. M. Huo and S. Wang, Anal. Methods, 2015, 7(20), 8617-8625.

228 K. Malisova, R. Koplik and O. Mestek, Anal. Lett., 2015, 48(15), 2446-2462.

229 P. Novak, T. Zuliani, R. Milacic and J. Scancar, Anal. Chim. Acta, 2016, 915, 27-35.

230 D. P. Bao, Z. G. Oh and Z. Chen, Frontiers in Plant Science, 2016, 7, Article No. 32.

231 J. Navratilova, A. Praetorius, A. Gondikas, W. Fabienke, F. von der Kammer and T. Hofmann, Int. J. Env. Res. Public Health, 2015, 12(12), 15756-15768.

232 B. Meermann, K. Wichmann, F. Lauer, F. Vanhaecke and T. A. Ternes, J. Anal. At. Spectrom., 2016, 31(4), 890-901.

233 E. Chamizo, M. Christl and L. K. Fifield, Nucl. Instrum. Meth. B, 2015, 358, 45-51.

234 H. Matsuzaki, C. Nakano, Y. S. Tsuchiya, S. Ito, A. Morita, H. Kusuno, Y. Miyake, M. Honda, A. T. Bautista, M. Kawamoto and H. Tokuyama, Nucl. Instrum. Meth. B, 2015, 361, 63-68.

235 Y. Satou, K. Sueki, K. Sasa, T. Matsunaka, T. Takahashi, N. Shibayama, D. Izumi, N. Kinoshita and H. Matsuzaki, Nucl. Instrum. Meth. B, 2015, 361, 233-236.

236 Q. Liu, X. L. Zhao, X. L. Hou, G. Burr, W. J. Zhou, Y. C. Fu, N. Chen and L. Y. Zhang, Radiocarbon, 58(1), 147-156. 
237 Y. Shibahara, T. Kubota, T. Fujii, S. Fukutani, K. Takamiya, M. Konno, S. Mizuno and H. Yamana, J. Radioanal. Nucl. Chem., 2016, 307(3), 2281-2287.

238 S. Paul, A. K. Pandey, R. V. Shah, D. Alamelu and S. K. Aggarwal, RSC. Adv., 2016, 6(4), 3326-3334.

239 Q. C. Xu, Y. L. Dong, H. Y. Zhu and A. D. Sun, Int. J. Anal. Chem., 2015, 6. Article No. 364242.

240 M. S. Snow, D. C. Snyder, N. R. Mann and B. M. White, Int. J. Mass spectrom., 2015, 381, 17-24.

241 S. C. Jantzi, V. Motto-Ros, F. Trichard, Y. Markushin, N. Melikechi and A. De Giacomo, Spectrochim. Acta Pt. B-Atom. Spectrosc., 2016, 115, 52-63.

242 N. B. Zorov, A. M. Popov, S. M. Zaytsev and T. A. Labutin, Russ. Chem. Rev., 2015, 84(10), 1021-1050.

243 K. Q. Yu, Y. R. Zhao, F. Liu, J. Y. Peng and Y. He, Spectrosc. Spectr. Anal., 2016, 36(3), 827-833.

244 D. S. Meng, N. J. Zhao, M. J. Ma, Y. Wang, L. Hu, Y. Yu, L. Fang and W. Q. Liu, Plasma Sci. Technol., 2015, 17(8), 632-637.

245 G. Nicolodelli, G. S. Senesi, R. A. Romano, I. L. D. Perazzoli and D. Milori, Spectrochim. Acta Pt. B-Atom. Spectrosc., 2015, 111, 23-29.

246 R. X. Yi, L. B. Guo, C. M. Li, X. Y. Yang, J. M. Li, X. Y. Li, X. Y. Zeng and Y. F. Lu, J. Anal. At. Spectrom., 2016, 31(4), 961-967.

247 R. X. Yi, L. B. Guo, X. H. Zou, J. M. Li, Z. Q. Hao, X. Y. Yang, X. Y. Li, X. Y. Zeng and Y. F. Lu, Opt. Express, 2016, 24(3), 2607-2618.

248 A. M. Popov, M. O. Kozhnov, S. M. Zaytsev, N. B. Zorov and T. A. Labutin, J. Appl. Spectrosc., 2015, 82(5), 739-743.

249 A. A. Ambushe, A. du Plessis and R. I. McCrindle, Bull. Chem. Soc. Ethiop., 2015, 29(3), 357-366.

250 B. H. Zhang, Y. C. Jiang, X. Y. Zhang and Z. F. Cui, Spectrosc. Spectr. Anal., 2015, 35(6), 1715-1718.

251 Z. Haider, J. Ali, M. Arab, Y. bin Munajat, S. Roslan, R. Kamarulzman and N. Bidin, Anal. Lett., 2016, 49(6), 808-817.

252 T. B. Chen, L. Huang, M. Y. Yao, H. Q. Hu, C. H. Wang and M. H. Liu, Appl. Opt., 2015, 54(25), 7807-7812.

253 P. C. Zheng, M. J. Shi, J. M. Wang and H. D. Liu, Plasma Sci. Technol., 2015, 17(8), 664-670.

254 M. B. B. Guerra, A. Adame, E. de Almeida, G. G. A. de Carvalho, M. A. S. Brasil, D. Santos and F. J. Krug, J. Anal. At. Spectrom., 2015, 30(7), 1646-1654.

255 E. C. Ferreira, J. A. G. Neto, D. Milori, E. J. Ferreira and J. M. Anzano, Spectrochim. Acta Pt. B-Atom. Spectrosc., 2015, 110, 96-99.

256 P. R. Villas-Boas, R. A. Romano, M. A. D. Franco, E. C. Ferreira, E. J. Ferreira, S. Crestana and D. Milori, Geoderma, 2016, 263, 195-202.

257 G. Yang, S. J. Qiao, P. F. Chen, Y. Ding and D. Tian, Plasma Sci. Technol., 2015, 17(8), 656-663.

258 L. Borgese, F. Bilo, R. Dalipi, E. Bontempi and L. E. Depero, Spectrochim. Acta Pt. B-Atom. Spectrosc., 2015, 113, 1-15.

259 P. Vijayan, I. R. Willick, R. Lahlali, C. Karunakaran and K. K. Tanino, Plant Cell Phsiol, , 2015, 56(7), 1252-1263.

260 N. Kallithrakas-Kontos, S. Foteinis, K. Paigniotaki and M. Papadogiannakis, Environ. Monit. Assess., 2016, 188(2), Article No. 120.

261 Y. T. Kim, J. Lee, H. O. Yoon and N. C. Woo, Microchem. J., 2016, 124, 594-599. 
262 N. V. Campos, M. B. B. Guerra, J. W. V. Mello, C. Schaefer, F. J. Krug, E. E. N. Alves and A. A. Azevedo, J. Anal. At. Spectrom., 2015, 30(12), 2375-2383.

263 E. V. Chuparina, A. N. Smagunova and L. A. Eliseeva, J. Anal. Chem., 2015, 70(8), 949-955.

264 J. An, J. Lee and H. O. Yoon, Microchem. J., 2015, 122, 76-81.

265 A. R. Schneider, B. Cances, C. Breton, M. Ponthieu, X. Morvan, A. Conreux and B. Marin, J. Soils Sed., 2016, 16(2), 438-448.

266 U. Stockmann, S. R. Cattle, B. Minasny and A. B. McBratney, Catena, 2016, 139, 220-231.

267 K. G. McIntosh, D. Guimaraes, M. J. Cusack, A. Vershinin, Z. W. Chen, K. Yang and P. J. Parsons, Int. J. Environ. Anal. Chem., 2016, 96(1), 15-37.

268 E. K. Towett, K. D. Shepherd and B. L. Drake, X-Ray Spectrom., 2016, 45(2), $117-$ 124.

269 E. K. Towett, K. D. Shepherd, A. Sila, E. Aynekulu and G. Cadisch, Soil Sci. Soc. Amer., 2015 79(5), 1375-1385.

270 D. C. Weindorf, S. Chakraborty, J. Herrero, B. Li, C. Castaneda and A. Choudhury, Eur. J. Soil Sci., 2016, 67(2), 173-183.

271 J. Barros, P. F. de Souza, D. Schiavo and J. A. Nobrega, J. Anal. At. Spectrom., 2016, 31(1), 337-343.

272 C. A. Martins, C. Cerveira, G. L. Scheffler and D. Pozebon, Food Anal. Meth., 2015, 8(7), 1652-1660.

273 L. Ma, L. Wang, J. Tang and Z. G. Yang, Food Chem., 2016, 204, 283-288.

274 K. Chandrasekaran, P. R. Mamatha and D. Karunasagar, At. Spectrosc., 2015, 36(5), 202-209.

275 G. Ahmed, D. Takuwa, I. T. Chibua, Z. Bagai, L. Morekisi, H. Shoniwa, B. Sethebe and K. Sichilongo, Commun. Soil Sci. Plant Anal., 2016, 47(4), 512-520.

276 A. L. H. Muller, E. I. Muller, J. S. Barin and E. M. M. Flores, Anal. Methods, 2015, 7(12), 5218-5225.

277 M. H. Rashid, Z. Fardous, M. A. Z. Chowdhury, M. K. Alam, M. L. Bari, M. Moniruzzaman and S. H. Gan, Chem. Cent. J., 2016, 10, Article No. 7.

278 S. F. Ferrarini, H. S. dos Santos, L. G. Miranda, C. M. N. Azevedo, S. M. Maia, E. S. Chaves and M. J. R. Pires, At. Spectrosc., 2015, 36(5), 187-195.

279 S. R. Choudhury, D. C. Dutta, A. Karmakar, A. Das and Y. K. Shami, At. Spectrosc., 2016, 37(2), 37-42.

280 H. Altundag, Fresenius Environ. Bull., 2015, 24(12A), 4452-4457.

281 V. C. D. Peronico and J. L. Raposo, Food Chem., 2016, 196, 1287-1292.

282 A. M. S. Mimura, M. A. L. Oliveira, V. S. T. Ciminelli and J. C. J. Silva, J. AOAC Int., 2016, 99(1), 252-259.

283 H. Altundag, S. Albayrak, M. S. Dundar, M. Tuzen and M. Soylak, At. Spectrosc., 2015, 36(4), 159-164.

284 L. L. S. Almeida, M. D. R. Oliveira, J. B. B. Silva and N. M. M. Coelho, Microchem. J., 2016, 124, 326-330.

285 L. A. Mampuru, N. A. Panichev, P. Ngobeni, K. L. Mandiwana and M. M. Kalumba, South Afr. J. Chem.-Suid-Afr. Tydskr. Chem., 2015, 68, 57-60.

286 M. Soylak and S. Yigit, At. Spectrosc., 2015, 36(4), 165-170.

287 Z. Bahadir, V. N. Bulut, H. Bektas and M. Soylak, RSC Adv., 2016, 6(9), 6896-6904.

288 E. Yilmaz and M. Soylak, Anal. Chim. Acta, 2015, 886, 75-82.

289 Naeemullah, M. Tuzen and T. G. Kazi, RSC Adv., 2016, 6(34), 28767-28773.

290 L. dos Santos, Q. O. dos Santos, I. Moreno, C. G. Novaes, M. J. S. dos Santos and M. A. Bezerra, J. Braz. Chem. Soc., 2016, 27(4), 745-752. 
291 M. Karimi, A. M. H. Shabani and S. Dadfarnia, Microchim. Acta, 2016, 183(2), $563-$ 571.

292 F. Aydin, E. Yilmaz and M. Soylak, RSC Adv., 2015, 5(115), 94879-94886.

293 E. Yilmaz and M. Soylak, J. Anal. At. Spectrom., 2015, 30(7), 1629-1635.

294 C. Labrecque, P. J. Lebed and D. Lariviere, J. Environ. Radioact., 2016, 155, 15-22.

295 G. Leng, W. J. Chen and Y. Wang, J. Sep. Sci., 2015, 38(15), 2684-2691.

296 J. Barros, M. A. Aguirre, N. Kovachev, A. Canals and J. A. Nobrega, Anal. Methods, 2016, 8(4), 810-815.

297 M. Shokri, A. Beiraghi and S. Seidi, Anal. Chim. Acta, 2015, 889, 123-129.

298 M. Tuzen and O. Z. Pekiner, Food Chem., 2015, 188, 619-624.

299 F. Omidi, M. Behbahani, S. J. Shahtaheri and S. Salimi, Environ. Monit. Assess., 2015, 187(6), 10.

300 M. Amjadi, A. Samadi, J. L. Manzoori and N. Arsalani, Anal. Methods, 2015, 7(14), 5847-5853.

301 A. Duran, M. Tuzen and M. Soylak, J. AOAC Int., 2015, 98(6), 1733-1738.

302 Y. E. Unsal, M. Tuzen and M. Soylak, J. AOAC Int., 2016, 99(2), 534-538.

303 S. A. Rezvani and A. Soleymanpour, J. Chromatogr., 2016, 1436, 34-41.

304 S. Sivrikaya, M. Imamoglu, S. Z. Yildiz and D. Kara, Anal. Lett., 2016, 49(7), 943957.

305 M. Khan, E. Yilmaz, B. Sevinc, E. Sahmetlioglu, J. Shah, M. R. Jan and M. Soylak, Talanta, 2016, 146, 130-137.

306 M. Shirani, A. Akbari and M. Hassani, Anal. Methods, 2015, 7(14), 6012-6020.

307 H. Alkan, R. Gul-Guven, K. Guven, S. Erdogan and M. Dogru, Pol. J. Environ. Stud., 2015, 24(5), 1903-1910.

308 H. Bagheri, A. A. Asgharinezhad and H. Ebrahimzadeh, Food Anal. Meth., 2016, 9(4), 876-888.

309 S. Z. Mohammad, T. Shamspur, E. Shahsavani and S. Fozooni, J. AOAC Int., 2015, 98(3), 828-833.

310 A. A. Gouda and S. M. Al Ghannam, Food Chem., 2016, 202, 409-416.

311 N. B. Burham, S. M. Abdel-Azeem, S. R. Abdel-Hafeez and M. F. El-Shahat, Desalin. Water Treat., 2015, 56(11), 3024-3035.

312 M. Behbahani, P. G. Hassanlou, M. M. Amini, F. Omidi, A. Esrafili, M. Farzadkia and A. Bagheri, Food Chem., 2015, 187, 82-88.

313 S. Ozdemir, E. Kilinc, V. Okumus, A. Poli, B. Nicolaus and I. Romano, Bioresour. Technol., 2016, 201, 269-275.

314 E. Yilmaz, I. Ocsoy, N. Ozdemir and M. Soylak, Anal. Chim. Acta, 2016, 906, 110117.

315 M. Habila, Y. E. Unsal, Z. A. Alothman, A. Shabaka, M. Tuzen and M. Soylak, Anal. Lett., 2015, 48(14), 2258-2271.

316 L. Zhang, X. D. Gao, Z. C. Xiong, L. Y. Zhang, B. H. Yu, R. S. Zhang and W. B. Zhang, RSC Adv., 2015, 5(72), 58873-58879.

317 Z. A. Alothman, E. Yilmaz, M. Habila and M. Soylak, Turk. J. Chem., 2015, 39(5), 1038-1049.

318 E. Yavuz, S. Tokalioglu, H. Sahan and S. Patat, Food Chem., 2016, 194, 463-469.

N. Ashouri, A. Mohammadi, M. Shekarchi, R. Hajiaghaee and H. Rastegar, Desalin. Water Treat., 2015, 56(8), 2135-2144.

320 M. A. Karimi and M. Kafi, Arabian J. Chem., 2015, 8(6), 812-820.

321 N. B. Wutke, K. M. Diniz, M. Z. Corazza, F. M. de Oliveira, E. S. Ribeiro, B. T. da Fonseca, M. G. Segatelli and C. R. T. Tarley, Anal. Lett., 2016, 49(5), 723-736. 
322 R. H. Su, G. H. Ruan, Z. Y. Chen, F. Y. Du and J. P. Li, J. Sep. Sci., 2015, 38(24), $4262-4268$.

323 D. M. Nanicuacua, M. G. Segatelli, M. Z. Corazzaa and C. R. T. Tarley, Anal. Methods, 2016, 8(13), 2820-2830.

324 A. Mehdinia, M. Asiabi and A. Jabbari, Int. J. Environ. Anal. Chem., 2015, 95(12), 1099-1111.

325 W. I. Mortada, A. F. Moustafa, A. M. Ismail, M. M. Hassanien and A. A. Aboud, RSC $A d v ., 2015$, 5(77), 62414-62423.

326 F. Z. Teng, W. Y. Li, S. Ke, W. Yang, S. A. Liu, F. Sedaghatpour, S. J. Wang, K. J. Huang, Y. Hu, M. X. Ling, Y. Xiao, X. M. Liu, X. W. Li, H. O. Gu, C. K. Sio, D. A. Wallace, B. X. Su, L. Zhao, J. Chamberlin, M. Harrington and A. Brewer, Geostand. Geoanal. Res., 2015, 39(3), 329-339.

327 T. Cheng, O. Nebel, P. Sossi and F. K. Chen, Int. J. Mass Spectrom., 2015, 386, 6166.

328 P.-P. Zhao, J. Li, L. Zhang, Z.-B. Wang, D.-X. Kong, J.-L. Ma, G.-J. Wei and J.-F. Xu, Geostand. Geoanal. Res., 2016, 40(2), 217-226.

329 A. Fourny, D. Weis and J. S. Scoates, Geochem. Geophys. Geosyst., 2016, 17(3), 739773.

330 J. Jweda, L. Bolge, C. Class and S. L. Goldstein, Geostand. Geoanal. Res., 2016, 40(1), 101-115.

331 K. P. Jochum, U. Weis, B. Schwager, B. Stoll, S. A. Wilson, G. H. Haug, M. O. Andreae and J. Enzweiler, Geostand. Geoanal. Res., 2016, 40(3), 333-350.

332 K. P. Jochum, S. A. Wilson, H. Becker, D. Garbe-Schonberg, N. Groschopf, Y. Kadlag, D. S. Macholdt, R. Mertz-Kraus, L. M. Otter, B. Stoll, A. Stracke, U. Weis, G. H. Haug and M. O. Andreae, Chem. Geol., 2016, 432, 34-40.

333 L. Zhu, Y. Liu, T. Ma, J. Lin, Z. Hu and C. Wang, J. Anal. At. Spectrom., 2016, 31(7), 1414-1422.

334 L. P. Bedard, K. H. Esbensen and S. J. Barnes, Anal. Chem., 2016, 88(7), 3504-3511.

335 C. Spandler, J. Hammerli, P. Sha, H. Hilbert-Wolf, Y. Hu, E. Roberts and M. Schmitz, Chem. Geol., 2016, 425, 110-126.

336 B. X. Su, X. Y. Gu, E. Deloule, H. F. Zhang, Q. L. Li, X. H. Li, N. Vigier, Y. J. Tang, G. Q. Tang, Y. Liu, K. N. Pang, A. Brewer, Q. Mao and Y. G. Ma, Geostand. Geoanal. Res., 2015, 39(3), 357-369.

337 K. Suga, T. Hirata, M. Fukuyama and M. Ogasawara, Geochem. J., 2015, 49(4), 421424.

338 C. J. Soares, R. Mertz-Kraus, S. Guedes, D. F. Stockli and T. Zack, Geostand. Geoanal. Res., 2015, 39(3), 305-313.

339 S. D. Zhang, M. H. He, Z. B. Yin, E. Y. Zhu, W. Hang and B. L. Huang, J. Anal. At. Spectrom., 2016, 31(2), 358-382.

340 J. Fietzke and M. Frische, J. Anal. At. Spectrom., 2016, 31(1), 234-244.

341 T. Ubide, C. A. McKenna, D. M. Chew and B. S. Kamber, Chem.Geol., 2015, 409, 157-168.

342 J. Hirata, K. Takahashi, Y. V. Sahoo and M. Tanaka, Chem. Geol., 2016, 427, 65-72.

343 M. Bonta, A. Limbeck, C. D. Quarles Jr, D. Oropeza, R. E. Russo and J. J. Gonzalez, J. Anal. At. Spectrom., 2015, 30(8), 1809-1815.

344 S. J. M. Van Malderen, A. J. Managh, B. L. Sharp and F. Vanhaecke, J. Anal. At. Spectrom., 2016, 31(2), 423-439.

345 D. N. Douglas, A. J. Managh, H. J. Reid and B. L. Sharp, Anal. Chem., 2015, 87(22), 11285-11294. 
346 A. Gundlach-Graham, M. Burger, S. Allner, G. Schwarz, H. A. O. Wang, L. Gyr, D. Grolimund, B. Hattendorf and D. Gunther, Anal. Chem., 2015, 87(16), 8250-8258.

347 M. Burger, A. Gundlach-Graham, S. Allner, G. Schwarz, H. A. O. Wang, L. Gyr, S. Burgener, B. Hattendorf, D. Grolimund and D. Gunther, Anal. Chem., 2015, 87(16), 8259-8267.

348 M. Harlaux, O. Borovinskaya, D. A. Frick, D. Tabersky, S. Gschwind, A. Richard, D. Gunther and J. Mercadier, J. Anal. At. Spectrom., 2015, 30(9), 1945-1969.

349 C. C. Wohlgemuth-Ueberwasser and K. P. Jochum, J. Anal. At. Spectrom., 2015, 30(12), 2469-2480.

350 M. Lazarov and I. Horn, Spectrochim. Acta Pt. B-Atom. Spectrosc., 2015, 111, 64-73.

351 C. Toyama, J. I. Kimura, Q. Chang, B. S. Vaglarov and J. Kuroda, J. Anal. At. Spectrom., 2015, 30(10), 2194-2207.

352 M. N. Dai, Z. A. Bao, K. Y. Chen and H. L. Yuan, Chin. J. Anal. Chem., 2016, 44(2), 173-177.

353 Y. Kon and T. Hirata, Geochem. J., 2015, 49(4), 351-375.

354 Z. A. Bao, H. L. Yuan, C. L. Zong, Y. Liu, K. Y. Chen and Y. L. Zhang, J. Anal. At. Spectrom., 2016, 31(4), 1012-1022.

355 J. I. Kimura, Q. Chang, N. Kanazawa, S. Sasaki and B. S. Vaglarov, J. Anal. At. Spectrom., 2016, 31(3), 790-800.

356 D. R. Viete, A. R. C. Kylander-Clark and B. R. Hacker, Chem. Geol., 2015, 415, 70 86.

357 J. H. Marsh and D. F. Stockli, Litho, 2015, 239, 170-185.

358 B. R. Hacker, A. C. Kylander-Clark, R. Holder, T. B. Andersen, E. M. Peterman, E. O. Walsh and J. K. Munnikhuis, Chem. Geol., 2015, 409, 28-41.

359 E. Bolea-Fernandez, S. J. M. Van Malderen, L. Balcaen, M. Resano and F. Vanhaecke, J. Anal. At. Spectrom., 2016, 31(2), 464-472.

360 T. Zack and K. J. Hogmalm, Chem. Geol., 2016, 437, 120-133.

361 W. Muller and R. Anczkiewicz, J. Anal. At. Spectrom., 2016, 31(1), 259-269.

362 Y. L. Sun, M. H. Ren, X. P. Xia, C. Y. Li and W. D. Sun, Spectrochim. Acta Pt. BAtom. Spectrosc., 2015, 113, 22-29.

363 E. A. Dennis, S. J. Ray, C. G. Enke and G. M. Hieftje, J. Am. Soc. Mass Spectrom., 2015, 27(3), 380-387.

364 E. A. Dennis, S. J. Ray, C. G. Enke, A. W. Gundlach-Graham, C. J. Barinaga, D. W. Koppenaal and G. M. Hieftje, J. Am. Soc. Mass Spectrom., 2015, 27(3), 371-379.

365 A. A. Bol'shakov, X. L. Mao, J. J. Gonzalez and R. E. Russo, J. Anal. At. Spectrom., 2016, 31(1), 119-134.

366 T. Xu, J. Liu, Q. Shi, Y. He, G. H. Niu and Y. X. Duan, Spectrochim. Acta Pt. BAtom. Spectrosc., 2016, 115, 31-39.

367 J. E. Birdwell and K. E. Washburn, Energy \& Fuels, 2015, 29(11), 6999-7004.

368 Q. Shi, G. H. Niu, Q. Y. Lin, T. Xu, F. J. Li and Y. X. Duan, J. Anal. At. Spectrom., 2015, 30(12), 2384-2393.

369 M. T. Sweetapple and S. Tassios, Am. Mineral., 2015, 100(10), 2141-2151.

370 K. A. Kochelek, N. J. McMillan, C. E. McManus and D. L. Daniel, Am. Mineral., 2015, 100(8-9), 1921-1931.

371 S. Maurice, S. M. Clegg, R. C. Wiens, O. Gasnault, W. Rapin, O. Forni, A. Cousin, V. Sautter, N. Mangold, L. Le Deit, M. Nachon, R. B. Anderson, N. L. Lanza, C. Fabre, V. Payre, J. Lasue, P. Y. Meslin, R. J. Leveille, L. Barraclough, P. Beck, S. C. Bender, G. Berger, J. C. Bridges, N. T. Bridges, G. Dromart, M. D. Dyar, R. Francis, J. Frydenvang, B. Gondet, B. L. Ehlmann, K. E. Herkenhoff, J. R. Johnson, Y. Langevin, M. B. Madsen, N. Melikechi, J. L. Lacour, S. Le Mouelic, E. Lewin, H. E. 
Newsom, A. M. Ollila, P. Pinet, S. Schroder, J. B. Sirven, R. L. Tokar, M. J. Toplis, C. d'Uston, D. T. Vaniman and A. R. Vasavada, J. Anal. At. Spectrom., 2016, 31(4), 863-889.

372 M. N. Abedin, A. T. Bradley, S. K. Sharma, A. K. Misra, P. G. Lucey, C. P. McKay, S. Ismail and S. P. Sandford, Appl. Opt., 2015, 54(25), 7598-7611.

373 M. B. Neuland, V. Grimaudo, K. Mezger, P. Moreno-Garcia, A. Riedo, M. Tulej and P. Wurz, Meas. Sci. Tech., 2016,27(3), 13.

374 M. Tulej, A. Neubeck, M. Ivarsson, A. Riedo, M. B. Neuland, S. Meyer and P. Wurz, Astrobiology, 2015,15(8), 669-682.

375 J. P. Sertek, S. Andrade and H. H. Ulbrich, Geostand. Geoanal. Res., 2015, 39(3), 381-397.

376 W. Zhang, L. Qi, Z. Hu, C. Zheng, Y. Liu, H. Chen, S. Gao and S. Hu, Geostand. Geoanal. Res., 2016, 40(2), 195-216.

377 P. J. Potts, P. C. Webb and M. Thompson, Geostand. Geoanal. Res., 2015, 39(3), 315-327.

378 A. Tamura, N. Akizawa, R. Otsuka, K. Kanayama, M. Python, T. Morishita and S. Arai, Geochem. J., 2015, 49(3), 243-258.

379 Z. W. He, F. Huang, H. M. Yu, Y. L. Xiao, F. Y. Wang, Q. L. Li, Y. Xia and X. C. Zhang, Geostand. Geoanal. Res., 2016, 40(1), 5-27.

380 Y. Wang, L. A. Baker and I. D. Brindle, Talanta, 2016, 148, 419-426.

381 D. S. Xue, H. Y. Wang, Y. H. Liu, P. Shen and J. F. Sun, Anal. Methods, 2016, 8(1), 29-39.

382 C. Du, L. Luo, W. Guo, L. L. Jin, B. Chen and S. H. Hu, At. Spectrosc., 2015, 36(3), 141-145.

383 H. Cui, W. Guo, M. T. Cheng, P. Zhang, L. L. Jin, Q. H. Guo and S. H. Hu, Anal. Methods, 2015, 7(20), 8970-8976.

384 D. S. Xue, H. Y. Wang, Y. H. Liu and P. Shen, Miner. Eng., 2015, 81, 149-151.

385 A. Zuber, M. Purdey, E. Schartner, C. Forbes, B. van der Hoek, D. Giles, A. Abell, T. Monro and H. Ebendorff-Heidepriem, Sens. Actuator B-Chem., 2016, 227, 117-127.

386 L. Whitty-Leveille, E. Drouin, M. Constantin, C. Bazin and D. Lariviere, Spectrochim. Acta Pt. B-Atom. Spectrosc., 2016, 118, 112-118.

387 S. D. Fernandez, J. R. Encinar, A. Sanz-Medel, K. Isensee and H. M. Stoll, Geochem. Geophys. Geosyst., 2015, 16(6), 2005-2014.

388 E. Bolea-Fernandez, L. Balcaen, M. Resano and F. Vanhaecke, J. Anal. At. Spectrom., 2016, 31(1), 303-310.

389 G. Schudel, V. Lai, K. Gordon and D. Weis, Chem. Geol., 2015, 410, 223-236.

390 Q. Xu, W. Guo, L. L. Jin, Q. H. Guo and S. H. Hu, J. Anal. At. Spectrom., 2015, 30(9), 2010-2016.

391 A. Michel, J. Noireaux and M. Tharaud, Geostand. Geoanal. Res., 2015, 39(4), 489495.

392 R. M. Gaschnig, R. L. Rudnick and W. F. McDonough, Geostand. Geoanal. Res., 2015, 39(3), 371-379.

393 S. J. Romaniello, M. P. Field, H. B. Smith, G. W. Gordon, M. H. Kim and A. D. Anbar, J. Anal. At. Spectrom., 2015, 30(9), 1906-1912.

394 J. Irrgeher and T. Prohaska, Anal. Bioanal. Chem., 2016, 408(2), 369-385.

395 M. Horsky, J. Irrgeher and T. Prohaska, Anal. Bioanal. Chem., 2016, 408(2), 351-367.

396 F. Z. Teng, Q. Z. Yin, C. V. Ullmann, R. Chakrabarti, P. von Strandmann, W. Yang, W. Y. Li, S. Ke, F. Sedaghatpour, J. Wimpenny, A. Meixner, R. L. Romer, U. Wiechert and S. B. Jacobsen, Geochem. Geophys. Geosyst., 2015, 16(9), 3197-3209. 
397 J. Vogl, B. Brandt, J. Noordmann, O. Rienitz and D. Malinovskiy, J. Anal. At. Spectrom., 2016, 31(7), 1440-1458.

398 M. J. Pribil, W. I. Ridley and P. Emsbo, Chem. Geol., 2015, 412, 99-106.

399 C. H. Liu, X. P. Bian, T. Yang, A. J. Lin and S. Y. Jiang, Talanta, 2016, 151, 132140.

400 S. G. Nielsen, J. D. Owens and T. J. Horner, J. Anal. At. Spectrom., 2016, 31(2), 531536.

401 F. Wu, Y. H. Qi, H. M. Yu, S. Y. Tian, Z. H. Hou and F. Huang, Chem. Geol., 2016, 421, 17-25.

402 H. Z. Wei, S. Y. Jiang, Z. Y. Zhu, T. Yang, J. H. Yang, X. Yan, H. P. Wu and T. L. Yang, Talanta, 2015, 143, 302-306.

403 J. Lin, Y. S. Liu, H. H. Chen, L. Zhou, Z. C. Hu and S. Gao, J. Earth Sci., 2015, 26(5), 763-774.

404 D. Egli, W. Muller and N. Mancktelow, Terr. Nova, 2016, 28(1), 35-42.

405 L. P. Feng, L. Zhou, L. Yang, S. Y. Tong, Z. C. Hu and S. Gao, J. Anal. At. Spectrom., 2015, 30(12), 2403-2411.

406 G. O. Lehn and A. D. Jacobson, J. Anal. At. Spectrom., 2015, 30(7), 1571-1581.

407 M. O. Naumenko-Dezes, C. Bouman, T. F. Nagler, K. Mezger and I. M. Villa, Int. J. Mass Spectrom., 2015, 387, 60-68.

408 Q. Li, M. Thirlwall and W. Muller, Chem. Geol., 2016, 422, 1-12.

409 M. Klaver, R. J. Smeets, J. M. Koornneef, G. R. Davies and P. Z. Vroon, J. Anal. At. Spectrom., 2016, 31(1), 171-178.

410 A. von Quadt, J. F. Wotzlaw, Y. Buret, S. J. E. Large, I. Peytcheva and A. Trinquier, J. Anal. At. Spectrom., 2016, 31(3), 658-665.

411 A. Didier, V. Bosse, J. Bouloton, S. Mostefaoui, M. Viala, J. L. Paquette, J. L. Devidal and R. Duhamel, Contrib. Mineral Petrol., 2015, 170(5-6), 21.

412 Y. Y. Gao, X. H. Li, W. L. Griffin, Y. J. Tang, N. J. Pearson, Y. Liu, M. F. Chu, Q. L. Li, G. Q. Tang and S. Y. O'Reilly, Sci. Rep., 2015, 5, 11.

413 S. Goderis, R. Chakrabarti, V. Debaille and J. Kodolanyi, J. Anal. At. Spectrom., 2016, 31(4), 841-862.

414 M. J. Bojanowski, B. Baginski, C. Guillermier and I. A. Franchi, Chem. Geol., 2015, 416, 51-64.

415 E. H. Hauri, D. Papineau, J. H. Wang and F. Hillion, Chem. Geol., 2016, 420, 148161.

416 M. G. Śliwiński, K. Kitajima, R. Kozdon, M. J. Spicuzza, J. H. Fournelle, A. Denny and J. W. Valley, Geostand. Geoanal. Res., 2016, 40(2), 157-172.

417 M. G. Śliwiński, K. Kitajima, R. Kozdon, M. J. Spicuzza, J. H. Fournelle, A. Denny and J. W. Valley, Geostand. Geoanal. Res., 2016, 40(2), 173-184.

418 L. B. Corbett, P. R. Bierman and D. H. Rood, Quat. Geochronol., 2016, 33, 24-34.

419 M. E. Keillor, C. E. Aalseth, L. M. Arrigo, J. M. Brandenberger, J. M. Cloutier, G. C. Eiden, J. E. Fast, Z. S. Finch, G. A. Gill, T. W. Hossbach, C. T. Overman, B. N. Seiner and J. E. Strivens, J. Radioanal. Nucl. Chem., 2016, 307(3), 2313-2319.

420 P. Vermeesch, G. Balco, P. H. Blard, T. J. Dunai, F. Kober, S. Niedermann, D. L. Shuster, S. Strasky, F. M. Stuart, R. Wieler and L. Zimmermann, Quat. Geochronol., 2015, 26, 20-28.

421 Y. Ma, Y. Wu, D. M. Li and D. W. Zheng, Int. J. Mass spectrom., 2015, 380, 26-33.

422 P. Vermeesch, Geochim. Cosmochim. Acta, 2015, 171, 325-337.

423 K. Li, B. Etschmann, N. Rae, F. Reith, C. G. Ryan, R. Kirkham, D. Howard, D. R. N. Rosa, C. Zammit, A. Pring, Y. Ngothai, A. Hooker and J. Brugger, Econ. Geol., 2016, 111(2), 487-501. 
424 L. A. Fisher, D. Fougerouse, J. S. Cleverley, C. G. Ryan, S. Micklethwaite, A. Halfpenny, R. M. Hough, M. Gee, D. Paterson, D. L. Howard and K. Spiers, Miner. deposita., 2015, 50(6), 665-674.

425 F. Gergely, J. Osan, B. K. Szabo and S. Torok, Spectrochim. Acta Pt. B-Atom. Spectrosc., 2016, 116, 75-84.

426 J. Buckles and H. D. Rowe, Chem. Geol., 2016, 426, 28-32.

427 K. Kuhn, J. A. Meima, D. Rammlmair and C. Ohlendorf, J. Geochem. Explor., 2016, 161, 72-84.

428 S. Chawchai, M. E. Kylander, A. Chabangborn, L. Lowemark and B. Wohlfarth, Boreas, 2015, 45(1), 180-189.

429 V. Chubarov, D. Suvorova, A. Mukhetdinova and A. Finkelshtein, X-Ray Spectrom., 2015, 44(6), 436-441.

430 X. L. Li, Y. M. Wang and Q. Zhang, Spectrosc. Lett., 2016, 49(3), 151-154.

431 J. Quye-Sawyer, V. Vandeginste and K. J. Johnston, J. Anal. At. Spectrom., 2015, 30(7), 1490-1499.

432 D. A. Burkett, I. T. Graham and C. R. Ward, Can. Mineral., 2015, 53(3), 429-454.

433 D. Bish, D. Blake, D. Vaniman, P. Sarrazin, T. Bristow, C. Achilles, P. Dera, S. Chipera, J. Crisp, R. T. Downs, J. Farmer, M. Gailhanou, D. Ming, J. M. Morookian, R. Morris, S. Morrison, E. Rampe, A. Treiman and A. Yen, IUCrJ., 2014, 1, 514-522.

434 X. Y. Nan, F. Wu, Z. F. Zhang, Z. H. Hou, F. Huang and H. M. Yu, J. Anal. At. Spectrom., 2015, 30(11), 2307-2315.

435 K. Murphy, M. Rehkamper, K. Kreissig, B. Coles and T. van de Flierdt, J. Anal. At. Spectrom., 2016, 31(1), 319-327.

436 P. Bonnand, I. J. Parkinson and M. Anand, Geochim. Cosmochim. Acta, 2016, 175, 208-221.

437 P. Bonnand, H. M. Williams, I. J. Parkinson, B. J. Wood and A. N. Halliday, Earth Planet. Sci. Lett., 2016, 435, 14-21.

438 Z. Y. Zhu, S. Y. Jiang, T. Yang and H. Z. Wei, Int. J. Mass Spectrom., 2016, 393, 3440.

439 Q. H. Hou, L. Zhou, S. Gao, T. Zhang, L. P. Feng and L. Yang, J. Anal. At. Spectrom., 2016, 31(1), 280-287.

440 Y. S. He, S. Ke, F. Z. Teng, T. T. Wang, H. J. Wu, Y. H. Lu and S. G. Li, Geostand. Geoanal. Res., 2015, 39(3), 341-356.

441 V. A. Finlayson, J. G. Konter and L. Ma, Geochem. Geophys. Geosyst., 2015, 16(12), 4209-4222.

442 F. X. D'Abzac, J. Davies, J. F. Wotzlaw and U. Schaltegger, Chem. Geol., 2016, 433, 12-23.

443 S. T. M. Peters, C. Munker, F. Wombacher and B. M. Elfers, Chem. Geol., 2015, 413, 132-145.

444 R. Bast, E. E. Scherer, P. Sprung, M. Fischer-Godde, A. Stracke and K. Mezger, J. Anal. At. Spectrom., 2015, 30(11), 2323-2333.

445 J. Lin, Y. S. Liu, Z. C. Hu, L. Yang, K. Chen, H. H. Chen, K. Q. Zong and S. Gao, J. Anal. At. Spectrom., 2016, 31(2), 390-397.

446 K. Van Hoecke, J. Belza, T. Croymans, S. Misra, P. Claeys and F. Vanhaecke, J. Anal. At. Spectrom., 2015, 30(12), 2533-2540.

447 V. Migeon, B. Bourdon, E. Pili and C. Fitoussi, J. Anal. At. Spectrom., 2015, 30(9), 1988-1996.

448 Y. Nagai and T. Yokoyama, J. Anal. At. Spectrom., 2016, 31(4), 948-960.

449 S. M. Chernonozhkin, S. Goderis, L. Lobo, P. Claeys and F. Vanhaecke, J. Anal. At. Spectrom., 2015, 30(7), 1518-1530. 
450 N. S. Saji, D. Wielandt, C. Paton and M. Bizzarro, J. Anal. At. Spectrom., 2016, 31(7), 1490-1504.

451 T. Struve, T. van de Flierdt, L. F. Robinson, L. I. Bradtmiller, S. K. Hines, J. F. Adkins, M. Lambelet, K. C. Crocket, K. Kreissig, B. Coles and M. E. Auro, Geochem. Geophys. Geosyst., 2015, 17(1), 232-240.

452 Z. Y. Chu, C. F. Li, Z. Chen, J. J. Xu, Y. K. Di and J. H. Guo, Anal. Chem., 2015, 87(17), 8765-8771.

453 M. Carpentier, A. Gannoun, C. Pin and O. Sigmarsson, Geostand. Geoanal. Res., 2016, 40(2), 239-256.

454 K. Abraham, J. Barling, C. Siebert, N. Belshaw, L. Gall and A. N. Halliday, J. Anal. At. Spectrom., 2015, 30(11), 2334-2342. 